Supporting Information for

\title{
Inhibition and Crystal Structure of the Human DHTKD1-Thiamin Diphosphate Complex
}

João Leandro, ${ }^{\dagger, \ddagger}$ Susmita Khamrui,§ Hui Wang, ${ }^{\S, \|}$ Chalada Suebsuwong,, ,I Natalia S. Nemeria, ${ }^{\perp}$ Khoi Huynh,, ,ll Moses Moustakim,,$\| l$ Cody Secor,, May Wang, ${ }^{\dagger, \ddagger}$ Tetyana Dodatko, ${ }^{\dagger, \ddagger}$ Brandon Stauffer," Christopher G. Wilson, ${ }^{\nabla}$ Chunli Yu, ${ }^{\dagger, \#}$ Michelle R. Arkin, ${ }^{\nabla}$ Frank Jordan, ${ }^{\perp}$ Roberto Sanchez,, ,l Robert J. DeVita,, ,l Michael B. Lazarus, ${ }^{\S, *}$ Sander M. Houten ${ }^{\dagger, \ddagger, \star}$

tDepartment of Genetics and Genomic Sciences, Icahn School of Medicine at Mount Sinai, New York, NY 10029, USA

\#lcahn Institute for Data Science and Genomic Technology, Icahn School of Medicine at Mount Sinai, New York, NY 10029, USA

§Department of Pharmacological Sciences, Icahn School of Medicine at Mount Sinai, New York, NY 10029, USA

"Drug Discovery Institute, Icahn School of Medicine at Mount Sinai, New York, NY 10029, USA

${ }^{\perp}$ Department of Chemistry, Rutgers, The State University of New Jersey, Newark, New Jersey 07102, USA

\#Mount Sinai Genomics, Inc, Stamford, CT 06902, USA

$\nabla$ Small Molecule Discovery Center and Department of Pharmaceutical Chemistry, University of California, San Francisco, CA 94143, USA

Corresponding Authors

${ }^{*}$ Michael B. Lazarus, Sander M. Houten

Email: michael.lazarus@mssm.edu, sander.houten@mssm.edu

\section{Table of Contents}

Supplementary Methods S2

Supplementary Figures S12

Figure S1. The degradation of L-lysine occurs mainly via the mitochondrial saccharopine pathway ..S12

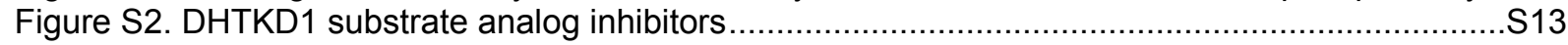

Figure S3. Adipoylphosphonic acid inhibits DHTKD1 in a cellular model......................................S15

Figure S4. Pilot HTS and assay quality indicators for identification of DHTKD1 inhibitors ................S16

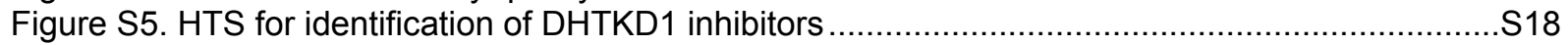

Figure S6. DHTKD1 inhibition concentration-response curves …........................................ 19

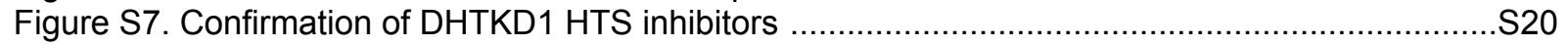

Figure S8. Dose-response curves of omeprazole and pantoprazole and their sulfone

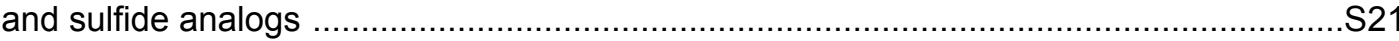

Figure S9. Tenatoprazole is a noncompetitive DHTKD1 inhibitor .............................................S22

Figure S10. Electron density around ThDP ligands in the two active sites of DHTKD1 dimer ...........S23

Figure S11. DHTKD1 structure, comparison with $M$. smegmatis KGD and docking of the substrate $O A$ and the inhibitor adipoylphosphonic acid

Figure S12. DHTKD1 variant expression and enzyme kinetics for evaluation of substrate specificity.

Figure S13. Expression and enzyme kinetics of human DHTKD1 variants ...................................S26

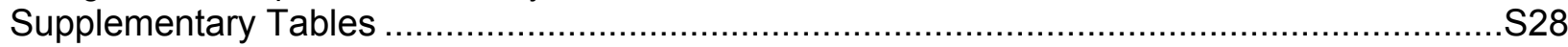

Table S1. Evaluation of DHTKD1 substrate analogs as inhibitors and confirmed HTS hits ..............S28

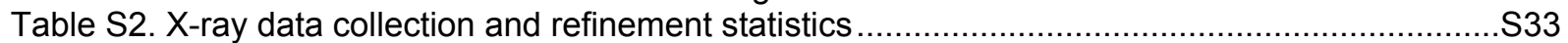

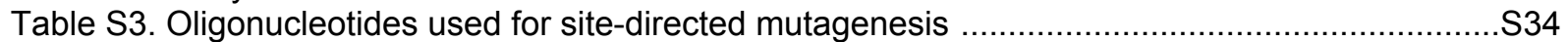

References......

S35

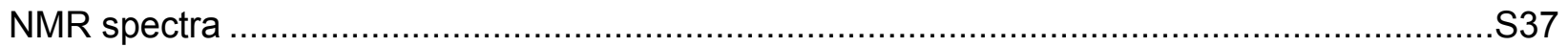




\section{Supplementary Methods}

\section{Synthesis of phosphonic acid analogs}

General Experimental Conditions Reactions in anhydrous solvents were carried out in glassware that was flame-dried or oven-dried. Unless noted, reactions were magnetically stirred and conducted under an atmosphere. Air-sensitive reagents and solutions were transferred via syringe and were introduced to the reaction vessel through rubber septa. Solids were introduced under a positive pressure of Ar. Temperatures, other than room temperature (rt); refer to bath temperatures unless otherwise indicated. All commercially obtained solvents and reagents were used as received. Deionized water was used for all aqueous reactions, work-ups, and for the preparation of all aqueous solutions. The phrase "concentrated in vacuo" refers to removal of solvents by means of a Büchi rotary-evaporator attached to a variable vacuum pump followed by pumping to a constant weight $(<1$ Torr). Proton and carbon nuclear magnetic resonance (NMR) spectra were obtained on a Bruker Avance $600(600 \mathrm{MHz})$. Chemical shifts are reported in ppm (ठ). ${ }^{1} \mathrm{H}$ NMR data are reported as follows: chemical shift (multiplicity, coupling constant $(\mathrm{Hz})$, number of hydrogens). Multiplicities are denoted accordingly: s (singlet), d (doublet), dd (doublet of doublets), ddd (doublet of doublet of doublets), dt (doublet of triplets), tt (triplet of triplets), dq (doublet of quartets), $\mathrm{t}$ (triplet), q (quartet), $\mathrm{p}$ (pentet), $\mathrm{m}$ (multiplet). High resolution mass spectra (LCMS) were obtained using an Agilent 1200 Series Rapid Resolution LC/MS. The chromatography was performed by using Teledyne ISCO RediSep normal phase (40-60 microns) silica Gel disposable flash columns using a Teledyne ISCO Combiflash Rf purification system (for detailed synthesis and NMR spectra see supporting information).

\section{Synthesis of glutarylphosphonic acid.}

1a. To a solution of dihydro-2H-pyran-2,6(3H)-dione $(3 \mathrm{~g}, 26.31 \mathrm{mmol}, 1$ equiv.) and benzyl alcohol $(2.85$ $\mathrm{g}, 1$ equiv.) in DMF (10 mL) was added with DMAP $(0.5 \mathrm{~g}, 15 \mathrm{~mol} \%)$, the reaction mixture was stirred at room temperature for $5 \mathrm{~h}$. Then concentrated under high vacuum and purified via FCC (Hexanes/EtOAc, $20 \%$ to $50 \%$ ) to give product 5-(benzyloxy)-5-oxopentanoic acid $1 \mathrm{a}(2 \mathrm{~g}, 34 \%)$.

${ }^{1} \mathrm{H}-\mathrm{NMR}\left(600 \mathrm{MHz}, \mathrm{CDCl}_{3}\right)$ : $\delta$ 7.40-7.34 (m, 5H), 2.47-2.44 (m, 4H), 2.03-1.98 (m, 2H);

LCMS (TOF-ESI) for $\mathrm{C}_{12} \mathrm{H}_{14} \mathrm{O}_{4}$ [M] 222.0892;

Calculated [M+H]: 223.0962; Found [M+ H] $]^{+}$for 223.0970.

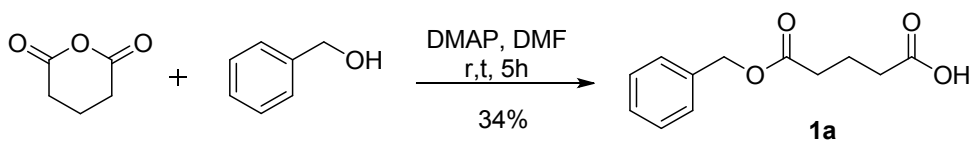

2a. To a solution of 5-(benzyloxy)-5-oxopentanoic acid $1 \mathrm{a}\left(1.8 \mathrm{~g}, 8.1 \mathrm{mmol}, 1\right.$ equiv.) in $\mathrm{CH}_{2} \mathrm{Cl}_{2}(20 \mathrm{~mL})$ was added with $\mathrm{SOCl}_{2}(1.64 \mathrm{~g}, 2.5$ equiv.) at room temperature, the whole solution was stirred at reflux for $6 \mathrm{~h}$. After cooled to room temperature, the solution was concentrated to remove any volatiles under high vacuum to give corresponding benzyl 5-chloro-5-oxopentanoate as clear oil which was used for next step without purification.

${ }^{1} \mathrm{H}-N M R\left(600 \mathrm{MHz} \mathrm{CDCl}_{3}\right)$ : $\delta$ 7.41-7.36 (m, $5 \mathrm{H}$ ), 3.02-3.00 (t, 2H), 2.49-2.47 (t, 2H), 2.08-2.03 (m, 2H); benzyl 5-chloro-5-oxopentanoate $(1.0 \mathrm{~g}, 4.16 \mathrm{mmol}, 1$ equiv.) was added into trimethyl phosphite $(0.57 \mathrm{~g}$, 1.1 equiv.) at $0^{\circ} \mathrm{C}$ dropwise, upon the completion of addition, the mixture was stirred at room temperature for $12 \mathrm{~h}$. Then the mixture was subjected to high vacuum to remove any unreacted trimethyl phosphite and gave the desired product benzyl 5-(dimethoxyphosphoryl)-5-oxopentanoate $2 \mathrm{a}(1.2 \mathrm{~g}, 92 \%)$.

${ }^{1} \mathrm{H}-\mathrm{NMR}\left(600 \mathrm{MHz}, \mathrm{CDCl}_{3}\right)$ : $\delta$ 7.40-7.28 (m, 5H), $5.14(\mathrm{~s}, 2 \mathrm{H}), 3.88(\mathrm{~s}, 3 \mathrm{H}), 3.86(\mathrm{~s}, 3 \mathrm{H}), 2.95-2.93(\mathrm{t}, 2 \mathrm{H})$, 2.44-2.42 (s, 2H), 2.00-1.97 (m, 2H).

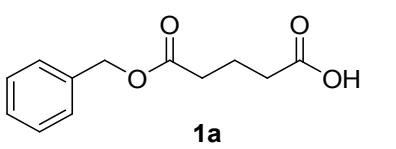
1) $\mathrm{SOCl}_{2}, \mathrm{CH}_{2} \mathrm{Cl}_{2}$, reflux, $6 \mathrm{~h}$
2) $\mathrm{P}(\mathrm{OMe})_{3}$, r.t

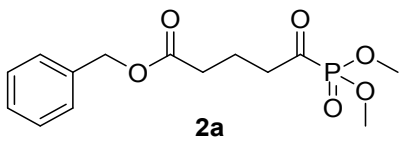


3a. To a solution of benzyl 5-(dimethoxyphosphoryl)-5-oxopentanoate $2 \mathrm{a}(0.2 \mathrm{~g}, 0.64 \mathrm{mmol}, 1$ equiv.) in THF $(5 \mathrm{~mL})$ was added with $\mathrm{Pd} / \mathrm{C}(70 \mathrm{mg}, 10 \mathrm{~mol} \%)$, the system was flushed with Argon and hydrogen gas sequentially, and then stirred under $\mathrm{H}_{2}$ (balloon) environment for $12 \mathrm{~h}$. After filtration, the filtrated was collected and concentrated to give product 5-(dimethoxyphosphoryl)-5-oxopentanoic acid as oil.

${ }^{1} \mathrm{H}-\mathrm{NMR}\left(600 \mathrm{MHz}, \mathrm{CDCl}_{3}\right)$ : $\delta 3.90(\mathrm{~s}, 3 \mathrm{H}), 3.88(\mathrm{~s}, 3 \mathrm{H}), 2.98-2.96(\mathrm{t}, 2 \mathrm{H}), 2.43-2.41$ (t, 2H), 1.99-1.95 $(\mathrm{m}, 2 \mathrm{H})$;

To a solution of above obtained 5-(dimethoxyphosphoryl)-5-oxopentanoic acid in $\mathrm{CH}_{2} \mathrm{Cl}_{2}(5 \mathrm{~mL})$ was added with $\mathrm{TMSBr}\left(0.58 \mathrm{~g}, 6\right.$ equiv.) at $0^{\circ} \mathrm{C}$ dropwise, upon completion of addition, the reaction was slowly warmed up to room temperature and stirred for $12 \mathrm{~h}$. The reaction was then quenched with $\mathrm{MeCN} / \mathrm{H}_{2} \mathrm{O}(1 \mathrm{~mL} / 0.5 \mathrm{~mL})$ and stirred for $1 \mathrm{~h}$. Then solvent was removed and the residue was washed with $\mathrm{CH}_{2} \mathrm{Cl}_{2}$ and dried under high vacuum to give product 5-oxo-5-phosphonopentanoic acid $\mathbf{3 a}$ as light brown oil.

${ }^{1} \mathrm{H}-N M R\left(600 \mathrm{MHz}, \boldsymbol{d}_{2}\right.$ - $\left.\mathrm{D}_{2} \mathrm{O}\right): \delta$ 2.78-2.76 (t, 2H), 2.31-2.25 (tt, 4H), 1.75-1.72 (m, 2H).

${ }^{31} \mathrm{P}-\mathrm{NMR}\left(600 \mathrm{MHz}, d_{2}-\mathrm{D}_{2} \mathrm{O}\right): \delta:-2.44$.

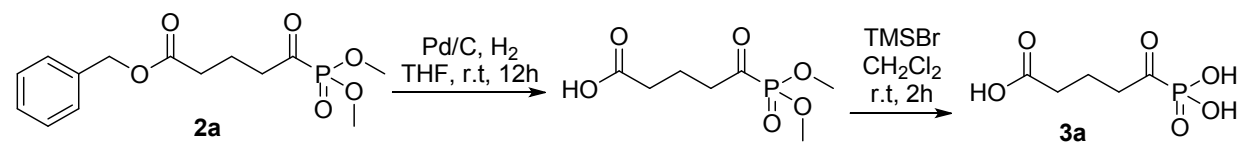

\section{Synthesis of adipoylphosphonic acid.}

1b. A solution of adipic acid (4 g, 2 equiv.), benzyl alcohol 5 (1.5 g, 1 equiv.) and pyridinium ptoluenesulfonate $(0.2 \mathrm{~g}, 10 \mathrm{~mol} \%)$ in toluene $(300 \mathrm{~mL})$ was stirred at reflux for $12 \mathrm{~h}$. After cooled to room temperature, the mixture was filtered and the filtrate was collected, concentrated and purified via FCC (Hexanes/EtOAc, 0 to $40 \%$ ) to give product 6-(benzyloxy)-6-oxohexanoic acid $\mathbf{1 b}(0.75 \mathrm{~g}, 23 \%)$ as colorless oil.

${ }^{1} \mathrm{H}-\mathrm{NMR}\left(600 \mathrm{MHz} \mathrm{CDCl}_{3}\right)$ : $\delta$ 7.38-7.35 (m, 5H), $5.14(\mathrm{~s}, 2 \mathrm{H}), 2.43-2.39(\mathrm{~m}, 4 \mathrm{H}), 1.75-1.68(\mathrm{~m}, 4 \mathrm{H})$;

LCMS (TOF-ESI) for $\mathrm{C}_{13} \mathrm{H}_{16} \mathrm{O}_{4}$ [M] 236.1049;

Calculated [M+H]: 237.1119; Found [M+ H] $]^{+}$for 237.1119.

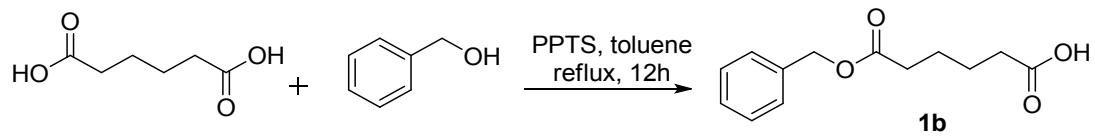

1bl. A solution of 6-(benzyloxy)-6-oxohexanoic acid $1 \mathrm{~b}(0.5 \mathrm{~g}, 2.12 \mathrm{mmol}, 1$ equiv.) and DMF (1 drop) in $\mathrm{CH}_{2} \mathrm{Cl}_{2}$ was added with oxalyl chloride $\left(0.54 \mathrm{~g}, 1.5\right.$ equiv.) dropwise at $0^{\circ} \mathrm{C}$. The mixture was stirred at room temperature for $2 \mathrm{~h}$ and then concentrated under high vacuum to provide product benzyl 6-chloro-6oxohexanoate as light yellow oil.

${ }^{1} \mathrm{H}-\mathrm{NMR}\left(600 \mathrm{MHz}, \mathrm{CDCl}_{3}\right)$ : $\delta$ 7.41-7.35 (m, 5H), 5.14 (s, 2H), 2.94-2.92 (t, 2H), 2.43-2.40 (t, 2H), 1.78$1.72(\mathrm{~m}, 4 \mathrm{H})$;<smiles>O=C(O)CCCCC(=O)OCc1ccccc1</smiles>

1b
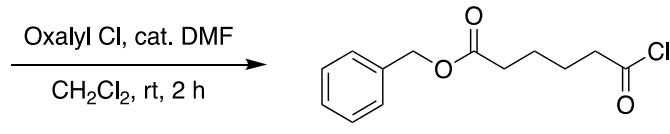

1bl

2b. benzyl 6-chloro-6-oxohexanoate $(0.52 \mathrm{~g}, 2.05 \mathrm{mmol}, 1$ equiv.) was added into trimethyl phosphite $(0.3$ $\mathrm{g}, 1.1$ equiv.) at $0^{\circ} \mathrm{C}$ dropwise, upon the completion of addition, the mixture was stirred at room temperature for $12 \mathrm{~h}$. Then the mixture was subjected to high vacuum to remove any unreacted trimethyl 
phosphite and gave the desired product benzyl 6-(dimethoxyphosphoryl)-6-oxohexanoate $2 \mathrm{~b}$ (0.64 g, 95\%).

${ }^{1} \mathrm{H}-\mathrm{NMR}\left(600 \mathrm{MHz}, \mathrm{CDCl}_{3}\right): \delta$ 7.40-7.34 (m, 5H), $5.13(\mathrm{~s}, 2 \mathrm{H}), 3.88(\mathrm{~d}, 3 \mathrm{H}), 3.87(\mathrm{~d}, 3 \mathrm{H}), 2.88-2.86(\mathrm{~m}$, $2 \mathrm{H}), 2.41-2.39(\mathrm{~m}, 2 \mathrm{H}), 1.70-1.66(\mathrm{~m}, 4 \mathrm{H})$;

LCMS (TOF-ESI) for $\mathrm{C}_{15} \mathrm{H}_{21} \mathrm{O}_{6} \mathrm{P}[\mathrm{M}] 328.1076$;

Calculated [M+H]: 329.1146; Found [M+ H] for 329.1151.

${ }^{31} \mathrm{P}-\mathrm{NMR}\left(600 \mathrm{MHz}, d_{2}-\mathrm{D}_{2} \mathrm{O}\right)$ : $\delta:-0.78$.

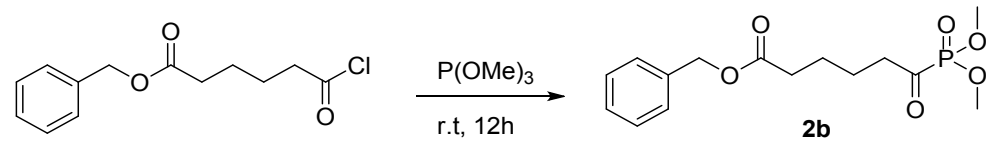

3b. To a solution of benzyl 6-(dimethoxyphosphoryl)-6-oxohexanoate $\mathbf{2 b}(0.2 \mathrm{~g}, 0.61 \mathrm{mmol}, 1$ equiv.) in THF $(5 \mathrm{~mL})$ was added with $\mathrm{Pd} / \mathrm{C}(70 \mathrm{mg}, 10 \mathrm{~mol} \%)$, the system was flushed with Argon and hydrogen gas sequentially, and then stirred under $\mathrm{H}_{2}$ (balloon) environment for $12 \mathrm{~h}$. After filtration, the filtrated was collected and concentrated to give product 6-(dimethoxyphosphoryl)-6-oxohexanoic acid as oil.

To a solution of above obtained 6-(dimethoxyphosphoryl)-6-oxohexanoic acid in $\mathrm{CH}_{2} \mathrm{Cl}_{2}(5 \mathrm{~mL})$ was added with $\mathrm{TMSBr}\left(0.58 \mathrm{~g}, 6\right.$ equiv.) at $0^{\circ} \mathrm{C}$ dropwise, upon completion of addition, the reaction was slowly warmed up to room temperature and stirred for $12 \mathrm{~h}$. The reaction was then quenched with $\mathrm{CH}_{3} \mathrm{CN} / \mathrm{H}_{2} \mathrm{O}(1 \mathrm{~mL} / 0.5 \mathrm{~mL})$ and stirred for $1 \mathrm{~h}$. Then solvent was removed and the residue was washed with $\mathrm{CH}_{2} \mathrm{Cl}_{2}$ and dried under high vacuum to give product 6-oxo-6-phosphonohexanoic acid $\mathbf{3 b}$ as resinlike solid.

${ }^{1} \mathrm{H}-\mathrm{NMR}\left(600 \mathrm{MHz}, \boldsymbol{d}_{2}-\mathrm{D}_{2} \mathrm{O}\right): \delta$ 2.77-2.75(t, 2H), 2.33-2.30 (m, 2H), 1.55-1.49 (m, 4H).

${ }^{31} \mathrm{P}-\mathrm{NMR}\left(600 \mathrm{MHz}, d_{2}-\mathrm{D}_{2} \mathrm{O}\right): \delta:-2.25$

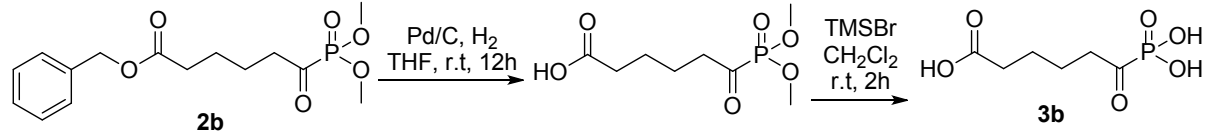

Resynthesis of adipoylphosphonic acid.

Adipoylphosphonic acid was resynthesized as outlined below and its inhibitory effect evaluated. In the DCPIP-based DHTKD1 assay, the resynthesized material $\left(\mathrm{IC}_{50}=0.19 \pm 0.01 \mu \mathrm{M}\right)$ displayed a similar efficacy as the original material $\left(\mathrm{IC}_{50}=0.21 \pm 0.02 \mu \mathrm{M}\right)$.

1b. To a suspension of adipic acid $(1000 \mathrm{mg}, 6.84 \mathrm{mmol})$ and potassium carbonate $(515.8 \mathrm{mg}, 3.73$ $\mathrm{mmol})$ in DMA $(20 \mathrm{~mL})$ was added benzyl bromide $(0.74 \mathrm{~mL}, 6.22 \mathrm{mmol})$. The reaction was stirred at 80 ${ }^{\circ} \mathrm{C}$ for $2 \mathrm{~h}$. After cooled to room temperature, water $(100 \mathrm{~mL})$ was added. The aqueous layer was extracted with EtOAc $(3 \times 50 \mathrm{~mL})$. The combined organic extracts were washed with brine, dried over anhydrous $\mathrm{Na}_{2} \mathrm{SO}_{4}$, filtered, and concentrated. The residue was purified by column chromatography on silica gel (Hexanes:EtOAc, 0 to 40\%) to afford 6-(benzyloxy)-6-oxohexanoic acid 1b (710 mg, 48\%) as a clear oil.

${ }^{1} \mathrm{H}-\mathrm{NMR}\left(600 \mathrm{MHz}, \mathrm{CDCl}_{3}\right): \delta$ 7.38-7.31 (m, 5H), $5.12(\mathrm{~s}, 2 \mathrm{H}), 2.40-2.36(\mathrm{~m}, 4 \mathrm{H}), 1.71-1.67(\mathrm{~m}, 4 \mathrm{H})$; HRMS (TOF-ESI) $\mathrm{C}_{13} \mathrm{H}_{16} \mathrm{O}_{4}[\mathrm{M}] 236.1049$

Calculated [M+H]: 237.1119; Found [M+ H] for 237.1130.<smiles>O=C(O)CCCCC(=O)O</smiles>

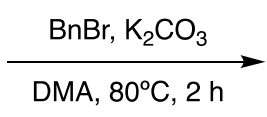<smiles>O=C(O)CCCCC(=O)OCc1ccccc1</smiles> 
1bl. To a solution of $1 \mathrm{~b}(500 \mathrm{mg}, 2.12 \mathrm{mmol})$ in $\mathrm{CH}_{2} \mathrm{Cl}_{2}(20 \mathrm{~mL})$ was added catalytic amount of DMF then oxalyl chloride $(0.28 \mathrm{~mL}, 3.17 \mathrm{mmol})$ was slowly under nitrogen atmosphere. The reaction was stirred at room temperature for $2 \mathrm{~h}$. The solvent was removed in vacuo. Toluene $(10 \mathrm{~mL})$ was added and removed in vacuo to give benzyl 6-chloro-6-oxohexanoate $1 \mathrm{bl}(540 \mathrm{mg}, 99 \%)$ as a yellow oil. The crude product was used in next step without further purification.

${ }^{1} \mathrm{H}-\mathrm{NMR}\left(600 \mathrm{MHz}, \mathbf{C D C l}_{3}\right): \delta$ 7.38-7.32 (m, 5H), $5.12(\mathrm{~s}, 2 \mathrm{H}), 2.91(\mathrm{t}, \mathrm{J}=7.3 \mathrm{~Hz}, 2 \mathrm{H}), 2.39$ (t, J = $7.3 \mathrm{~Hz}$, $2 \mathrm{H}), 1.74-1.71(\mathrm{~m}, 4 \mathrm{H})$.<smiles>O=C(O)CCCCC(=O)OCc1ccccc1</smiles>

$1 \mathrm{~b}$

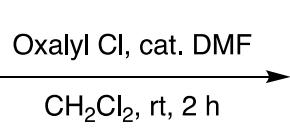

$$
\mathrm{CH}_{2} \mathrm{Cl}_{2} \text {, rt, } 2 \mathrm{~h}
$$

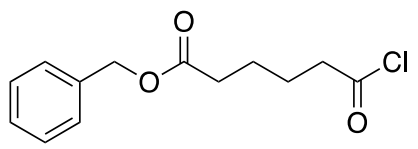

$1 b \mid$

2b. To a solution of $\mathbf{1 b l}(457 \mathrm{mg}, 1.79 \mathrm{mmol})$ in $\mathrm{CH}_{2} \mathrm{Cl}_{2}(3 \mathrm{~mL})$ was slowly added trimethyl phosphite $(0.23$ $\mathrm{mL}, 1.97 \mathrm{mmol}$ ) at $0^{\circ} \mathrm{C}$ under nitrogen atmosphere. The reaction was stirred at $0^{\circ} \mathrm{C}$ to room temperature for $16 \mathrm{~h}$. The solvent and excess trimethyl phosphite were removed in vacuo. to afford benzyl 6(dimethoxyphosphoryl)-6-oxohexanoate $\mathbf{2 b}(540 \mathrm{mg}, 99 \%)$ as a yellow oil. The crude product was used directly in next step.

${ }^{1} \mathrm{H}-\mathrm{NMR}\left(600 \mathrm{MHz}, \mathbf{C D C l}_{3}\right): \delta 7.37-7.32(\mathrm{~m}, 5 \mathrm{H}), 5.11(\mathrm{~s}, 2 \mathrm{H}), 3.87(\mathrm{~s}, 3 \mathrm{H}), 3.85(\mathrm{~s}, 3 \mathrm{H}), 2.85(\mathrm{~s}, 2 \mathrm{H})$, $2.38(\mathrm{~s}, 2 \mathrm{H}), 1.67(\mathrm{~s}, 4 \mathrm{H})$

HRMS (TOF-ESI) $\mathrm{C}_{15} \mathrm{H}_{21} \mathrm{O}_{6} \mathrm{P}$ [M] 328.1076

Calculated [M+H]: 329.1149; Found [M+ H] ${ }^{+}$for 329.1571<smiles>O=C(Cl)CCCCC(=O)OCc1ccccc1</smiles>

1 bl

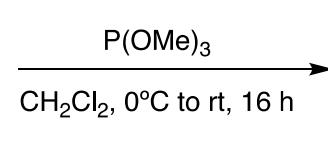<smiles>COP(=O)(OC)C(=O)CCCCC(=O)OCc1ccccc1</smiles>

2b

2bl. To a solution of $\mathbf{2 b}(318 \mathrm{mg}, 0.97 \mathrm{mmol})$ in EtOAc $(8 \mathrm{~mL})$ and formic acid $(2 \mathrm{~mL})$ was added $10 \%$ $\mathrm{Pd} / \mathrm{C}(32 \mathrm{mg})$. The reaction was purged with $\mathrm{H}_{2}$ and stirred at room temperature for $16 \mathrm{~h}$. The reaction mixture was filtered through a Celite pad and solvent was removed in vacuo to afford 6(dimethoxyphosphoryl)-6-oxohexanoic acid $\mathbf{2 b l}(230 \mathrm{mg}, 99 \%)$ as a clear oil. The crude product was used in next step without further purification.

${ }^{1} \mathrm{H}-\mathrm{NMR}\left(600 \mathrm{MHz}, \mathrm{CDCl}_{3}\right): \delta 3.87(\mathrm{~s}, 3 \mathrm{H}), 3.85(\mathrm{~s}, 3 \mathrm{H}), 2.86(\mathrm{t}, J=7.3 \mathrm{~Hz}, 2 \mathrm{H}), 2.36$ (t, $\left.J=7.3 \mathrm{~Hz}, 2 \mathrm{H}\right)$, $1.68-1.64(\mathrm{~s}, 4 \mathrm{H})$

HRMS (TOF-ESI) $\mathrm{C}_{8} \mathrm{H}_{15} \mathrm{O}_{6} \mathrm{P}[\mathrm{M}] 238.0606$

Calculated [M+H]: 239.0679; Found [M+ H] 239.0682<smiles>COP(=O)(OC)C(=O)CCCCC(=O)OCc1ccccc1</smiles>

2b

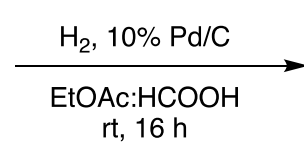
$\mathrm{rt}, 16 \mathrm{~h}$<smiles>COP(=O)(OC)C(=O)CCCCC(=O)O</smiles>

2bl

3b. To a solution of $2 \mathbf{b l}(144 \mathrm{mg}, 0.60 \mathrm{mmol})$ in $\mathrm{CH}_{2} \mathrm{Cl}_{2}(3 \mathrm{~mL})$ was slowly added $\mathrm{TMSBr}(0.47 \mathrm{~mL}, 3.62$ $\mathrm{mmol}$ ) at $0^{\circ} \mathrm{C}$ under Nitrogen atmosphere. The reaction was stirred at $0^{\circ} \mathrm{C}$ to room temperature for $20 \mathrm{~h}$. The solvent was removed in vacuo then $\mathrm{MeCN}(2 \mathrm{~mL})$ and water $(1 \mathrm{~mL})$ were added. The reaction mixture was stirred at room temperature for $1 \mathrm{~h}$ then the solvent was removed in vacuo. The crude product was washed with dichloromethane and hexane to afford adipoylphosphonic Acid 3b (97 mg, $76 \%)$ as a yellow solid.

${ }^{1} \mathrm{H}-\mathrm{NMR}\left(600 \mathrm{MHz}\right.$, DMSO- $\left.\boldsymbol{d}_{6}\right): \delta 2.73(\mathrm{t}, \mathrm{J}=7.3 \mathrm{~Hz}, 2 \mathrm{H}), 2.18(\mathrm{t}, \mathrm{J}=7.3 \mathrm{~Hz}, 2 \mathrm{H}), 1.51-1.44(\mathrm{~m}, 4 \mathrm{H})$ 
HRMS (TOF-ESI) $\mathrm{C}_{6} \mathrm{H}_{11} \mathrm{O}_{6} \mathrm{P}[\mathrm{M}] 210.0293$

Calculated [M+H]: 211.0366; Found [M+ H] 211.0370<smiles>COP(=O)(OC)C(=O)CCCCC(=O)O</smiles>

2bl<smiles>O=C(O)CCCCC(=O)P(=O)(O)O</smiles>

3b

\section{Synthesis of pimeloylphosphonic acid.}

1c. A solution of heptanedioic acid ( $4.5 \mathrm{~g}, 2$ equiv.), benzyl alcohol (1.5 g, 1 equiv.) and pyridinium $\mathrm{p}$ toluenesulfonate $(0.2 \mathrm{~g}, 10 \mathrm{~mol} \%)$ in toluene $(300 \mathrm{~mL})$ was stirred at reflux for $12 \mathrm{~h}$. After cooled to room temperature, the mixture was filtered and the filtrate was collected, concentrated and purified via FCC (Hexanes/EtOAc, 0 to $40 \%$ ) to give product 7-(benzyloxy)-7-oxoheptanoic acid $1 \mathrm{c}(1 \mathrm{~g}, 29 \%)$ as colorless oil.

${ }^{1} \mathrm{H}-\mathrm{NMR}\left(600 \mathrm{MHz}, \mathrm{CDCl}_{3}\right)$ : $\delta$ 7.39-7.34 (m, 5H), $5.14(\mathrm{~s}, 2 \mathrm{H}), 2.40-2.35(\mathrm{~m}, 4 \mathrm{H}), 1.72-1.64(\mathrm{~m}, 4 \mathrm{H}), 1.42-$ $1.37(\mathrm{~m}, 2 \mathrm{H})$;

LCMS (TOF-ESI) for $\mathrm{C}_{14} \mathrm{H}_{18} \mathrm{O}_{4}$ [M] 250.1205;

Calculated [M+H]: 251.1275; Found [M+ H] for 251.1284.

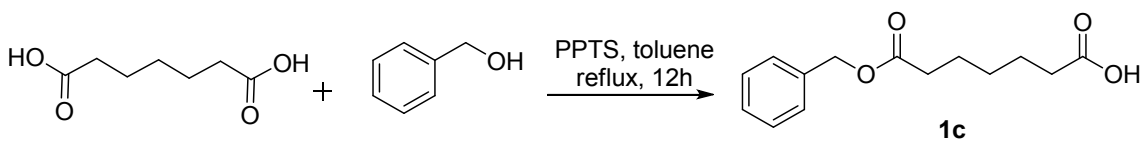

1cl. A solution of 6-(benzyloxy)-6-oxohexanoic acid 1c ( $0.54 \mathrm{~g}, 2.12 \mathrm{mmol}, 1$ equiv.) and DMF (1 drop) in $\mathrm{CH}_{2} \mathrm{Cl}_{2}$ was added with oxalyl chloride $\left(0.54 \mathrm{~g}, 1.5\right.$ equiv.) dropwise at $0^{\circ} \mathrm{C}$. The mixture was stirred at room temperature for $2 \mathrm{~h}$ and then concentrated under high vacuum to provide product benzyl 7-chloro-7oxoheptanoate as light yellow oil.

${ }^{1} \mathrm{H}-N M R\left(600 \mathrm{MHz}, \mathrm{CDCl}_{3}\right): \delta$ 7.40-7.35 (m, 5H), $5.14(\mathrm{~s}, 2 \mathrm{H}), 2.91-2.88$ (t, 2H), 2.40-2.38 (t, 2H), 1.76$1.72(\mathrm{q}, 2 \mathrm{H}), 1.71-1.67(\mathrm{q}, 2 \mathrm{H}), 1.43-1.38(\mathrm{~m}, 2 \mathrm{H})$.

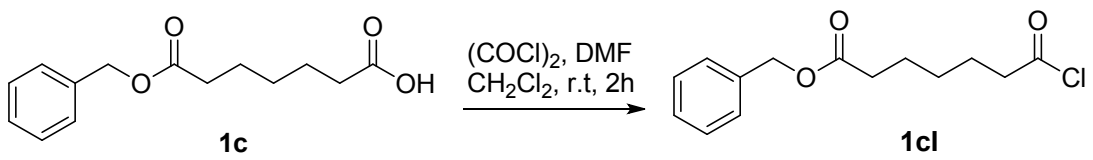

2c. benzyl 7-chloro-7-oxoheptanoate $(0.57 \mathrm{~g}, 2.05 \mathrm{mmol}, 1$ equiv.) was added into trimethyl phosphite $\left(0.3 \mathrm{~g}, 1.1\right.$ equiv.) at $0^{\circ} \mathrm{C}$ dropwise, upon the completion of addition, the mixture was stirred at room temperature for $12 \mathrm{~h}$. Then the mixture was subjected to high vacuum to remove any unreacted trimethyl phosphite and gave the desired product benzyl 7-(dimethoxyphosphoryl)-7-oxoheptanoate $2 \mathrm{c}(0.7 \mathrm{~g}$, 95\%).

${ }^{1} \mathrm{H}-\mathrm{NMR}\left(600 \mathrm{MHz}, \mathrm{CDCl}_{3}\right): \delta$ 7.40-7.34 (m, 5H), $5.13(\mathrm{~s}, 2 \mathrm{H}), 3.89(\mathrm{~s}, 3 \mathrm{H}), 3.87(\mathrm{~s}, 3 \mathrm{H}), 2.85-2.83(\mathrm{t}, 2 \mathrm{H})$, 2.39-2.36 (t, 2H), 1.70-1.64 (m, 4H), 1.38-1.35 (m, 2H);

LCMS (TOF-ESI) for $\mathrm{C}_{16} \mathrm{H}_{23} \mathrm{O}_{6} \mathrm{P}$ [M] 342.1232;

Calculated [M+H]: 343.1302; Found [M+ H] ${ }^{+}$for 343.1302.

${ }^{31} \mathrm{P}-\mathrm{NMR}\left(600 \mathrm{MHz}, d_{2}-\mathrm{D}_{2} \mathrm{O}\right)$ : $\delta:-0.68$.<smiles>COP(=O)(OC)C(=O)CCCCCC(=O)OCc1ccccc1</smiles> 
3c. To a solution of benzyl benzyl 7-(dimethoxyphosphoryl)-7-oxoheptanoate $2 \mathrm{c}(0.21 \mathrm{~g}, 0.61 \mathrm{mmol}, 1$ equiv.) in THF (5 mL) was added with $\mathrm{Pd} / \mathrm{C}(70 \mathrm{mg}, 10 \mathrm{~mol} \%)$, the system was flushed with Argon and hydrogen gas sequentially, and then stirred under $\mathrm{H}_{2}$ (balloon) environment for $12 \mathrm{~h}$. After filtration, the filtrated was collected and concentrated to give product 7-(dimethoxyphosphoryl)-7-oxoheptanoic acid as oil.

To a solution of above obtained 7-(dimethoxyphosphoryl)-7-oxoheptanoic acid in $\mathrm{CH}_{2} \mathrm{Cl}_{2}(5 \mathrm{~mL})$ was added with $\mathrm{TMSBr}\left(0.58 \mathrm{~g}, 6\right.$ equiv.) at $0^{\circ} \mathrm{C}$ dropwise, upon completion of addition, the reaction was slowly warmed up to room temperature and stirred for $12 \mathrm{~h}$. The reaction was then quenched with $\mathrm{CH}_{3} \mathrm{CN} / \mathrm{H}_{2} \mathrm{O}(1 \mathrm{~mL} / 0.5 \mathrm{~mL})$ and stirred for $1 \mathrm{~h}$. Then solvent was removed and the residue was washed with $\mathrm{CH}_{2} \mathrm{Cl}_{2}$ and dried under high vacuum to give product 7-oxo-7-phosphonoheptanoic acid $3 \mathrm{c}$ as white solid.

${ }^{1} \mathrm{H}-\mathrm{NMR}\left(600 \mathrm{MHz}, \mathrm{CDCl}_{3}\right): \delta$ 2.76-2.73 (t, 2H), 2.30-2.28 (m, 2H), 1.53-1.49 (m, 4H), 1.27-1.23 (m, 2H); ${ }^{31}$ P-NMR(600 MHz, $\left.d_{2}-\mathrm{D}_{2} \mathrm{O}\right): \delta:-2.18$.

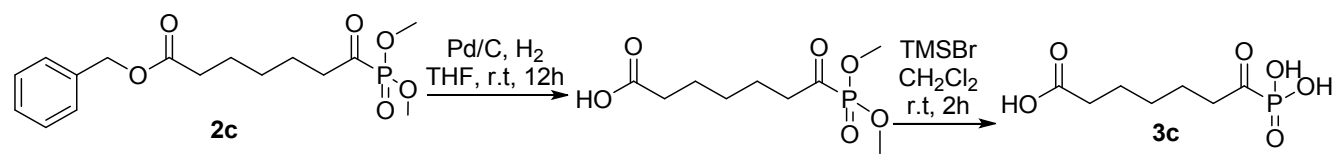

Materials. 2-oxoheptanedioic acid (2-oxopimelic acid; OP) was obtained from AKos GmbH, 4-oxo-5hexenoic acid was obtained from Santa Cruz Biotechnology and succinylphosphonic acid was from MedChem Express. OG, OA, OS, DCPIP, ThDP, coenzyme A (CoA), NAD, $\beta$-mercaptoethanol and Prionex $®$ were from Millipore-Sigma. HEK-293 cells were obtained from American Type Culture Collection (Manassas, VA, USA). DMEM, penicillin, streptomycin and fetal bovine serum were obtained from Thermo Fisher Scientific (Waltham, MA, USA). All other chemicals were of analytical grade.

Cloning of DHTKD1 into the pET28a(+) vector. Human DHTKD1 cDNA clone (Genbank accession BC007955) was provided by TransOMIC technologies (Huntsville, AL). The DHTKD1 open reading frame (amino acids 25-919) was amplified using PrimeSTAR GXL DNA Polymerase (Takara) and primers forward (5'-GGT TTA GAA TTC ATG CAG ACC GAG CGG GGC GTT TA-3') and reverse (5'-CTT TAC CTC GAG TCA TCA AGC GAA GGT CTT GGC GAG GAT-3'). These primers introduce an EcoRI and Xhol site (underlined). The pET-28a(+) vector (Novagen, EMD) was digested with EcoRI-HF and Xhol (NEB), treated by Calf Intestinal Alkaline Phosphatase (NEB) and purified by PureLink Quick Gel Extraction and PCR Purification combo kit (Invitrogen). The DHTKD1 PCR product was also digested with EcoRI-HF and Xhol, purified and ligated into the digested pET-28a(+) vector by T4 DNA Ligase (NEB). $\mathrm{DH} 5 \alpha$ competent cells were transformed with the ligated product and plasmid DNA from single clone was purified and sequence verified. The resulting pET-28a(+)-DHTKD1 plasmid encodes an N-terminal Histagged human DHTDK1 suitable for protein production.

Protein expression and purification of wild type DHTKD1. Rosetta 2(DE3)pLysS competent cells (Novagen, EMD) were transformed with the pET-28a(+)-encoding wild type DHTKD1 (amino acids 25919) and single clones were used for protein production. Cells were grown in LB medium with kanamycin $(25 \mu \mathrm{g} / \mathrm{ml}$ for $\mathrm{pET}-28 \mathrm{a})$ and chloramphenicol $(35 \mu \mathrm{g} / \mathrm{ml}$ for Rosetta cells). A culture for protein production was inoculated 1 in 1000 with a fresh overnight culture and cells were grown at $37^{\circ} \mathrm{C}$ with shaking for $3-4$ $\mathrm{h}$ with regular determination of the optical density at $600 \mathrm{~nm}\left(\mathrm{OD}_{600}\right)$. Once the culture reached an $\mathrm{OD}_{600}$ of 0.6-0.7, the culture was placed at RT, and protein production was induced by adding IPTG to a final concentration of $1 \mathrm{mM}$. Protein production was continued overnight, after which the cells were harvested by centrifugation and stored at $-20^{\circ} \mathrm{C}$. Protein extracts were prepared using BugBuster (Millipore Sigma) diluted in binding buffer $(20 \mathrm{mM}$ Tris- $\mathrm{HCl} \mathrm{pH} 7.8,500 \mathrm{mM} \mathrm{NaCl}, 5 \mathrm{mM}$ imidazole, $10 \mathrm{mM} \beta-$ mercaptoethanol, $50 \%$ BugBuster) with $1 \mathrm{x}$ cOmplete, mini, EDTA-free protease inhibitor cocktail. The extract was sonicated and the protein purified by IMAC and dialyzed against $100 \mathrm{mM}$ potassium phosphate $\mathrm{pH} 7,2.1 \mathrm{mM} \mathrm{MgCl} 2,0.21 \mathrm{mM}$ ThDP, $10 \%$ glycerol. The protein was stored at $-20{ }^{\circ} \mathrm{C}$ in dialysis buffer with $20 \%$ glycerol. Protein purity was analyzed by SDS-PAGE in a $4-12 \%(\mathrm{w} / \mathrm{v})$ 
polyacrylamide gel. Protein concentration was estimated by the Bradford method ${ }^{1}$ using bovine serum albumin (BSA) as standard.

DHTKD1 specific enzyme activity assay. In order to measure activity of the isolated DHTKD1 E1 component and to be able to screen for DHTKD1 inhibitors, we have adapted an assay using the redox dye 2,6-dichlorophenolindophenol (DCPIP), which oxidizes the enamine thiamin diphosphate (ThDP) intermediate and has been used for many years in the ThDP field..$^{2-4}$ The assay was optimized for $\mathrm{pH}$, $\mathrm{KCl}, \mathrm{ThDP}, \mathrm{MgCl}_{2}$, detergent and carrier protein concentration. The established assay conditions are 50 $\mathrm{mM}$ MOPS pH 7.4, $100 \mathrm{mM} \mathrm{KCl}, 2 \mathrm{mM} \mathrm{MgCl}$, $1 \mathrm{mM}$ ThDP, $0.1 \mathrm{mM}$ DCPIP, $0.1 \%$ Triton X-100 and $0.25 \%$ Prionex. Recombinant DHTKD1 E1 component was used at $0.025 \mathrm{mg} / \mathrm{mL}$ and OP was used at $62.5 \mu \mathrm{M}$ as substrate, unless otherwise indicated. The kinetics of the reaction was monitored as the decrease in absorption at $600 \mathrm{~nm}$ using 96-well plates and an EnVision Multilabel Plate Reader (PerkinElmer) or a similar plate reader. A substrate blank for correction of DCPIP reduction was included in all assays and subtracted. The millimolar extinction coefficient used for DCPIP was $20.6 \mathrm{mM}^{-1} \mathrm{~cm}^{-1}$. The stock solutions containing the substrates OG, OA, OP and OS were neutralized using $\mathrm{KOH}$. Compounds were dissolved in DMSO and tested at $300 \mu \mathrm{M}(1 \%$ DMSO final concentration), unless otherwise stated. $I_{50}$ was determined for selected compounds using the GraphPad Prism 7 software. Steady-state kinetic data were analyzed by nonlinear regression analysis using GraphPad Prism 7 software and a mixed model inhibition. The irreversible inhibitor 4-oxo-5-hexenoic acid was evaluated by the second-order rate constant $\mathrm{k}_{\text {inact }} / K_{\mathrm{i}}$ that describes the overall potency of inactivation, where $K_{\mathrm{i}}$ is the inhibition constant of the first reversible binding event and $k_{\text {inact }}$ is the maximum rate of inactivation. ${ }^{6}$ Progress curves were fitted to a single exponential equation to obtain the observed first order rate constant of inactivation, $\mathrm{k}_{\mathrm{obs}}$. The dependence of $\mathrm{k}_{\mathrm{obs}}$ on inhibitor concentration was used to calculate the $\mathrm{k}_{\text {inact }} / K_{\mathrm{i}}$ parameter.

OGDHc activity. OGDHc from porcine heart (Sigma K1502) was mixed with assay buffer (final concentration: $50 \mathrm{mM}$ MOPS, $\mathrm{pH} 7.4,0.2 \mathrm{mM} \mathrm{MgCl}_{2}, 0.01 \mathrm{mM} \mathrm{CaCl}, 0.3 \mathrm{mM}$ ThDP, $0.12 \mathrm{mM}$ CoA, 2 $\mathrm{mM} N A D, 2.6 \mathrm{mM} \beta$-mercaptoethanol). The reaction was started by the addition of $1 \mathrm{mM}$ substrate OG. The activity of OGDHc was followed by measuring the $\mathrm{NADH}$ production at $340 \mathrm{~nm}$ at $30{ }^{\circ} \mathrm{C}$ and steadystate velocities were taken from the linear portion of the time curve.

Overall OADHc activity of NADH production in vitro. The OADHc was assembled from recombinant DHTKD1, DLST (E2) and DLD (E3) components expressed and purified independently. For OADHc assembly, the DHTKD1 $(0.4 \mathrm{mg})$ in $0.1 \mathrm{M}$ Tris. $\mathrm{HCl}(\mathrm{pH} 7.5)$ containing $0.3 \mathrm{M} \mathrm{NH}_{4} \mathrm{Cl}, 0.5 \mathrm{mM}$ ThDP and $2.0 \mathrm{mM} \mathrm{MgCl}$ was mixed with DLST $(0.80 \mathrm{mg})$ and DLD $(2.0 \mathrm{mg})$ at a mass ratio $(\mathrm{mg} / \mathrm{mg} / \mathrm{mg})$ of $1: 2: 5$ and was incubated $40 \mathrm{~min}$ at $25^{\circ} \mathrm{C}$. An aliquot containing $0.01 \mathrm{mg}$ of DHTKD1 and the corresponding amounts of E2 and E3 was withdrawn and was placed into $1 \mathrm{ml}$ of the reaction assay containing all components necessary for the overall OADHc activity assay..$^{7-9}$ The reaction was initiated by addition of $\mathrm{OA}(1.0 \mathrm{mM})$ and $\mathrm{CoA}(400 \mu \mathrm{M})$ and the progress curves were recorded at $37^{\circ} \mathrm{C}$ for $3 \mathrm{~min}$. The reaction rates (slope/min at $340 \mathrm{~nm}$ ) were calculated from the linear part of the recorded progress curves.

Circular dichroism analysis of 1',4'-iminophosphonoadipoyl-ThDP intermediate. CD spectra of DHTKD1 (19.4 $\mu \mathrm{M}$ concentration of active centers) in $100 \mathrm{mM}$ HEPES ( $\mathrm{pH} 7.5)$ containing $0.5 \mathrm{mM}$ ThDP, $2.0 \mathrm{mM} \mathrm{MgCl} 2,0.15 \mathrm{M} \mathrm{NaCl}$ and $5 \%$ glycerol were recorded in the absence and in the presence of adipoylphosphonic acid (1-51 $\mu \mathrm{M})$ on a Chirascan CD spectrometer (Applied Photophysics, Leatherhead, UK) in $1-\mathrm{cm}$ path length cell in the near-UV CD region $(290-450 \mathrm{~nm})$ at $25^{\circ} \mathrm{C}$. The intensity of the CD band at $305 \mathrm{~nm}$ was estimated and was plotted versus the concentration of adipoylphosphonic acid or versus the [adipoylphosphonic acid]/[DHTKD1 active centers] ratio.

High-throughput screening. In order to identify DHTKD1 inhibitors with drug-like properties, we developed and performed a high-throughput screen based on the DHTKD1 activity assay (Figures S2A and S4A). We evaluated the robustness of the assay by performing a pilot screen of $\sim 4000$ molecules 
from a drug and bioactive collection and $\sim 600$ molecules from a diversity collection (ChemBridge). The screen was robust with a good assay window and percent coefficient of variance $\%$ CV $<5 \%$ and $Z^{\prime}$ of $0.84 \pm 0.10$ (Figure S4B). ${ }^{10}$ When considering compounds with inhibition greater than $3 \mathrm{SD}$ above the mean, the hit rate for drug (38 hit compounds, 1.7\%) and bio-actives (26 hit compounds, 1.4\%) was significantly higher when compared to the lower hit rate for diversity molecules (5 hit compounds, $0.8 \%$ ) (Figures S4C and S4D).

We then screened against a diversity library, a collection of 125,465 compounds from three libraries (ChemBridge, ChemDiv and CB Premium). Using a threshold criterion for inhibition greater than or equal to $3 S D$ above the mean (Bscore, inhibition and standard score), we identified 320 hit compounds (pilot screen and HTS) (Figure S5A). This group included 257 singletons and 63 compounds in 26 clusters ( $\geq 2$ members with similar structure) and corresponds to a hit rate of $\sim 0.25 \%$. Additional filtering resulted in a final number of 133 hit compounds (106 singletons and 27 compounds in 11 clusters, a hit rate of $\sim 0.17 \%$ ) (Figure S5B). We then selected 192 hit molecules from the primary screen (including all 133 hits after row exclusion and 59 after additional review but before row exclusion) for testing in a concentrationresponse inhibition assay. 40 out of the 192 hit molecules showed dose-response curves (Figure S6). 16 of these molecules had $\mathrm{IC}_{50} \leq 30 \mu \mathrm{M}$, and 13 were commercially available and advanced to the repurchase and re-evaluation phase (Figure S7).

The HTS was conducted by transferring fifty nanoliters of compound in DMSO (10 $\mu \mathrm{M}$ final compound concentration, $0.1 \% \mathrm{DMSO}$ ) by pin tool to $30 \mu \mathrm{L}$ of the reaction mixture A (buffer assay mixture and substrate) with shaking (Beckman Biomek FXP, Brea, CA). The activity assay was started by adding reaction mixture $B$ (enzyme in storage buffer; $20 \mu \mathrm{L}$ ). The reaction proceeded at room temperature for 30 min and was quenched by adding $100 \mu \mathrm{M}$ of $\mathrm{ZnCl}_{2}$, an inhibitor of DHTKD1 (IC $\left.50=2.7 \pm 0.1 \mu \mathrm{M}\right)$. The 384-well plates were read on an EnVision plate reader (PerkinElmer, Waltham, MA; absorbance at 600 $\mathrm{nm}$ ). Each plate included mock (no enzyme) and positive (adipoylphosphonic acid) controls. Assay performance was measured by $z$-prime $\left(Z^{\prime}\right)$, a dimensionless factor used to assess the quality of a HTS. ${ }^{10}$ Hit selection was based on dependent (\% inhibition) and independent (B score and standard score) activity parameters. The hit selection threshold was set at calculate mean $+3 S D$ and candidates must satisfy statistical criteria for all three parameters. Standard score (or z-score: (inhibition-mean)/SD)) and Bscore were measured as defined by Brideau et al. ${ }^{11}$ Additional further filtering of the screening hits was done by removing systematic influences (e.g. pattern of high absorbance/apparently inhibited rows). Compounds identified in the primary screen were cherry picked for dose-response assays. $150 \mathrm{~nL}$ of each compound was transferred by pin tool to each well with concentration ranging from $58 \mathrm{nM}$ to $30 \mu \mathrm{M}$. Primary screen results were analyzed using the UCSF SMDC web-based application HiTS. This webbased analysis platform provides a data analysis interface for viewing primary screen and dose-response results. Data analysis for dose-response inhibition experiments was carried out in GraphPad Prism 7 and curves were fit to a standard inhibition log dose-response curve to yield an $\mathrm{IC}_{50}$ value.

Repurchase of HTS compounds of interest. After dose-response evaluation of HTS hits, 13 out 17 hit compounds were commercially available and were purchased for further confirmation in DHTKD1 inhibition assays. HTS ID 255785 (Omeprazole, \#K253), Esomeprazole (\#J91970), and Omeprazole Sulfone (\#4281AC) were purchased from AK Scientific. HTS ID 255785 (Omeprazole, \#458520010), HTS ID 285797 (Pantoprazole sodium salt hydrate, \#460870010) were obtained from Acros Organics. HTS ID 757002 (Tenatoprazole, \#B1848) was from APExBio. HTS ID 130002 (Bithionol, \#T0865) and Pantoprazole Sulfide (\#P2066) were purchased from TCl America. HTS ID 48508 (\#5563352), HTS ID 49582 (\#5676527) were obtained from ChemBridge. HTS ID 155744 (\#5586-4259) and HTS ID 45447 (\#R052-1687) were from ChemDiv. HTS ID 29708 (\#Z44101855) was obtained from Enamine. HTS ID 49098 (\#STK758032), HTS ID 49259 (\#STL323879), HTS ID 48303 (\#STK398483) and HTS ID 36573 (\#STL297498) were purchased from Vitas-M Laboratory.

Assessment of DHTKD1 inhibitors in HEK-293 cells by amino acid analysis. HEK-293 cells (ATCC CRL-1573) were cultured in DMEM with $4.5 \mathrm{~g} / \mathrm{L}$ glucose, $584 \mathrm{mg} / \mathrm{L}$ L-glutamine and $110 \mathrm{mg} / \mathrm{L}$ sodium pyruvate, supplemented with $10 \% \mathrm{FBS}, 100 \mathrm{U} / \mathrm{mL}$ penicillin, $100 \mu \mathrm{g} / \mathrm{mL}$ streptomycin, in a humidified atmosphere of $5 \% \mathrm{CO}_{2}$ at $37{ }^{\circ} \mathrm{C}$. For quantification of 2-aminoadipic acid (AA) in HEK-293, the cells were incubated in DMEM supplemented with inhibitors using $0.1 \%$ DMSO or DMEM as the vehicle control for 
$24 \mathrm{~h}$. Cells were collected, washed in PBS, flash-frozen in liquid nitrogen and stored at $-80^{\circ} \mathrm{C}$ until further use. Samples were sonicated in ice cold demineralized water and then immediately deproteinized by adding ice cold acetonitrile up to $80 \%(\mathrm{v} / \mathrm{v})$. After $10 \mathrm{~min}$ centrifugation at maximum speed $\left(4{ }^{\circ} \mathrm{C}\right)$, the supernatant was dried under nitrogen and the residue was dissolved in $75 \mu \mathrm{L}$ of demineralized water. Amino acids were measured by LC-MS/MS (Sema4 formerly the Mount Sinai Genetic Testing Lab) as described. ${ }^{12}$ Protein pellets were dissolved in $25 \mathrm{mM} \mathrm{KOH}$ containing $0.1 \%$ Triton X-100, and the protein amount determined by the BCA method for subsequent normalization of the amino acid levels.

Protein purification for crystallography. DHTKD1 was cloned into a pET24 vector with a C-terminal $7 \mathrm{x}$ His tag. The plasmid was transformed into LOBSTR-BL21(DE3), a low background strain of $E$. coli. An overnight culture was used to inoculate $1 \mathrm{~L}$ of TB medium $(1: 1000)$ containing $50 \mu \mathrm{g} / \mathrm{ml}$ of kanamycin and grown at $37{ }^{\circ} \mathrm{C}$ until the cell density reached an $\mathrm{OD}_{600}$ of 1.0 . The cells were then cooled to $16{ }^{\circ} \mathrm{C}$ and induced overnight with $0.4 \mathrm{mM}$ isopropyl- $\beta$-D-thiogalactopyranoside (IPTG). The next day, cells were harvested and resuspended in Tris-buffered saline $(20 \mathrm{mM}$ Tris $\mathrm{pH} 8.0,250 \mathrm{mM} \mathrm{NaCl})$ and lysed with a French pressure cell at $25 \mathrm{~K}-30 \mathrm{~K}$ p.s.i. After pelleting down the cellular debris, the lysate was loaded onto a column containing HisPur ${ }^{\mathrm{TM}}$ Ni-NTA Resin (Thermo Scientific) for immobilized metal affinity chromatography (IMAC) purification. The column was equilibrated with 7 column volumes of TBS supplemented with $40 \mathrm{mM}$ imidazole $\mathrm{pH} 8.0$ then washed with 7 column volumes of $50 \mathrm{mM}$ Hepes buffer $\mathrm{pH}=7.5-7.6$ containing $150 \mathrm{mM} \mathrm{NaCl}, 25 \mathrm{mM}$ imidazole and adjusted to $\mathrm{pH} 7.5$. The column was then eluted step-wise with an elution buffer containing $20 \mathrm{mM}$ Tris- $\mathrm{HCl} \mathrm{pH}=8.0,2 \mathrm{mM} \mathrm{MgCl}$, $2 \mathrm{mM}$ ThDP and $250 \mathrm{mM}$ imidazole $\mathrm{pH}=8.0 \mathrm{in} 10 \%$ glycerol. The elution fractions were then pooled after the presence of protein was confirmed using SDS-PAGE. The pooled fractions were then dialyzed against a dialysis buffer (50 mM Hepes $\mathrm{pH}=7.6,150 \mathrm{mM} \mathrm{NaCl}, 2 \mathrm{mM} \mathrm{MgCl}, 1 \mathrm{mM}$ ThDP) at $4{ }^{\circ} \mathrm{C}$ using a $20 \mathrm{kDa}$ MWCO dialysis cassette (Thermo Scientific).

The protein did not produce diffracting crystals initially, so we then methylated the protein to improve crystal packing. Lysines were methylated following the method of Walter et al. ${ }^{13} 20 \mu \mathrm{L}$ of freshly prepared $1 \mathrm{M}$ dimethylamine-borane complex (DMAB) and $40 \mu \mathrm{L}$ of $1 \mathrm{M}$ formaldehyde ( $\mathrm{HCHO}$ ) were added to $1 \mathrm{ml}$ of $10 \mathrm{mg} / \mathrm{ml}$ of DHTKD1 in a $1.5 \mathrm{ml}$ Eppendorf tube. The tube was covered with aluminum foil and the reactions were gently mixed and incubated for $2 \mathrm{hrs}$ in cold room in that covered tube. Addition of DMAB and $\mathrm{HCHO}$ followed by $2 \mathrm{hrs}$ of incubation were repeated twice. Finally, $10 \mu \mathrm{L}$ of DMAB was added and the reaction was incubated overnight at $4{ }^{\circ} \mathrm{C}$ in the cold room. The next day, the methylation reaction was quenched by adding $125 \mu \mathrm{L}$ of $1 \mathrm{M}$ Tris, $\mathrm{pH}$ 7.5. Occasionally, this reaction caused some amount of protein to be precipitated, which was removed by high speed centrifugation prior to size exclusion chromatography. Following methylation, the protein was then purified by gel filtration on a Superdex 200 increase column (GE Lifescience) in a buffer of $20 \mathrm{mM}$ Tris- $\mathrm{HCl} \mathrm{pH} \mathrm{8.0,100} \mathrm{mM} \mathrm{KCl,} 1 \mathrm{mM} \mathrm{MgCl}, 1 \mathrm{mM}$ DTT and $0.5 \mathrm{mM}$ ThDP. Protein was then concentrated to approximately $10 \mathrm{mg} / \mathrm{ml}$ and flash frozen in liquid nitrogen.

Crystallization and structure determination. After screening crystal conditions, crystals were grown by the hanging drop vapor diffusion method by mixing $1 \mu \mathrm{l}$ protein with $1 \mu \mathrm{l}$ of reservoir containing $0.1 \mathrm{M}$ magnesium acetate, $0.1 \mathrm{M}$ MOPS pH 7.5, and 12\% PEG 8000 and $10 \%$ glycerol. Crystals were flash frozen in liquid nitrogen before collecting at the AMX (17-ID-1) beamline at NSLS II at Brookhaven National Laboratory. Data was processed using autoproc ${ }^{14}$ and scaled with Aimless. ${ }^{15}$ The structure was solved by molecular replacement, using the structure of the $M$. smegmatus 2-oxoglutarate dehydrogenase protein as a search model (PDB code $3 Z \mathrm{HQ}$ ) using the program Phaser ${ }^{16}$ after making a homology model using Phenix Sculptor. ${ }^{17}$ After molecular replacement, we performed multiples rounds of building using Phenix Autobuild. ${ }^{18}$ The models were subsequently refined using Phenix,${ }^{19}$ with rigid body refinement and multiple rounds of simulated annealing, minimization, atomic displacement parameter (ADP or B-factor) refinement and TLS refinement (determined using the TLSMD server), ${ }^{20,}{ }^{21}$ with interspersed manual adjustments using Coot. ${ }^{22}$ Geometric restraints for $\mathrm{N}$-methyl-lysine were generated with Phenix Elbow, ${ }^{23}$ and these restraints were used throughout refinement. All structural figures were made with Pymol. ${ }^{24}$ 
Ligand Docking. The crystal structure of DHTKD1 was prepared for docking using the Protein Preparation wizard in Maestro (Schrödinger) to add missing atoms, optimize hydrogen bonds, and minimize the structure (heavy atom convergence to RMSD $0.3 \AA$ ). Structures of ligands were prepared using ligprep (Schrödinger) with the OPLS3e force field and Epik ionization. Induced Fit Docking was carried out with Glide/Prime (Schrödinger) using the standard protocol and docking box centered on the active site of the crystal structure. Figures were generated using PyMOL (Schrödinger).

Site-specific mutagenesis and protein expression and purification of DHTKD1 variants. The DHTKD1 variants were constructed using the QuikChange $^{\circledR}$ || site-directed mutagenesis kit (Thermo Fisher Scientific Inc., MA, USA), the pET28a(+) vector encoding DHTKD1 as template and specific oligonucleotide primers listed in Table S3. Authenticity of the mutagenesis was verified by DNA sequencing. Variants for substrate specificity experiments were similarly generated by site-directed mutagenesis using overhanging primer PCR and Dpnl digestion and were verified by DNA sequencing.

Differential scanning fluorimetry. Differential scanning fluorimetry (DSF or thermal shift assay) for the DHTKD1 and its variants was performed on QuantStudio 3 real-time PCR system (Applied Biosystems). Purified proteins were diluted to a final concentration of $0.5 \mathrm{mg} / \mathrm{ml}$ in $100 \mathrm{mM}$ potassium phosphate, $\mathrm{pH}$, $2.1 \mathrm{mM} \mathrm{MgCl}_{2}, 0.21 \mathrm{mM}$ ThDP, $20 \%$ glycerol. $17.5 \mu \mathrm{L}$ of this $0.5 \mathrm{mg} / \mathrm{ml}$ protein was mixed with $2.5 \mu \mathrm{L}$ of $8 X$ SYPRO orange (Applied Biosystems) in a final $20 \mu \mathrm{L}$ reaction volume. This $8 X$ SYPRO orange was prepared by diluting the manufacturer supplied dye 250 -fold in $\mathrm{H}_{2} \mathrm{O}$. The reactions were kept at $25{ }^{\circ} \mathrm{C}$ for 2 min and then heated from 25 to $95{ }^{\circ} \mathrm{C}$ with a rate of $0.05{ }^{\circ} \mathrm{C} / \mathrm{s}$. The change in the fluorescence intensities of SYPRO orange was monitored as a function of the temperature and analyzed by Protein Thermal Shift Software 1.3. Each reaction was performed in 5 replicates. For substrates of DHTKD1 it was identical, except there were 4 replicates.

Statistics. Data are displayed as the mean \pm the standard deviation (SD). Differences between groups were evaluated using a one-way analysis of variance with Bonferroni's multiple comparison test (GraphPad Prism 7). Significance is indicated as follows: ${ }^{*} P<0.05,{ }^{* *} P<0.01,{ }^{* * *} P<0.001$ and ${ }^{* * * *} P<$ 0.0001 . 


\section{Supplementary Figures}

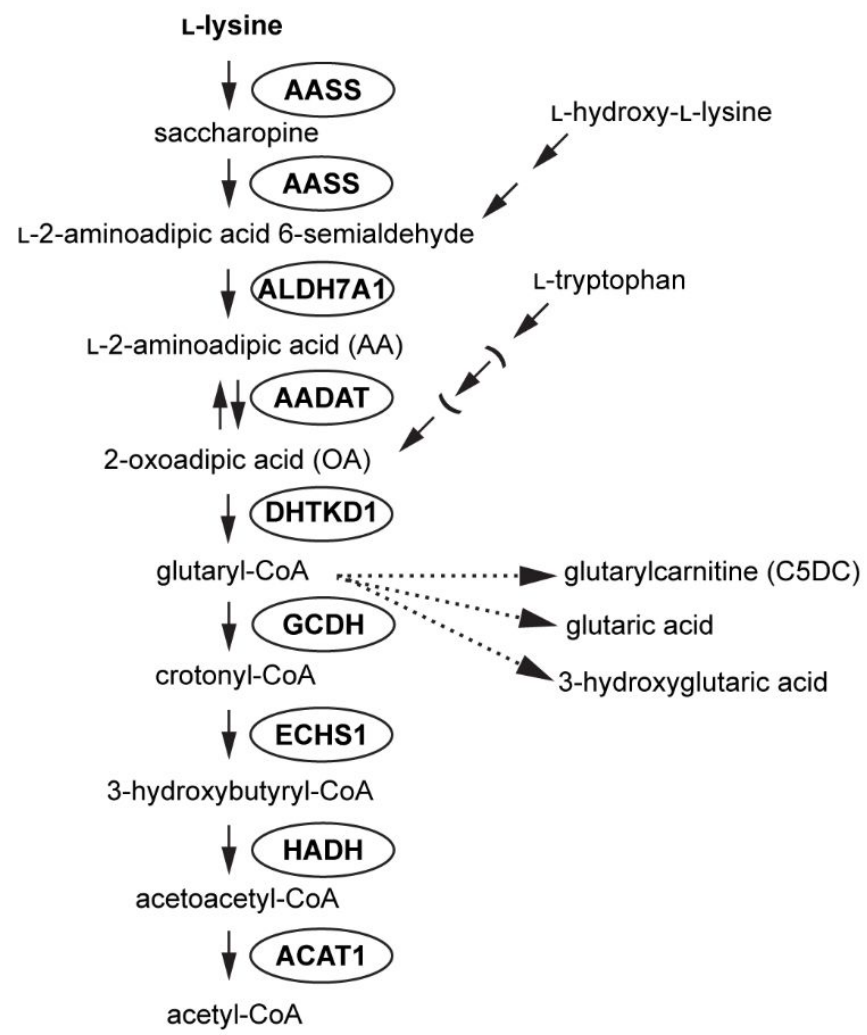

Figure S1. The degradation of L-lysine occurs mainly via the mitochondrial saccharopine pathway. The pathway consists of nine different enzymatic steps that ultimately yield 2 acetyl-CoAs and several reducing equivalents. Degradation of L-hydroxy-L-lysine leads to L-2-aminoadipic acid 6-semialdehyde and cytosolic degradation of tryptophan with kynurenine as intermediate leads to the production of 2oxoadipic acid (OA). The intermediate $O A$ is further metabolized into glutaryl-CoA via oxidative decarboxylation by the DHTKD1, the E1 component of the 2-oxoadipic acid dehydrogenase complex $(O A D H c)$. Defective DHTKD1 leads to accumulation of OA and AA (the level of AA correlates with the amount of OA by reversible transamination catalyzed by AADAT). Glutaryl-CoA is converted into crotonylCoA via oxidative decarboxylation by GCDH. The GCDH protein is deficient in GA1 leading to the accumulation of glutaryl-CoA metabolites: glutarylcarnitine (C5DC), glutaric acid and 3-hydroxyglutaric acid. AASS, alpha-aminoadipic semialdehyde synthase; ALDH7A1, alpha-aminoadipic semialdehyde dehydrogenase; AADAT, kynurenine/alpha-aminoadipate aminotransferase; DHTKD1, dehydrogenase $\mathrm{E} 1$ and transketolase domain containing 1; GCDH, glutaryl-CoA dehydrogenase; ECHS1, enoyl-CoA hydratase; HADH, hydroxyacyl-coenzyme A dehydrogenase; ACAT1, acetyl-CoA acetyltransferase. 
A

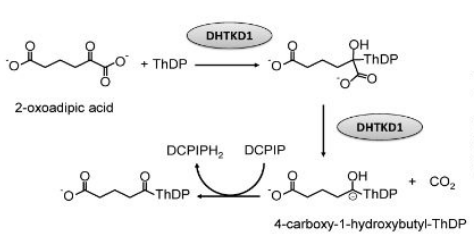

E

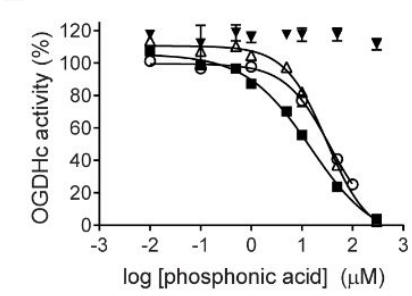

G

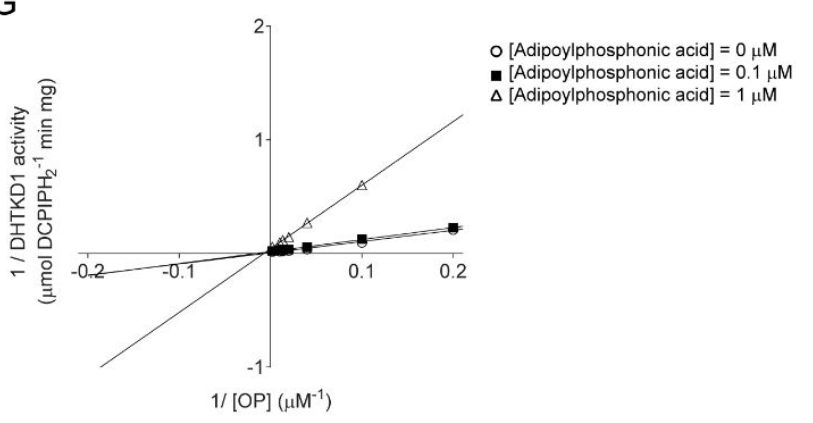

$\mathrm{H}$

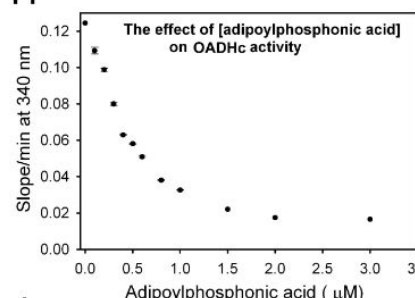

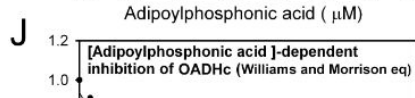

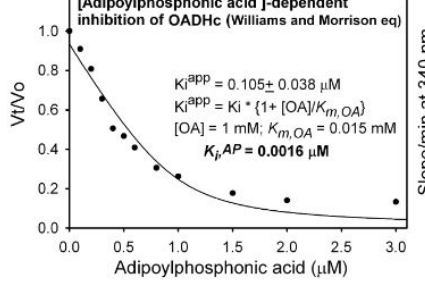

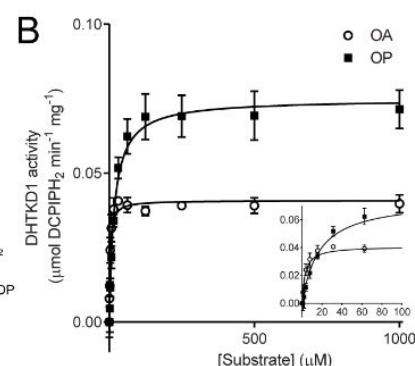

$\mathrm{F}$

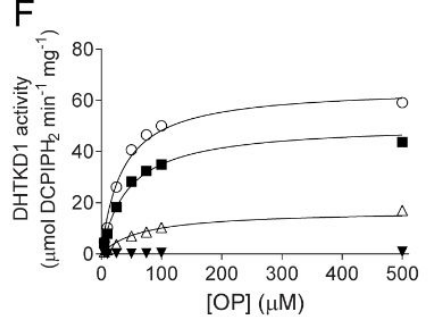

1

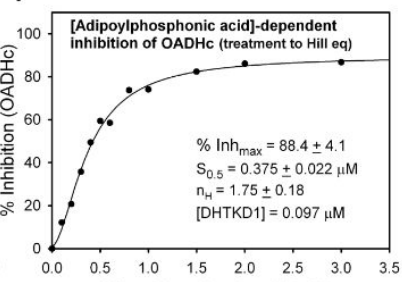

$\mathrm{K}$

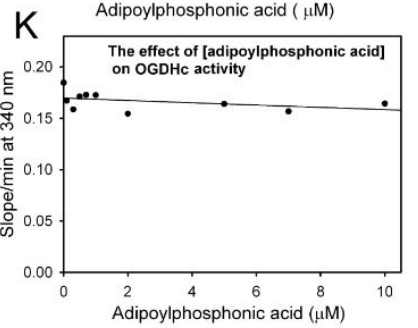

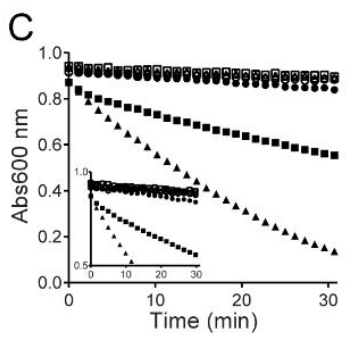

D
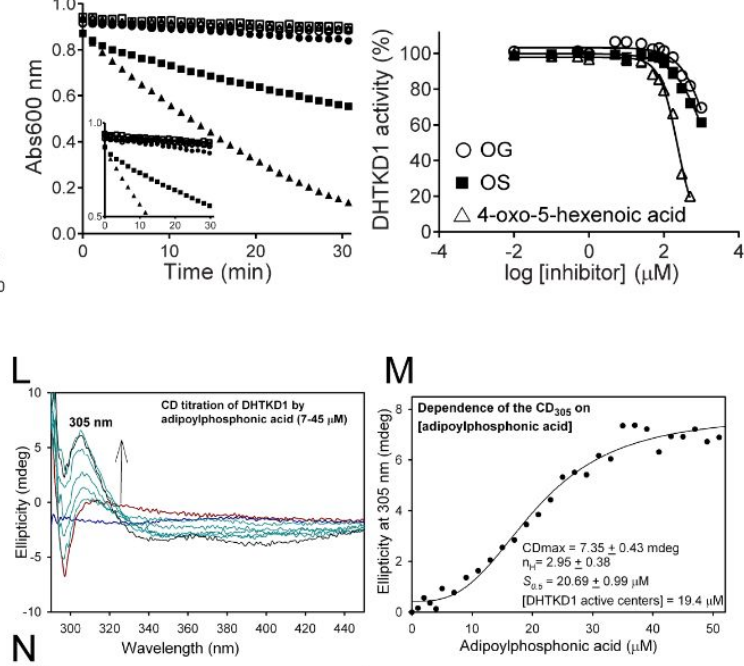

M
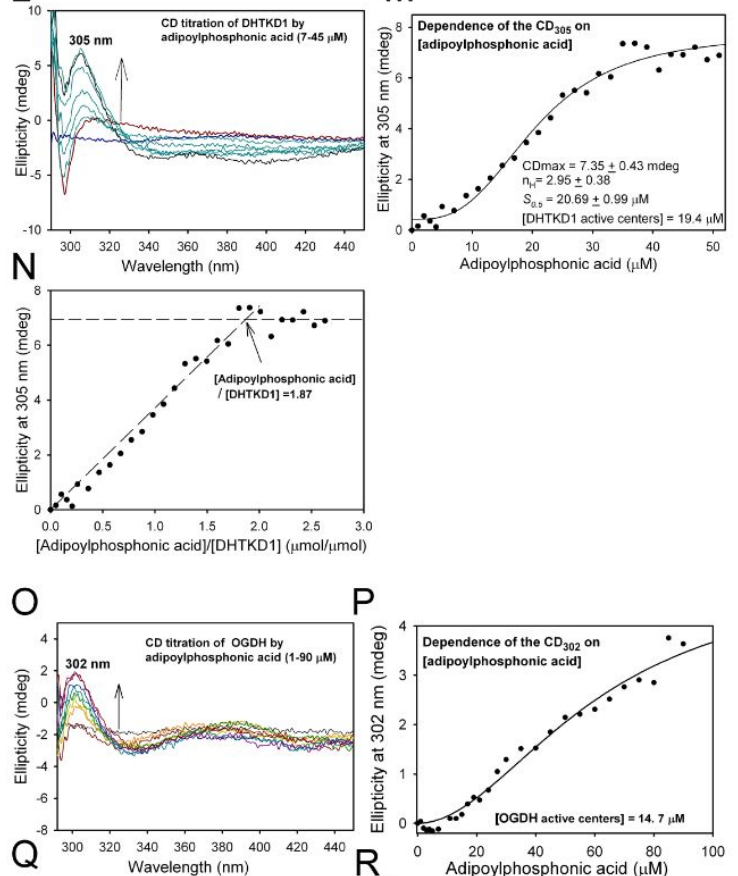

$P$
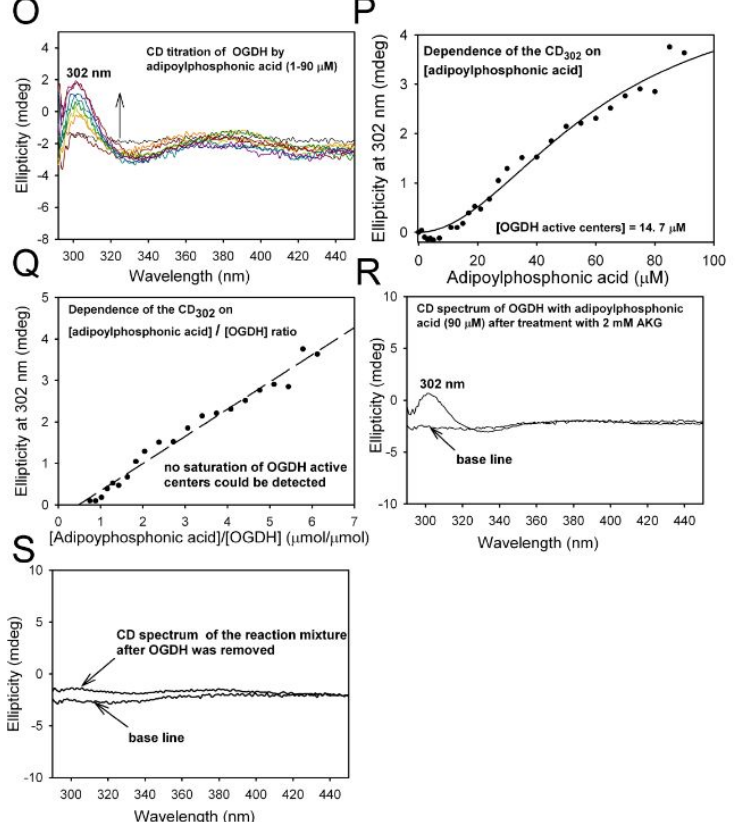

Figure S2. DHTKD1 substrate analog inhibitors. (A) DHTKD1 reaction using dark blue DCPIP as an artificial electron acceptor that turns transparent after reduction $\left(\mathrm{DCPIPH}_{2}\right)$. (B) Michaelis-Menten plots of DHTKD1 activity using $\mathrm{OA}$ or $\mathrm{OP}$ as substrates. The inset represents the data obtained in the concentration range $0-100 \mu \mathrm{M}$ of substrate $(C)$ Reaction progress curves of DHTKD1 using $1 \mathrm{mM}$ OG $(\bullet), 1 \mathrm{mM}$ OA $(\boldsymbol{\square})$ and $1 \mathrm{mM}$ OP $(\boldsymbol{\Delta})$ as substrates. Open symbols are the corresponding blanks. The inset (left-hand side) shows a close-up of the OA and OP curves at the start of the reaction. The DCPIPbased assay for E1 component was used, where DCPIP acts as an electron acceptor. The reaction was monitored by the decrease of absorbance at $600 \mathrm{~nm}$ corresponding to the formation of $\mathrm{DCPIPH}_{2}$. $(D)$ OG 
and OS are weak inhibitors of DHTKD1 whereas 4-oxo-5-hexenoic acid is an irreversible inhibitor. Preincubation of DHTKD1 with 4-oxo-5-hexenoic acid leads to a time-dependent increase in inhibition and a mass shift is observed upon separation in a SDS-PAGE gel, pointing to a covalent modification of the enzyme (data not shown). Dose-response curves of DHTKD1 inhibition by OG (O), OS ( $\mathbf{\square})$ and by 4-oxo5-hexenoic acid $(\triangle)$, using OP as substrate. The $\mathrm{IC}_{50}$ of OG, OS and 4-oxo-5-hexenoic acid are $1767 \pm$ $308,1470 \pm 139$ and $229 \pm 10 \mu \mathrm{M}$, respectively. $(E)$ Dose-response curves of porcine heart OGDHc inhibition by succinyl- $(\bigcirc)$, glutaryl- $(\boldsymbol{\nabla})$, adipoyl- $(\triangle)$ and pimeloyl- $(\boldsymbol{\nabla})$ phosphonic acids, using OG as substrate. $(F$ and $G$ ) Adipoylphosphonic acid is a DHTKD1 mixed competitive-noncompetitive inhibitor. DHTKD1 activity was measured at different concentrations of adipoylphosphonic acid: $0(\bigcirc), 0.1(\boldsymbol{\square}), 1$ $(\triangle)$ and $300 \mu \mathrm{M}(\boldsymbol{\nabla})$, in the presence of $62.5 \mu \mathrm{M}$ OP as substrate. A mixed-model of inhibition was used with the following parameters: $V_{\max }=65.1 \pm 1.8 \mu \mathrm{mol} \mathrm{DCPIPH} \mathrm{min}^{-1} \mathrm{mg}^{-1}, K_{\mathrm{m}}=34.9 \pm 3.0 \mu \mathrm{M}, \mathrm{K}_{\mathrm{i}}=0.15$ $\pm 0.03 \mu \mathrm{M}$ and $\alpha=2.3 \pm 0.8(\mathrm{~F})$. Double reciprocal plot showing inhibition of DHTKD1 by adipoylphosphonic acid. Linear regression analysis is consistent with mixed competitive-noncompetitive type of inhibition (G). (H-K) Inhibition of the human OADHc and OGDHc by adipoylphosphonic acid. Plot of the reaction rates as a function of [adipoylphosphonic acid]. The OADHc was assembled from DHTKD1 $(0.4 \mathrm{mg})$, DLST $(0.80 \mathrm{mg})$ and DLD $(5.0 \mathrm{mg})$ components in $0.1 \mathrm{M}$ Tris. $\mathrm{HCl}(\mathrm{pH} 7.5)$ containing $0.3 \mathrm{M}$ $\mathrm{NH}_{4} \mathrm{Cl}, 0.5 \mathrm{mM}$ ThDP and $2.0 \mathrm{mM} \mathrm{MgCl}_{2}$. After $40 \mathrm{~min}$ of incubation at $25^{\circ} \mathrm{C}$, an aliquot containing 0.01 $\mathrm{mg}$ of DHTKD1 and the corresponding amounts of DLST and DLD was withdrawn and was placed into 1 $\mathrm{ml}$ of the reaction assay containing all components necessary for the overall activity assay in the absence (control) and in the presence of 0.1-3 $\mu \mathrm{M}$ adipoylphosphonic acid. After $10 \mathrm{~min}$ incubation at $25^{\circ} \mathrm{C}$, the overall activity measurement was initiated by addition of 2-oxoadipic acid (1.0 mM) and CoA (400 $\mu \mathrm{M})$ and the progress curves were recorded at $37^{\circ} \mathrm{C}$ for $3 \mathrm{~min}$. The reaction rates (slope/min at $340 \mathrm{~nm}$ ) were calculated from a linear part of the recorded progress curves and were plotted versus [adipoylphosphonic acid] $(\mathrm{H})$. Plot of \% inhibition as a function of [adipoylphosphonic acid]. The solid curve shows the leastsquares fit of the data to the Hill plot equation: $y=y o+\left(\mathrm{V}_{\max }{ }^{*}\right.$ [adipoylphosphonic acid] $\left.{ }^{n}\right) /\left(\mathrm{S}_{0.5^{n}}{ }^{\mathrm{n}}+\right.$ [adipoylphosphonic acid] ${ }^{\mathrm{n}}$ (I). Plot of steady-state fractional velocity as a function of [adipoylphosphonic acid]. The solid curve shows the least-squares fit of the data to the Morrison equation for tight-binding inhibitors: ${ }^{25} \mathrm{v} / \mathrm{v}_{\mathrm{O}}=\left\{[\mathrm{E}]-[\mathrm{I}]-\mathrm{K}_{\mathrm{i}}^{\mathrm{app}}+\operatorname{sqrt}\left([\mathrm{E}]-[\mathrm{I}]-\mathrm{K}_{\mathrm{i}}^{\mathrm{app}}\right)^{2}+4[\mathrm{E}]^{*} \mathrm{~K}_{\mathrm{i}}^{\text {app }}\right\} / 2 \mathrm{E}$, where $[\mathrm{E}]$ is the concentration of DHTKD1 active centers, [l] is the total concentration of adipoylphosphonic acid, $\mathrm{K}_{\mathrm{i}}^{\mathrm{app}}$ is the dissociation constant of adipoylphosphonic acid, $v$ is the initial reaction velocity at different concentrations of the adipoylphosphonic acid, $v_{o}$, is the initial velocity in the absence of adipoylpohosphonic acid. If the inhibitor and substrate compete for the same active site, $\mathrm{K}_{\mathrm{i}}^{\text {app }}$ is related to the dissociation constant of the inhibitor $\left(\mathrm{K}_{\mathrm{i}}\right)$ by the following equation: $\mathrm{K}_{\mathrm{i}}^{\text {app }}=\mathrm{K}_{\mathrm{i}}\left(1+[\mathrm{S}] / K_{m}\right)$ where $K_{m}$ is the Michaelis constant and [S] is the concentration of substrate $(\mathrm{J})$. Plot of the reaction rates as a function of [adipoylphosphonic acid] for OGDHc with 2-oxoglutaric acid as substrate. The OGDH was assembled with DLST and DLD into OGDHc at $25{ }^{\circ} \mathrm{C}$ for 40 min similarly to that for DHTKD1 above. The overall activity measurement was initiated by addition of 2-oxoglutaric acid $(2.0 \mathrm{mM})$ and $\operatorname{CoA}(400 \mu \mathrm{M})$ and the progress curves were recorded at $37^{\circ} \mathrm{C}$ for $1 \mathrm{~min}(\mathrm{~K})$. $(L-N)$ Circular dichroism titration of DHTKD1 by adipoylphosphonic acid. The DHTKD1 (19.4 $\mu \mathrm{M}$ concentration of active centers) in $100 \mathrm{mM}$ HEPES (pH 7.5) containing $0.5 \mathrm{mM}$ ThDP, $2.0 \mathrm{mM} \mathrm{MgCl}_{2}, 0.15 \mathrm{M} \mathrm{NaCl}$ and $5 \%$ glycerol was titrated by adipoylphosphonic acid (1-51 $\left.\mu \mathrm{M}\right)(\mathrm{L})$. The intensity of the CD band at $305 \mathrm{~nm}$ was estimated and was plotted versus the concentration of adipoylphosphonic acid (M) or versus the [adipoylphosphonic acid]/[DHTKD1 active centers] ratio (N). $(\mathrm{O}-\mathrm{S})$ Circular dichroism titration of human OGDH by adipoylphosphonic acid. The OGDH (concentration of active centers of $14.7 \mu \mathrm{M})$ in $100 \mathrm{mM}$ HEPES $(\mathrm{pH} \mathrm{7.5)}$ containing $0.5 \mathrm{mM}$ ThDP, $2.0 \mathrm{mM} \mathrm{MgCl}, 0.15$ $\mathrm{M} \mathrm{NaCl}$ and $5 \%$ glycerol was titrated by adipoylphosphonic acid $(1-80 \mu \mathrm{M})(\mathrm{O})$. The intensity of the CD band at $302 \mathrm{~nm}$ was estimated and was plotted versus the concentration of adipoylphosphonic acid (P) or versus the [adipoylphosphonic acid]/[OGDH active centers] ratio (Q). The CD band at $302 \mathrm{~nm}$ was still observed after overnight incubation with $2.0 \mathrm{mM}$ 2-oxoglutaric acid; however, its intensity was reduced indicating weak binding of adipoylphosphonic acid to the active centers of OGDH and/or its partial replacement by an excess of 2-oxoglutaric acid overnight (R). On separation of OGDH from the reaction mixture, no CD band at $302 \mathrm{~nm}$ was detected as shown in panel (S), clearly demonstrating that the observed $\mathrm{CD}_{302}$ is a signature of the DHTKD1-bound pre-decarboxylation intermediate rather than product formation. 
A
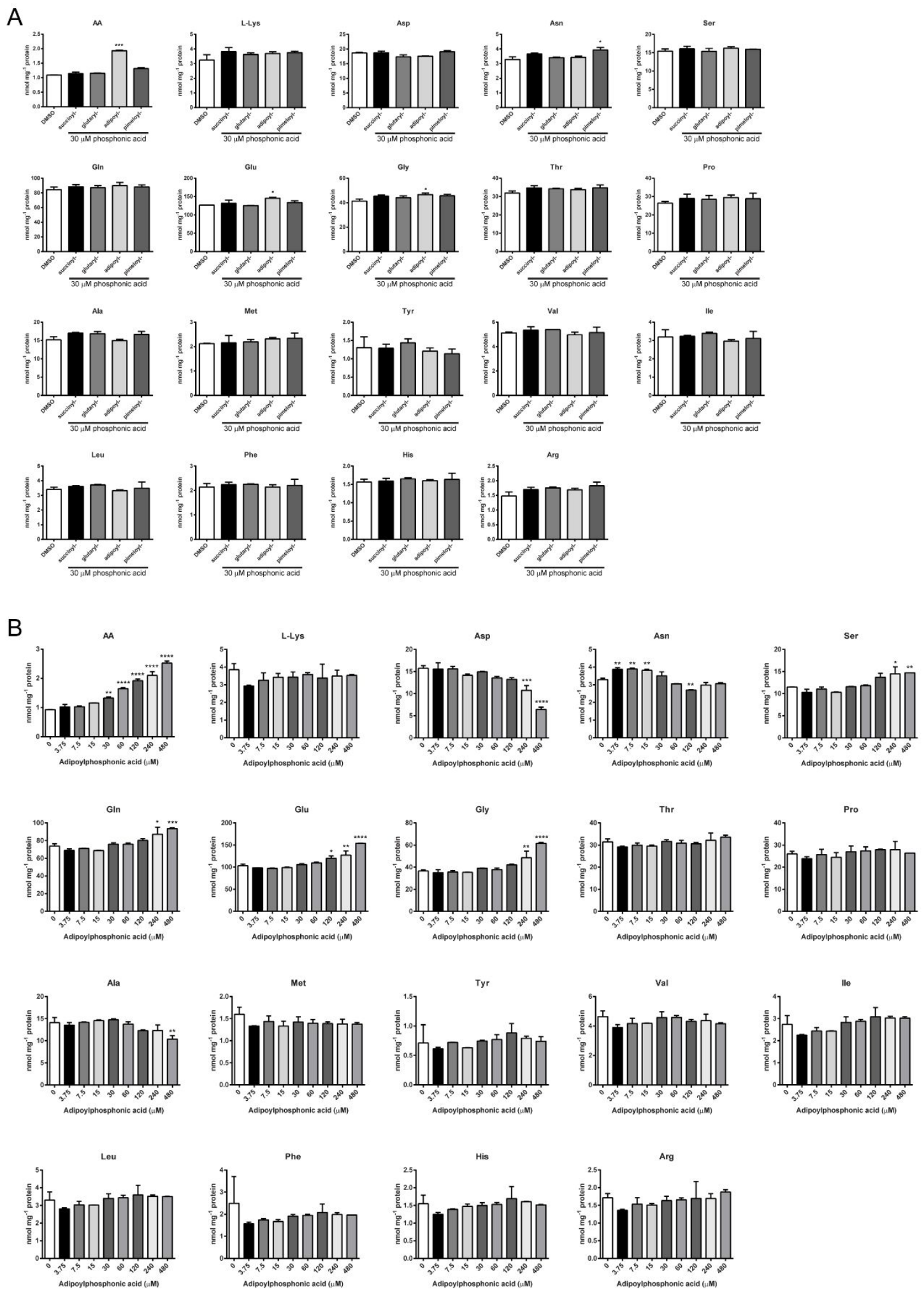

Figure S3. Adipoylphosphonic acid inhibits DHTKD1 in a cellular model. HEK-293 intracellular amino acid levels in the presence of different phosphonic acids $(30 \mu \mathrm{M})$ in DMEM medium $(A)$ and with increasing concentrations of adipoylphosphonic acid in DMEM medium (B). DMEM medium contained $0.8 \mathrm{mM} \mathrm{L}-$ lysine. ${ }^{*}, P<0.05 ;{ }^{* *}, P<0.01 ;{ }^{* * *}, P<0.001 ;{ }^{* * * *}, P<0.0001$. 
A

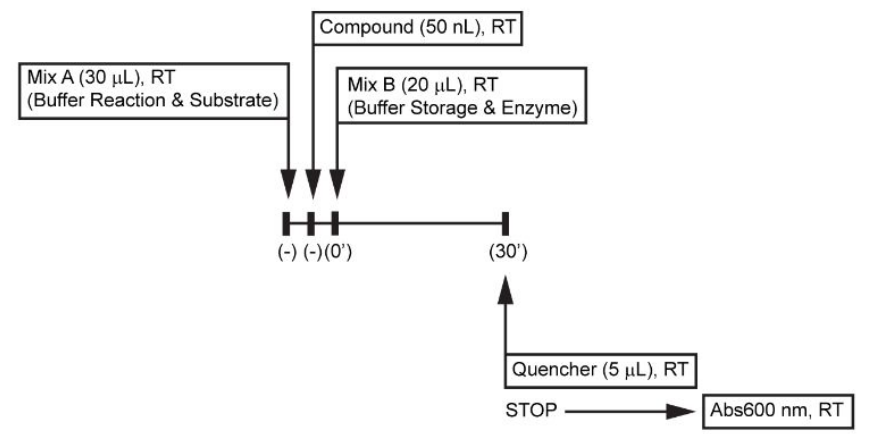

B

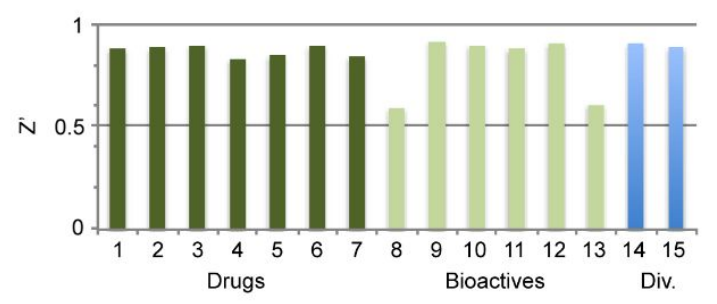

C

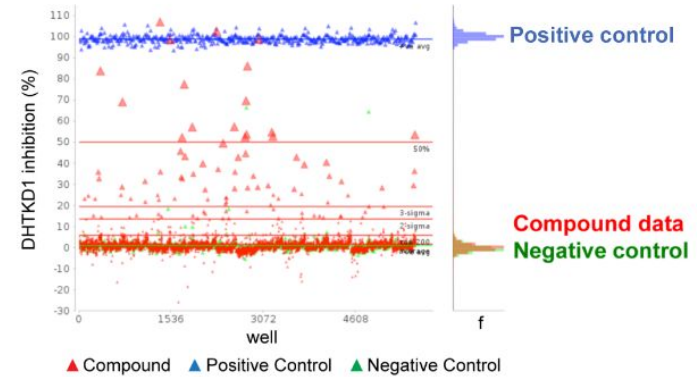

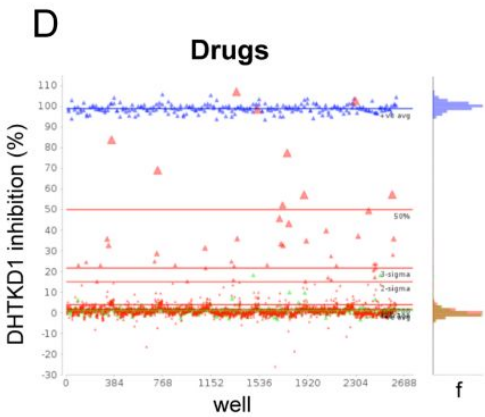

3SD limit: $20 \%$

Hits: $\quad 38$

Hit-rate: $1.7 \%$

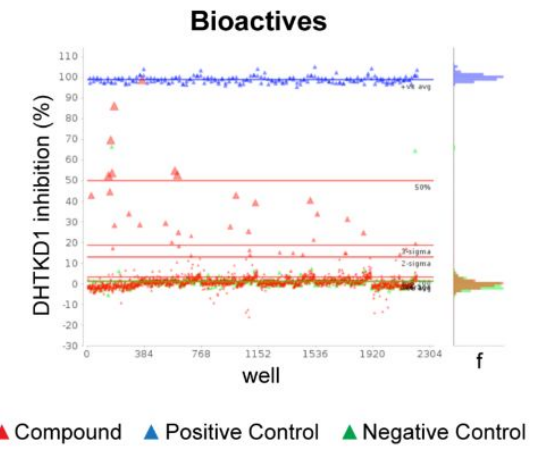

3SD limit: $18 \%$

Hits: $\quad 26$

Hit-rate: $1.4 \%$

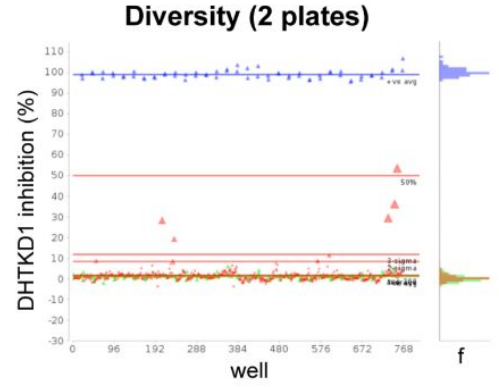

3SD limit: $11 \%$

Hits: 5

Hit-rate: $0.8 \%$

Figure S4. Pilot HTS and assay quality indicators for identification of DHTKD1 inhibitors. $(A)$ Schematic illustration of the inhibitor screen. Mix A (Buffer reaction \& Substrate, final concentration): $50 \mathrm{mM}$ MOPS, $\mathrm{pH} 7.4,100 \mathrm{mM} \mathrm{KCl}, 2 \mathrm{mM} \mathrm{MgCl} 2,1 \mathrm{mM}$ ThDP, $0.1 \mathrm{mM}$ DCPIP, $0.01 \%$ Triton X-100, 0.25\% Prionex and $62.5 \mu \mathrm{M}$ OP; Mix B (Buffer storage \& Enzyme, final concentration): $1.25 \mu \mathrm{g}$ DHTKD1 in dialysis buffer; Quencher: $100 \mu \mathrm{M} \mathrm{ZnCl}, 0.01 \%$ Triton X-100. (B) Z' performance over the 15 assay plates included in pilot phase: 2,177 compounds from the Drug collection (Pharmakon and SMDC drugs), 1,835 compounds from the Bioactive collection (SelleckChem bioactive) and 2 plates from the diversity collection (ChemBridge). The Z' was 0.8 (a Z' of 0.5 to 1.0 indicates a significant separation between positive and negative controls). The percent coefficient of variance ( $\% \mathrm{CV})$ was $<5 \%$ (a $\% \mathrm{CV}$ of $<15 \%$ is considered acceptable). (C) Scatter plot of DHTKD1 percentage inhibition of each well is shown for the screen pilot phase. Each symbol represents an assay well. Blue line is the mean inhibition of positive control (adipoylphosphonic acid inhibitor); red lines represent ' $50 \%$ inhibition', '3-sigma', and '2-sigma' above the mean of the population of compounds tested. $(D)$ Shows the same data as in (c), but the compounds tested have been grouped by library collection: drugs, bioactives and 2 plates from the diversity 
collection. The percentage of active compounds, number of hits, and hit-rate above three standard deviations are indicated for each collection. For each scatter plot the blue line is the mean inhibition of positive control (adipoylphosphonic acid); red lines represent ' $50 \%$ inhibition', '3-sigma', and '2-sigma' above the mean of the population of compounds tested. Green line represents the mean inhibition of negative control. 
A
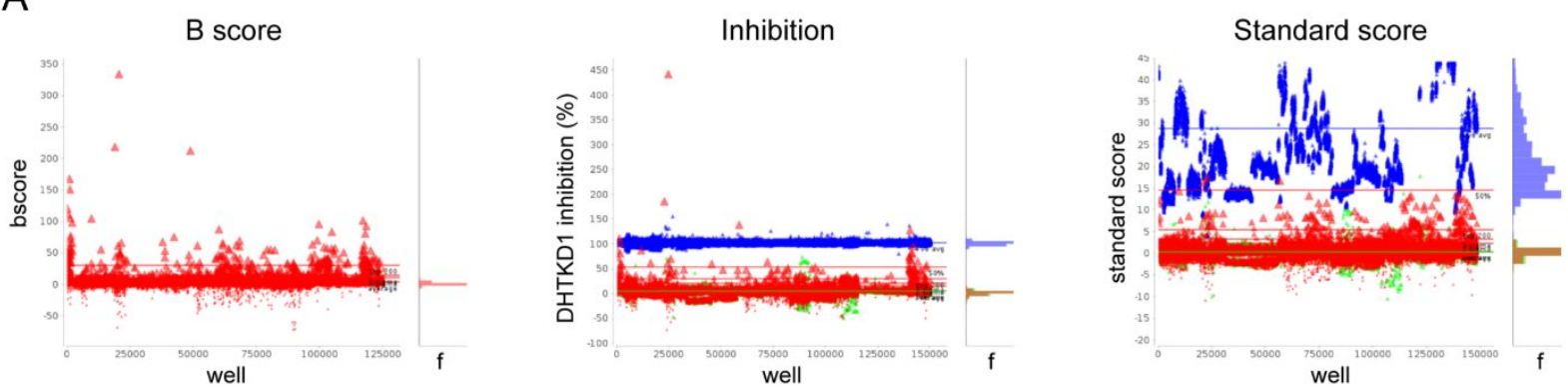

$\Delta$ Compound $\Delta$ Positive Control $\Delta$ Negative Control

B

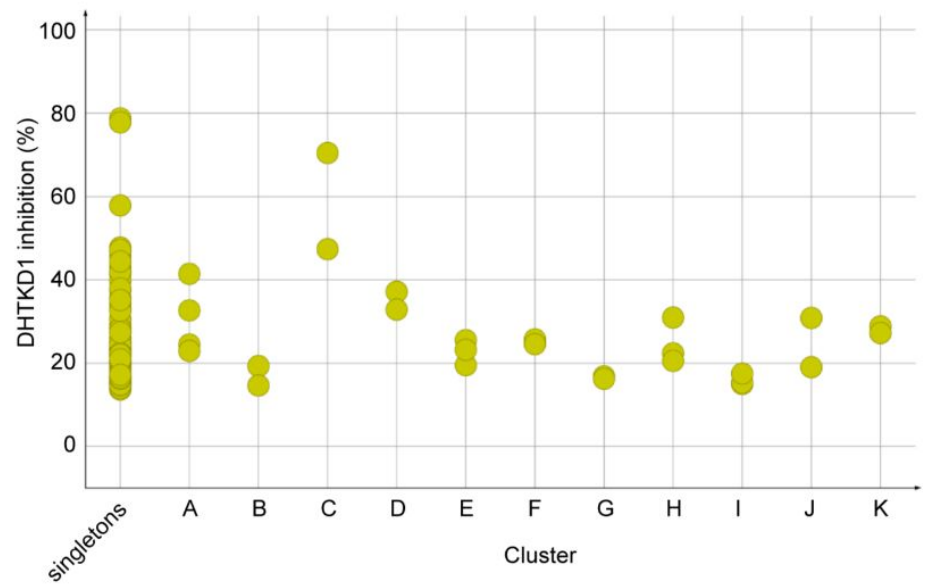

Figure S5. HTS for identification of DHTKD1 inhibitors. $(A)$ The B score, the DHTKD1 inhibition and standard score by well are shown for the HTS. Each symbol represents an assay well. The hit selection threshold was set at calculate mean $+3 S D$ for control dependent (\% inhibition) and independent (B score and standard score) activity parameters. The candidates must satisfy statistical criteria for all three parameters. Some outlier data points (inhibition $\geq 100 \%$ ) are occasionally seen. Blue line +ve avg, mean inhibition of positive control (adipoylphosphonic acid); red lines '3-sigma', '50\% inhibition', '2-sigma' above the mean of the population of compounds tested; red line top 200, top 200 active compounds above the mean of the population of compounds tested; red line average, mean of the population of compounds tested. Green line average, mean inhibition of negative control. Right graph represents the histogram of the compounds tested. $(B)$ HTS hit compounds meeting threshold criteria and after exclusion of persistent high absorbance row effect. 133 hit compounds were identified, including 106 singletons and 27 compounds in 11 clusters ( $\geq 2$ members, $A$ to K). Hit data clustered in DataWarrior, using default similarity limit $=0.8$. 
A

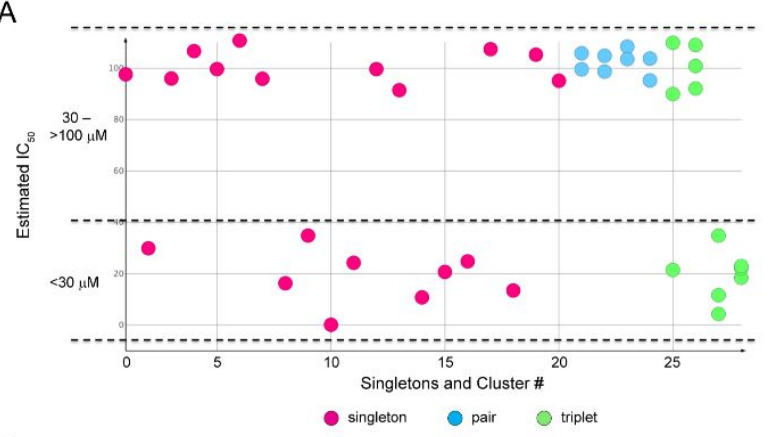

C

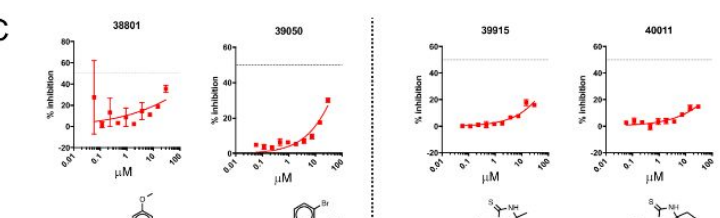

B
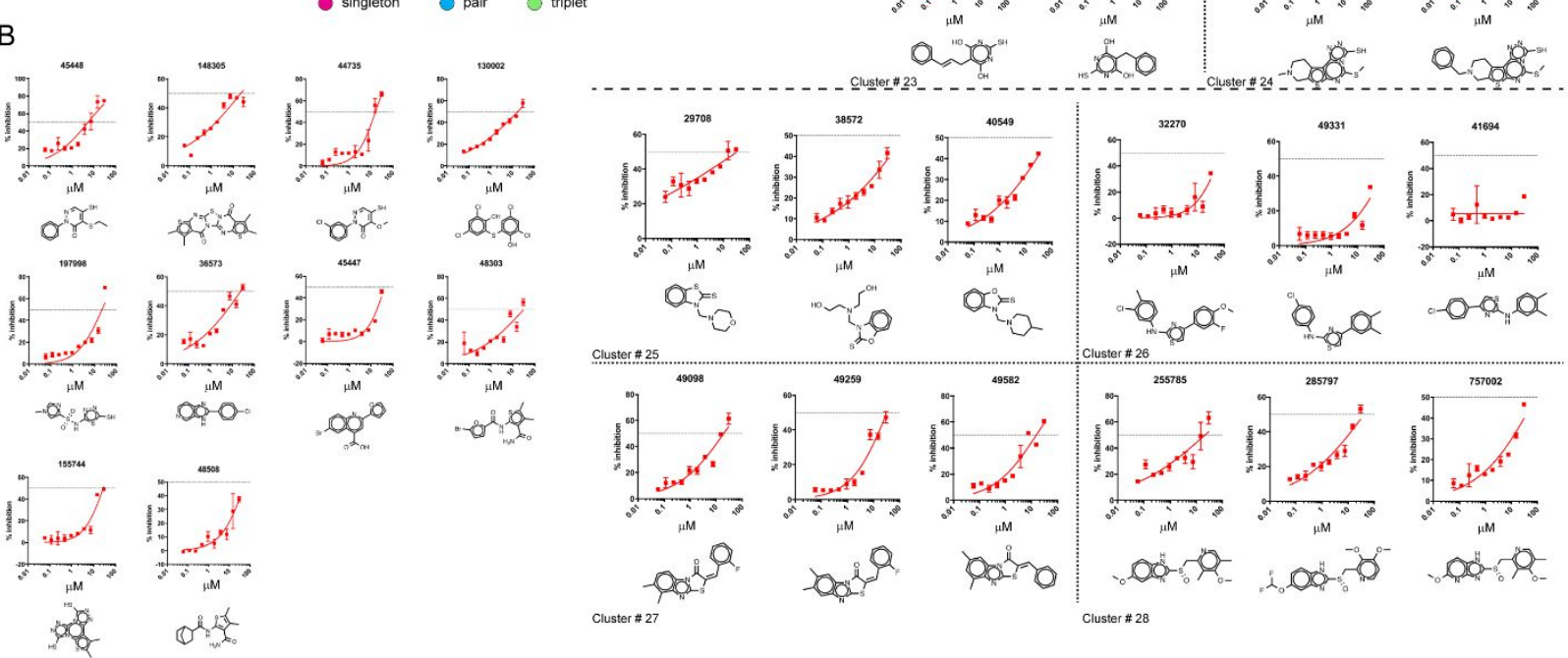

Figure S6. DHTKD1 inhibition concentration-response curves. (A) 40 out of 192 HTS hit compounds exhibited concentration responsive inhibition. 16 hit compounds had estimated $\mathrm{IC}_{50} \leq 30 \mu \mathrm{M}(9$ singletons and 7 compounds from 3 clusters). (B) Chemical structures and dose-response curves for singletons with $\mathrm{IC}_{50} \leq 30 \mu \mathrm{M}$. After evaluation of 64 extra HTS hit compounds, the hit $48508\left(\mathrm{IC}_{50} \sim 50 \mu \mathrm{M}\right)$ was added to the singleton list. $(C)$ Chemical structures and dose-response curves for compounds belonging to 8 structure clusters. No molecules retested yield complete dose curves, with greatest inhibition seen at $\sim 75 \%$. Several compounds display rollover (apparent saturation) at moderate inhibition, possibly due to poor compound solubility. 
Singletons
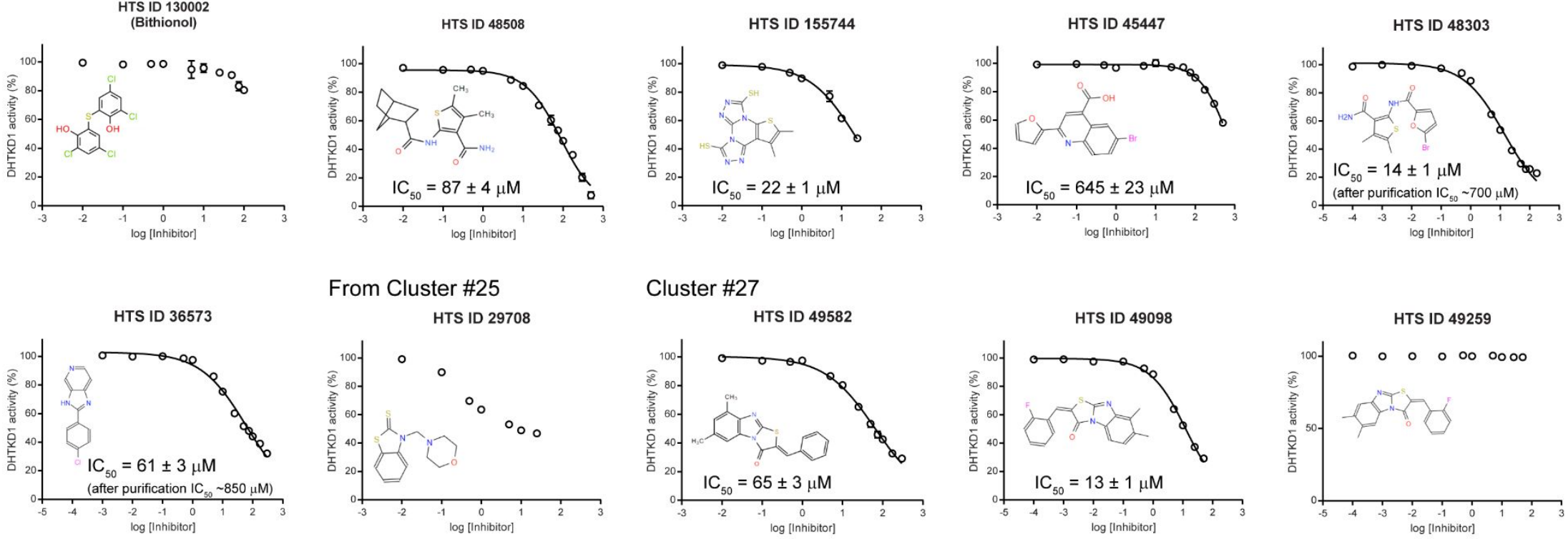

From Cluster \#25

Cluster \#27
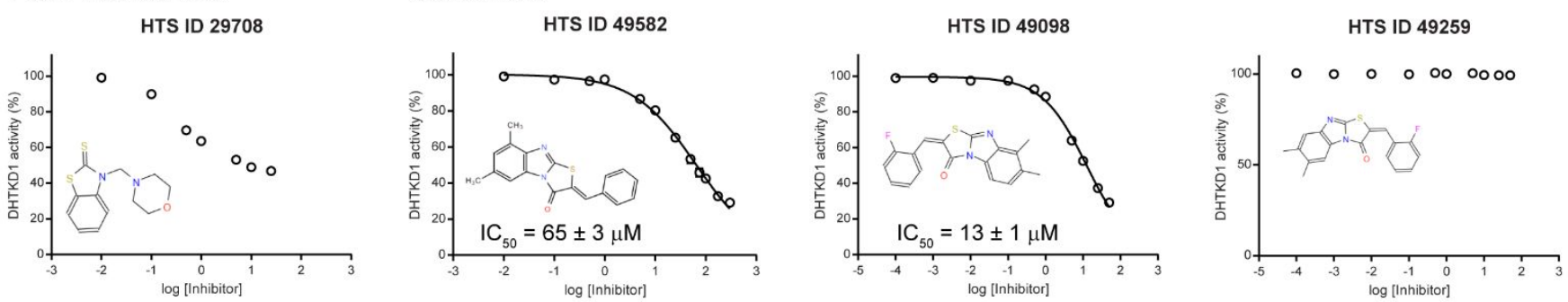

Cluster \#28
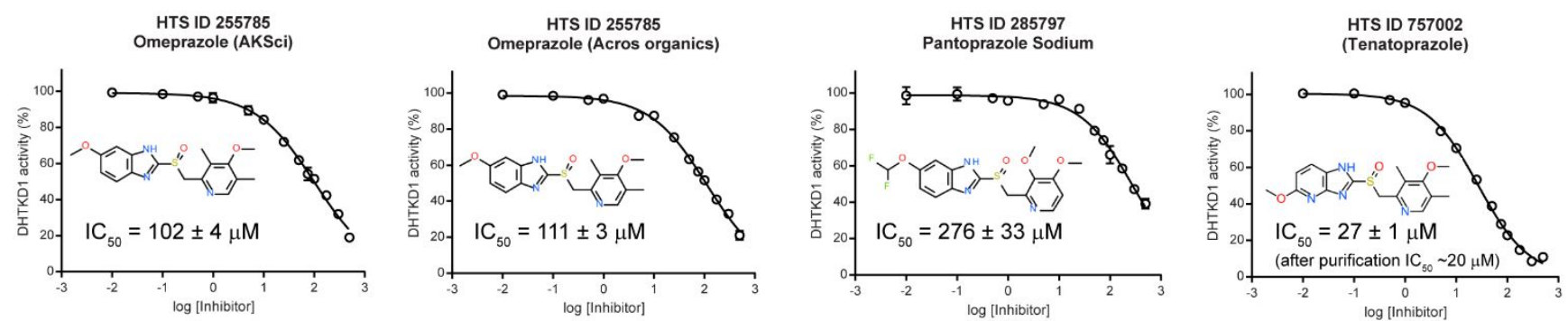

Figure S7. Confirmation of DHTKD1 HTS inhibitors. Chemical structures and dose-response curves of 13 repurchased hit compounds from commercial sources for confirmation. Hits 48303,36573 and 757002 were tested as repurchased material and after re-purification. The first two displayed much higher $\mathrm{IC}_{50} \mathrm{~S}$ values after purification. 

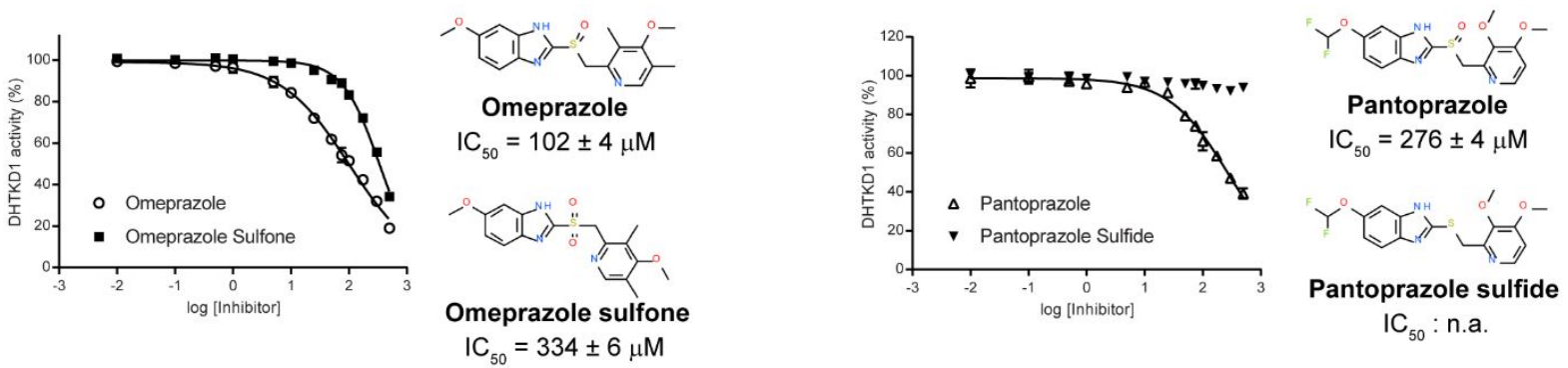

Figure S8. Dose-response curves of omeprazole and pantoprazole and their sulfone and sulfide analogs, respectively. 

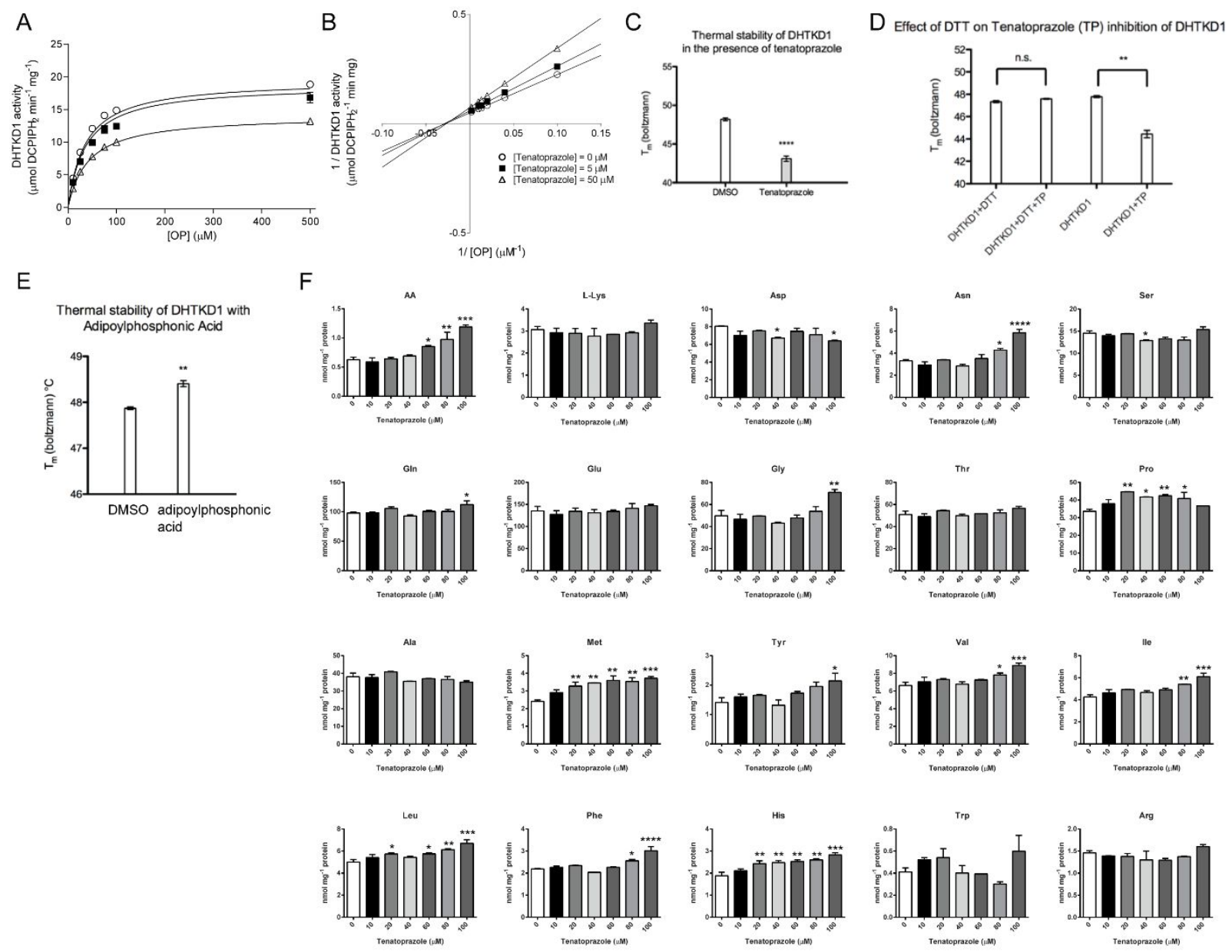

Figure S9. Tenatoprazole is a noncompetitive DHTKD1 inhibitor. $(A)$ DHTKD1 was incubated with $0(O)$, $5(\mathbb{\square})$ and $50 \mu \mathrm{M}(\triangle)$ of tenatoprazole. A mixed model of inhibition was used with $V_{\max }=19.5 \pm 0.6 \mu \mathrm{mol}$ DCPIPH ${ }_{2}$ min $^{-1} \mathrm{mg}^{-1}, K_{\mathrm{m}}=36 \pm 4 \mu \mathrm{M}, K_{\mathrm{i}}=83 \pm 34 \mu \mathrm{M}$ and $\alpha=1.5 \pm 0.9$. (B) Double reciprocal plot showing inhibition of DHTKD1 by tenatoprazole. Linear regression analysis is consistent with a noncompetitive type of inhibition. $(C)$ Thermal stability of DHTKD1 with or without $500 \mu \mathrm{M}$ tenatoprazole. (D) Effect of DTT on tenatoprazole thermal destabilization of DHTKD1. Tenatoprazole at $200 \mu \mathrm{M}$ or DMSO was incubated with DHTKD1 in the presence or absence of $2 \mathrm{mM} \mathrm{DTT.} \mathrm{(E)} \mathrm{Thermal} \mathrm{stability} \mathrm{of}$ DHTKD1 with or without $250 \mu \mathrm{M}$ adipoylphosphonic acid. $(F)$ HEK-293 cells were incubated with increasing concentrations of tenatoprazole and the level of intracellular amino acids was evaluated. Tenatoprazole was toxic to the cells above $100 \mu \mathrm{M} .{ }^{*}, P<0.05 ;{ }^{* *}, P<0.01$; ${ }^{* \star *}, P<0.001 ;{ }^{* \star *}, P<$ 0.0001 . 

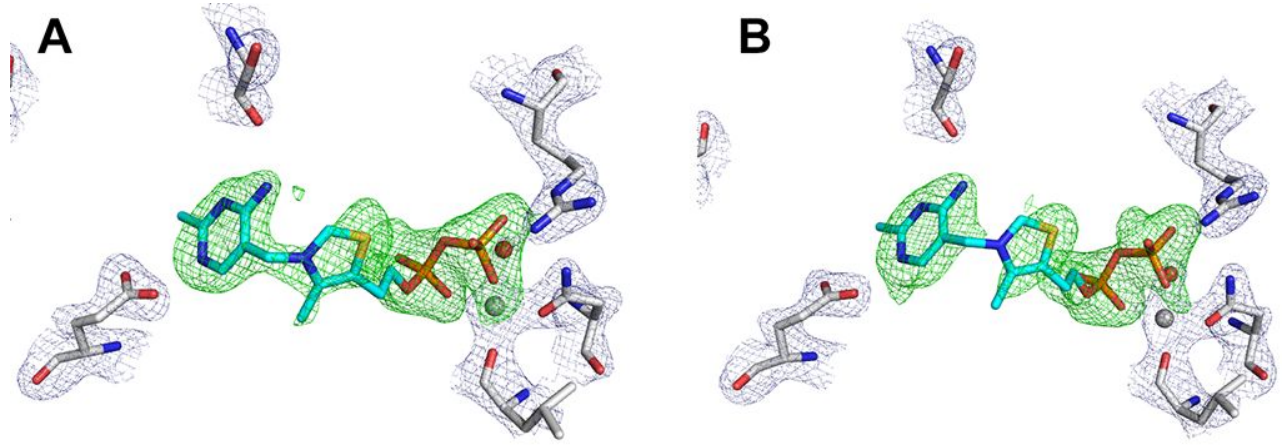

Figure S10. Electron density around ThDP cofactors in the two active sites of the DHTKD1 dimer. We generated simulated annealing omit maps around both ThDP cofactors to show unbiased $F_{o}-F_{c}$ density (in green), contoured at $2.8 \sigma$ around the ThDP and also $2 \mathrm{~F}_{\mathrm{o}}-\mathrm{F}_{\mathrm{c}}$ maps (in blue) for some of the surrounding sidechains, to demonstrate the density quality of the active site. The density is shown for ThDP in chain $A$ in $(A)$ and from chain $B$ in $(B)$. 

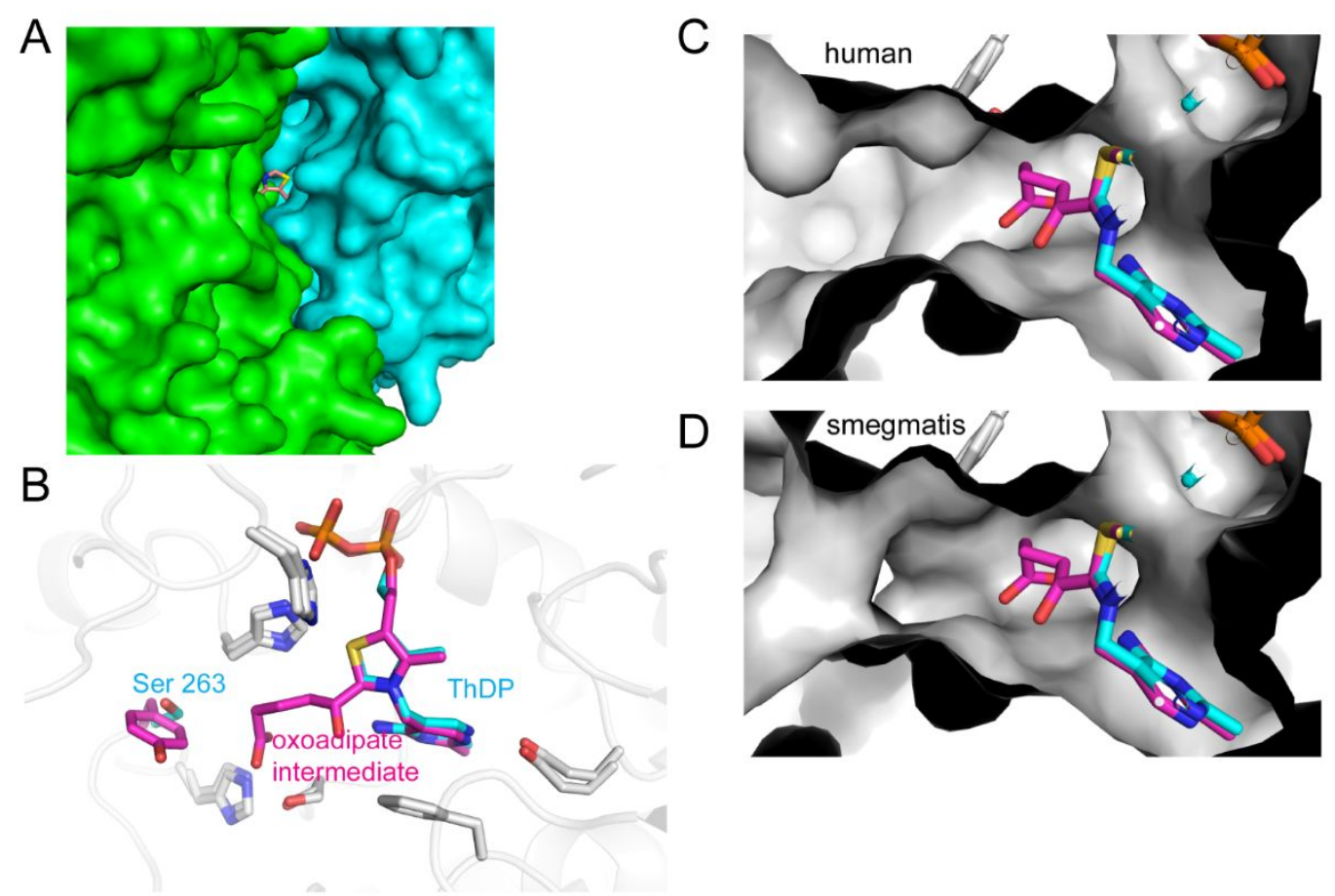

E
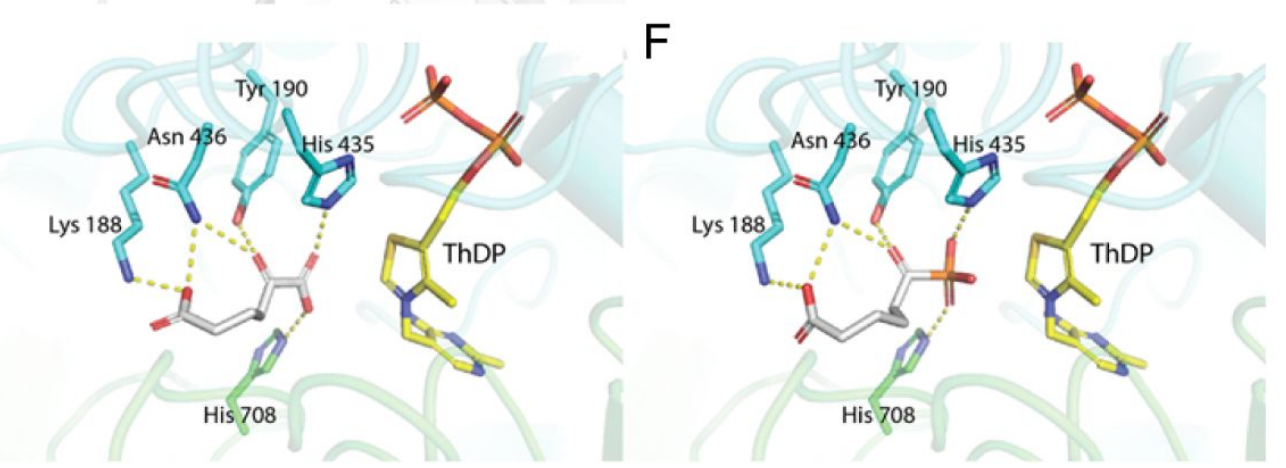

Figure S11. DHTKD1 structure, comparison with $M$. smegmatis KGD and docking of the substrate OA and the inhibitor adipoylphosphonic acid. $(A)$ View of the ThDP channel from outside the protein. $(B)$ Overlay of active sites of $M$. smegmatis (PDB code $3 Z \mathrm{HU})^{26}$ and our human DHTKD1 structure. (C) Surface rendering of human active site with modeled oxoadipate intermediate. $(D)$ Surface rendering of $M$. smegmatis structure with the OA intermediate. ( $E$ and $F$ ) Docking complex of OA (E) and docking complex of adipoylphosphonic acid (F). Polar contacts (hydrogen bonds and ionic interactions) interactions are shown as yellow dashed lines. Residues are colored according to the chain they belong to. Please see PyMOL session (ZIP). 
A
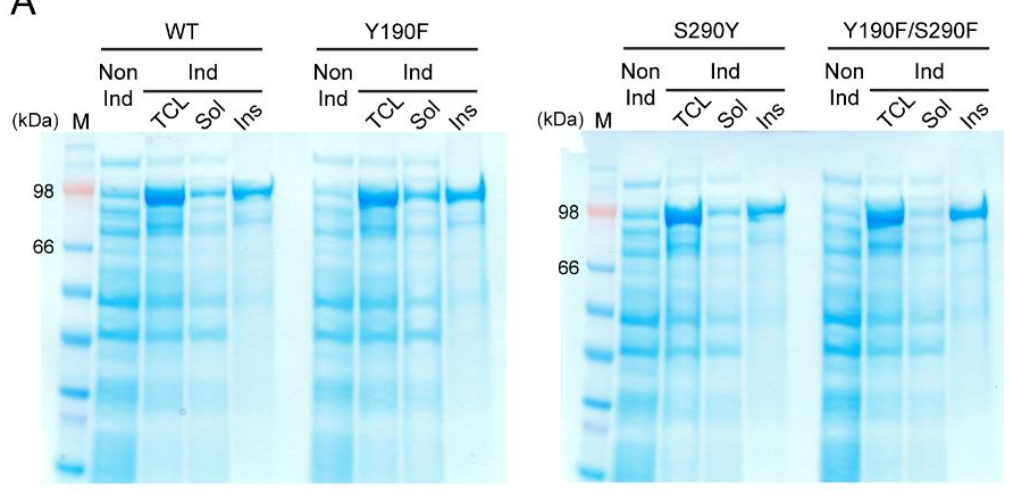

B
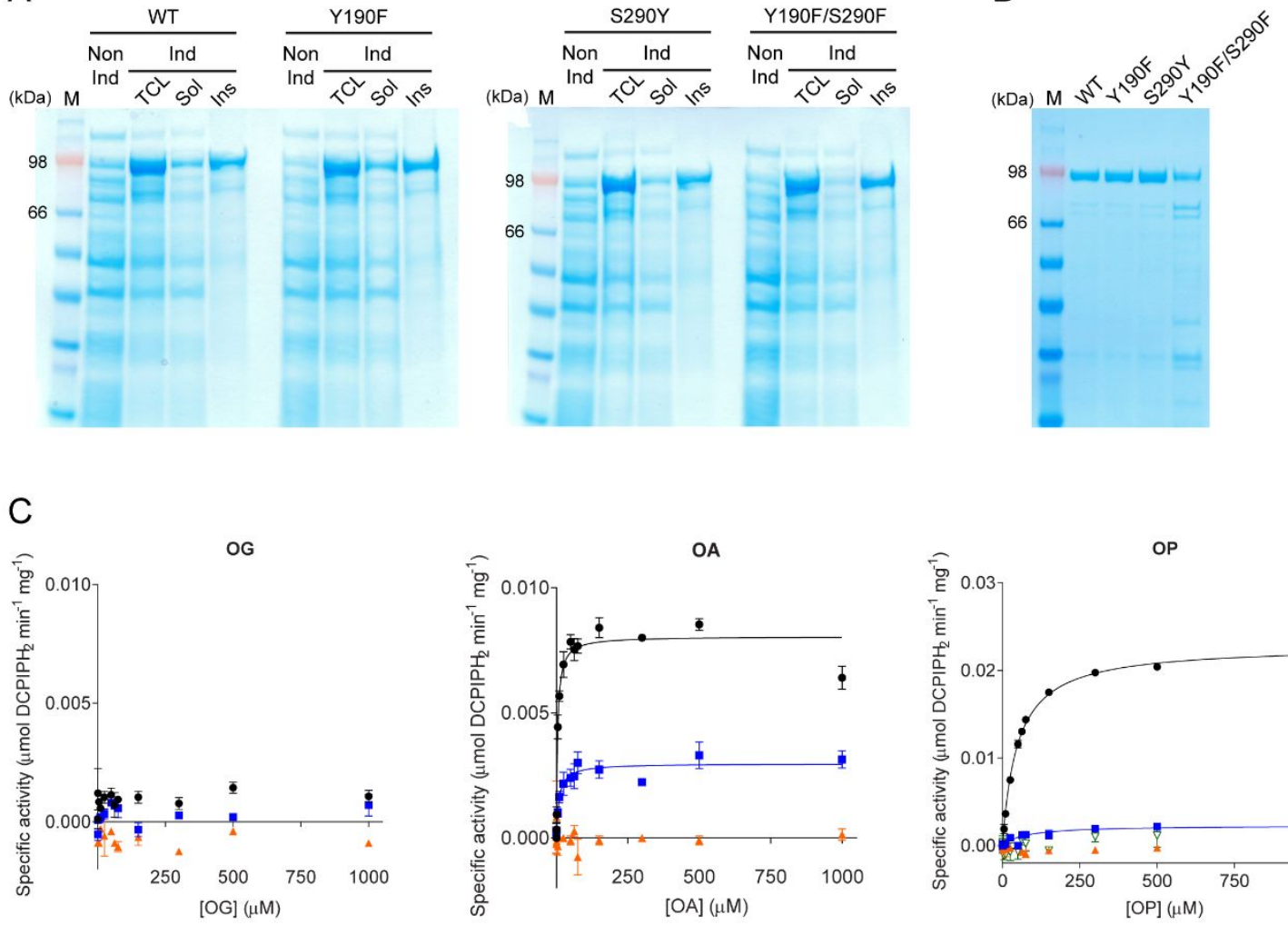

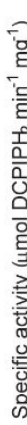
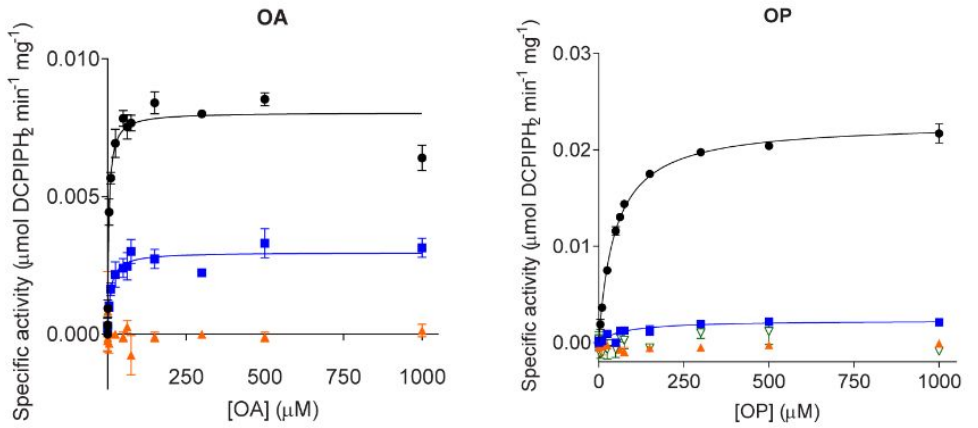

- WT

- Y190F

$4 \mathrm{~S} 288 \mathrm{Y}$

Y $190 \mathrm{~F} / \mathrm{S} 288 \mathrm{Y}$

\begin{tabular}{|c|c|c|c|c|c|c|c|c|c|c|c|c|}
\hline & \multicolumn{4}{|c|}{ OG } & \multicolumn{4}{|c|}{$O A$} & \multicolumn{4}{|c|}{ OP } \\
\hline DHTKD1 & $\begin{array}{l}\mathrm{V}_{\max } \\
\left(\mu \mathrm{mol} \mathrm{DCPIPH}_{2}\right. \\
\left.\mathrm{min}^{-1} \mathrm{mg}^{-1}\right)\end{array}$ & $\begin{array}{l}k_{\text {cat }} \\
\left(\mathrm{s}^{-1}\right)\end{array}$ & $\begin{array}{l}\mathrm{K}_{\mathrm{m}} \\
(\mu \mathrm{M})\end{array}$ & $\begin{array}{l}k_{\mathrm{cal} / \mathrm{I}} \mathrm{K}_{\mathrm{m}} \\
\left(\mathrm{M}^{-1} \mathrm{~s}^{-1}\right)\end{array}$ & $\begin{array}{l}V_{\max } \\
\left(\mu \mathrm{mol}^{-1} \mathrm{DCPIPH}_{2}\right. \\
\left.\mathrm{min}^{-1} \mathrm{mg}^{-1}\right)\end{array}$ & $\begin{array}{l}k_{\text {cat }} \\
\left(\mathrm{s}^{-1}\right)\end{array}$ & $\begin{array}{l}\mathrm{K}_{\mathrm{m}} \\
(\mu \mathrm{M})\end{array}$ & $\begin{array}{l}k_{\text {cac }} / \mathrm{K}_{\mathrm{m}} \\
\left(\mathrm{M}^{-1} \mathrm{~s}^{-1}\right)\end{array}$ & $\begin{array}{l}\text { Vmax } \\
\left(\mu \operatorname{mol}^{-1} \mathrm{DCPIPH}_{2}\right. \\
\left.\mathrm{min}^{-1} \mathrm{mg}^{-1}\right)\end{array}$ & $\begin{array}{l}k_{\text {cat }} \\
\left(\mathbf{s}^{-1}\right)\end{array}$ & $\begin{array}{l}\mathrm{Km} \\
(\mu \mathrm{M})\end{array}$ & $\begin{array}{l}k_{\mathrm{ca} a} / \mathrm{K}_{\mathrm{m}} \\
\left(\mathrm{M}^{-1} \mathrm{~s}^{-1}\right)\end{array}$ \\
\hline WT & inactive & - & - & - & $0.0081 \pm 0.0002$ & $0.027 \pm 0.001$ & $4.3 \pm 0.6$ & $6310 \pm 1036$ & $0.0228 \pm 0.0002$ & $0.076 \pm 0.001$ & $48 \pm 2$ & $1591 \pm 80$ \\
\hline Y190F & inactive & - & - & - & $\begin{array}{l}0.0030 \pm 0.0001 \\
(p<0.0001)\end{array}$ & $\begin{array}{l}0.010 \pm 0.001 \\
(p<0.0001)\end{array}$ & $\begin{array}{l}9.1 \pm 2.1 \\
(p=0.017)\end{array}$ & $\begin{array}{l}1104 \pm 292 \\
(p=0.0011)\end{array}$ & $\begin{array}{l}0.0023 \pm 0.0002 \\
(p<0.0001)\end{array}$ & $\begin{array}{l}0.008 \pm 0.001 \\
(p<0.0001)\end{array}$ & $74 \pm 19$ & $\begin{array}{l}104 \pm 36 \\
(p<0.0001)\end{array}$ \\
\hline S288Y & inactive & - & - & - & inactive & - & - & - & inactive & - & - & - \\
\hline Y190F/S288Y & n.d. ${ }^{a}$ & - & - & - & n.d. & - & - & - & inactive & - & - & - \\
\hline
\end{tabular}

an.d., not determined.

Figure S12. DHTKD1 variant expression and enzyme kinetics for evaluation of substrate specificity. $(A)$ SDS-PAGE analysis of the solubility of Y190F, S288Y and Y190F/S288Y double mutant DHTKD1 variants. M, low molecular mass marker; Non Ind, total cell lysate before induction; Ind, IPTG induced fraction; TCL, total cell lysate after $24 \mathrm{~h}$ induction of recombinant human DHTKD1 by $1 \mathrm{mM}$ IPTG at RT; Sol, soluble fraction; Ins, insoluble fraction. (B) Analysis of purified DHTKD1 (wild-type and variants) by SDS-PAGE. (C) (upper panel) The effect of substrates (OG, OA and OP) concentration on the catalytic activity of DHTKD1 wild type and variants. (lower panel) Steady-state kinetic properties of DHTKD1 wild type and variants. The data was analyzed by non-linear regression analysis using the GraphPad Prism 7 software and the Michaelis-Menten equation. The DHTKD1 activity was assayed at standard conditions $\left(0-1000 \mu \mathrm{M}\right.$ OG/OA/OP, $2 \mathrm{mM} \mathrm{MgCl}, 1 \mathrm{mM}$ ThDP and $\left.30^{\circ} \mathrm{C}\right)$ and the catalytic efficiency $\left(k_{\text {cat }} / \mathrm{K}_{\mathrm{m}}\right)$ was calculated on the basis of dimer molecular mass of $201 \mathrm{kDa}$ for the DHTKD1 processed form after removal of the mitochondrial transit peptide. 

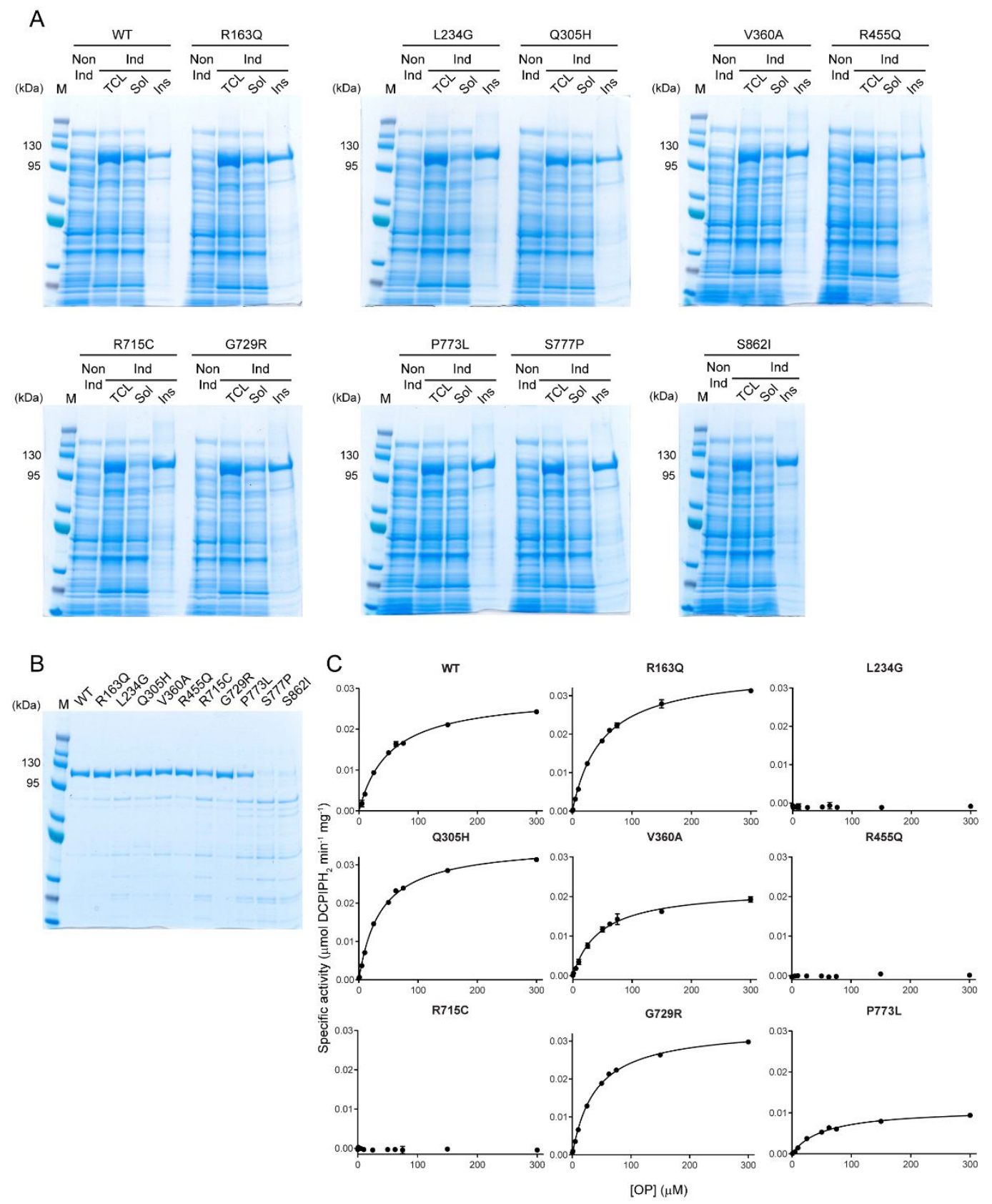

$\mathrm{D}$

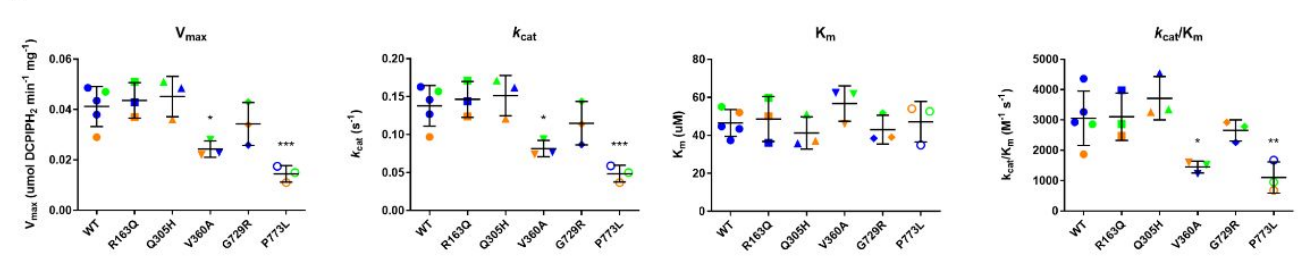

Figure S13. Expression and enzyme kinetics of human DHTKD1 variants. $(A)$ SDS-PAGE analysis of the solubility of the different DHTKD1 variants. M, low molecular mass marker; Non Ind, total cell lysate before induction; Ind, IPTG induced fraction; TCL, total cell lysate after $24 \mathrm{~h}$ induction of recombinant human DHTKD1 by $1 \mathrm{mM}$ IPTG at RT; Sol, soluble fraction; Ins, insoluble fraction. $(B)$ Analysis of purified 
DHTKD1 (wild-type and variants) by SDS-PAGE. (C) The effect of substrate (OP) concentration on the catalytic activity of wild type and variant DHTKD1 proteins. The DHTKD1 activity was assayed at standard conditions $\left(0-300 \mu \mathrm{M}\right.$ OP, $2 \mathrm{mM} \mathrm{MgCl} 2,1 \mathrm{mM}$ ThDP and $\left.30{ }^{\circ} \mathrm{C}\right)$. The data were analyzed by non-linear regression analysis using the GraphPad Prism 7 software and the Michaelis-Menten equation. (D) Steady-state kinetic properties of three protein batches of wild type and variant DHTKD1 protein (color coded). The mean \pm SEM values are shown in Table 1 . The catalytic efficiency $\left(k_{\text {cat }} / K_{m}\right)$ was calculated on the basis of dimer molecular mass of $201 \mathrm{kDa}$ for the DHTKD1 processed form after removal of the mitochondrial transit peptide. 


\section{Supplementary Tables}

Table S1. Evaluation of DHTKD1 substrate analogs as inhibitors and confirmed HTS hits.

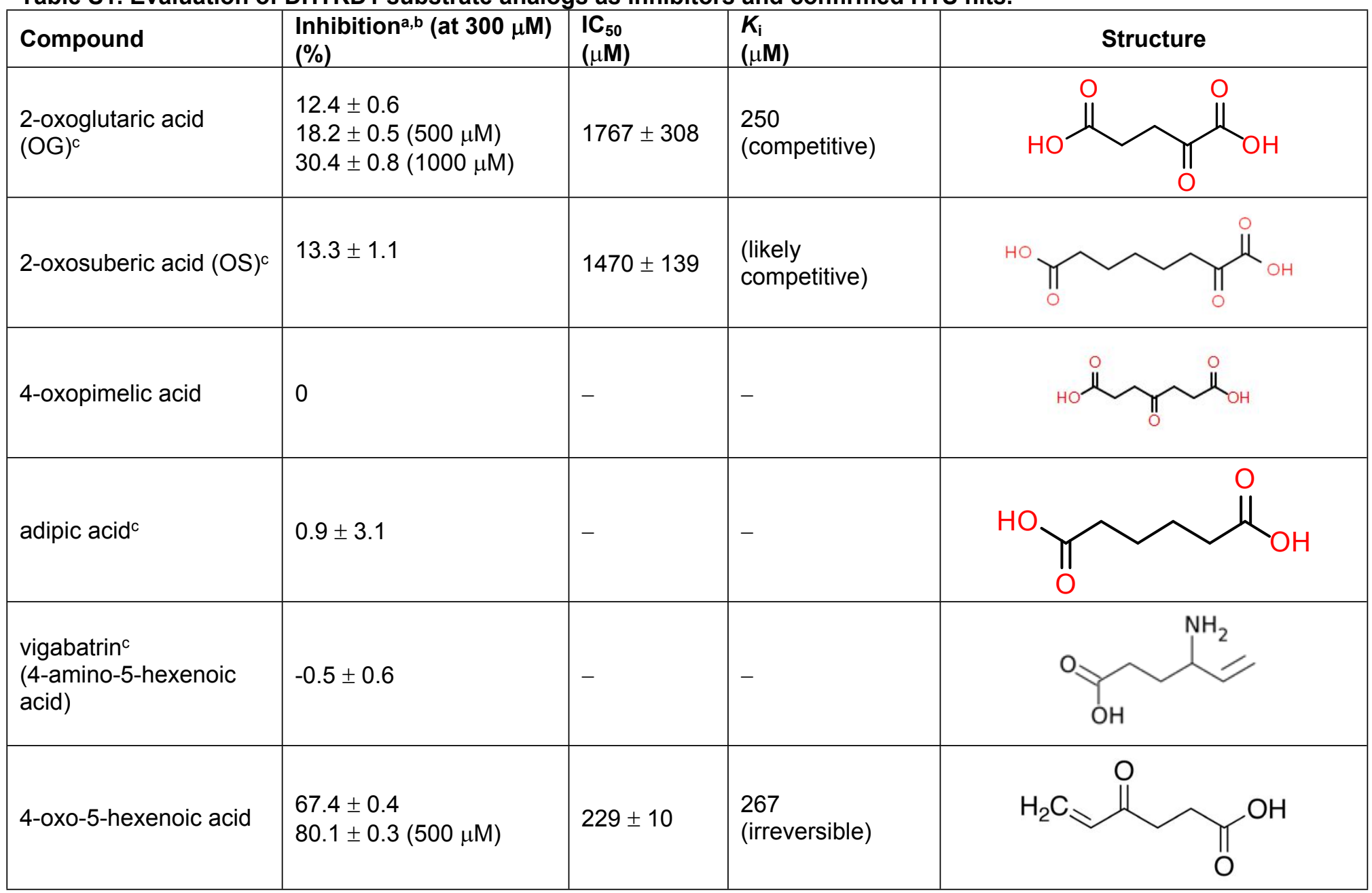




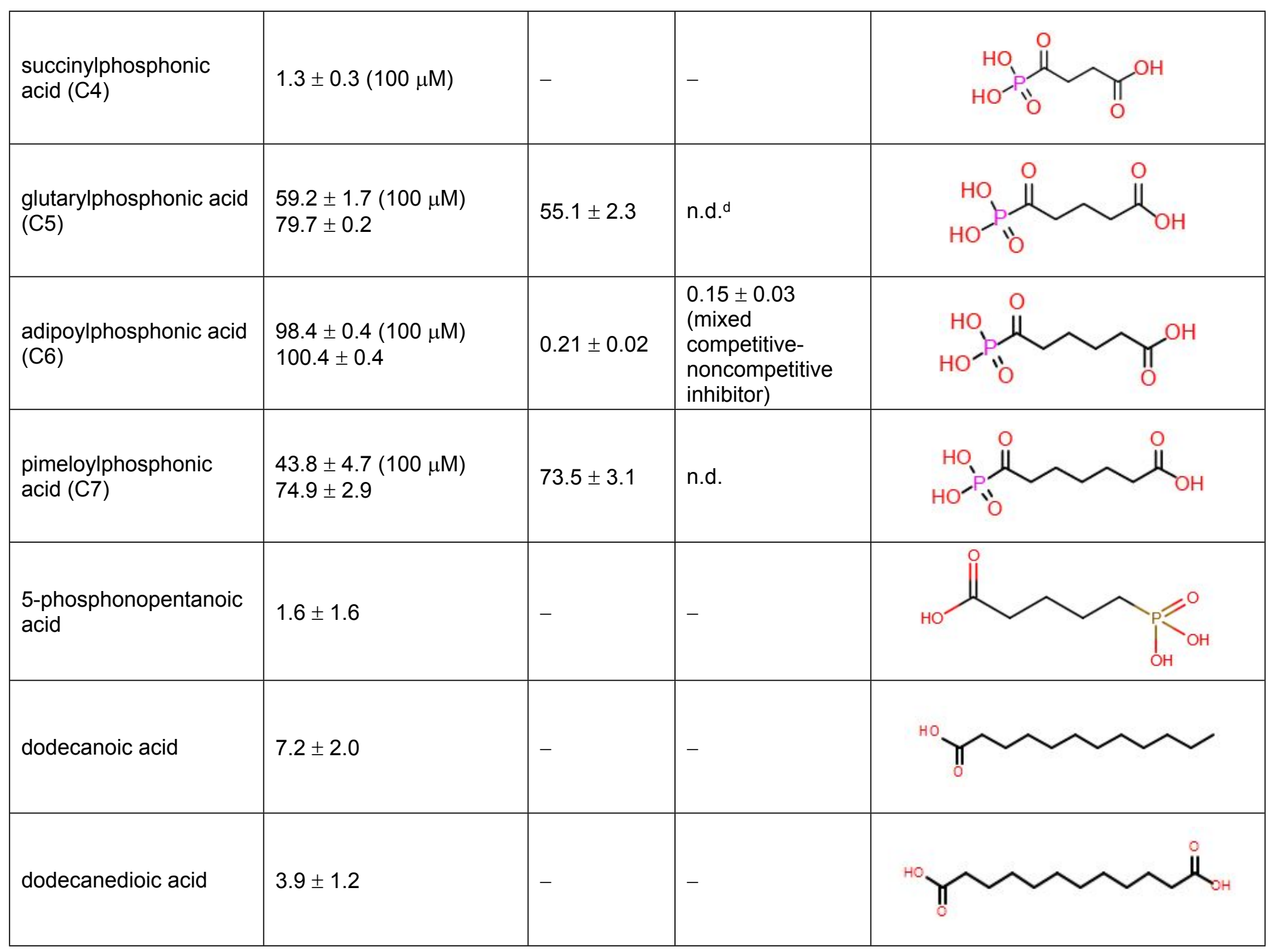




\begin{tabular}{|l|l|l|l|l|}
\hline suberic acid & $-2.1 \pm 2.8$ & - & - & \\
\hline sebacic acid & $3.5 \pm 2.4$ & - & - & -
\end{tabular}




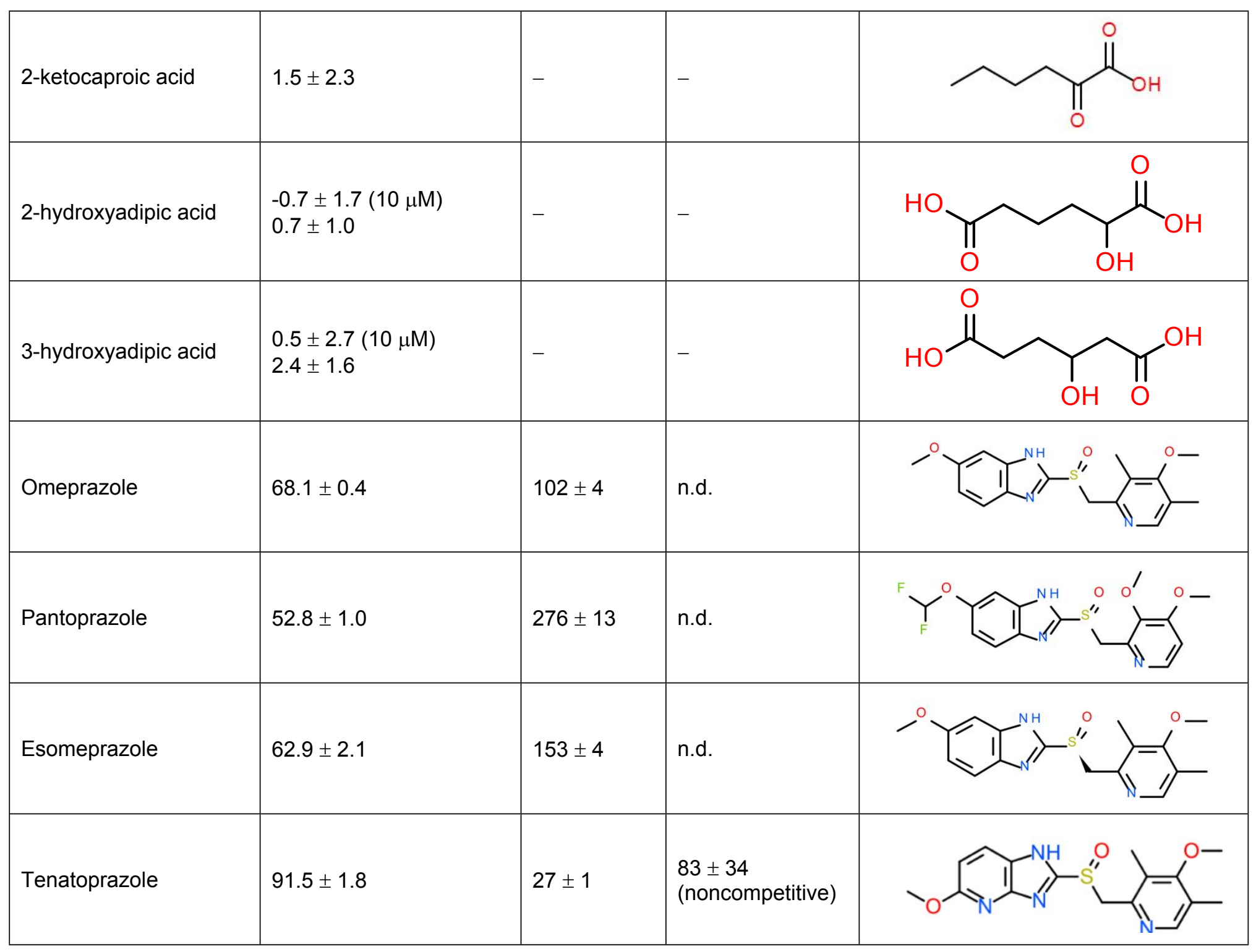




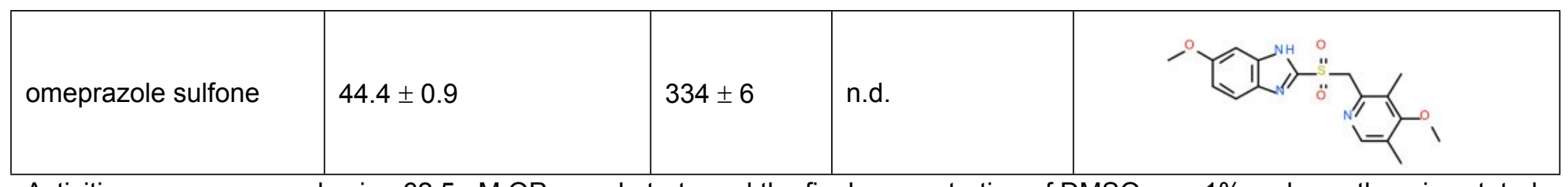

Activities were measured using $62.5 \mu \mathrm{M}$ OP as substrate and the final concentration of DMSO was $1 \%$, unless otherwise stated. alnhibition relative to control (1\% DMSO or water). ${ }^{b}$ Compounds were tested at $300 \mu \mathrm{M}$, unless otherwise stated. ${ }^{\mathrm{C}}$ Compound dissolved in water. ${ }^{d}$.d., not determined. 
Table S2. X-ray data collection and refinement statistics.

\begin{tabular}{|c|c|}
\hline & DHTKD1:ThDP \\
\hline \multicolumn{2}{|l|}{ Data collection } \\
\hline Space Group & C 121 \\
\hline \multicolumn{2}{|l|}{ Cell dimensions } \\
\hline$a, b, c(\AA)$ & 332.31472 .612379 .6752 \\
\hline \multirow{2}{*}{$\begin{array}{c}\alpha, \beta, \gamma\left({ }^{\circ}\right) \\
\text { Resolution }(\AA)\end{array}$} & 9091.865590 \\
\hline & $49-2.25 \quad(2.29-2.25)$ \\
\hline $\mathrm{R}_{\text {sym }}$ or $\mathrm{R}_{\text {merge }}$ & $0.239(1.178)$ \\
\hline $\mathrm{R}_{\mathrm{pim}}$ & $0.087(0.565)$ \\
\hline$I / \sigma I$ & $7.0(1.4)$ \\
\hline $\operatorname{CC}(1 / 2)$ & $0.991(0.504)$ \\
\hline Completeness (\%) & $99.9(98.6)$ \\
\hline Redundancy & $8.3(5.2)$ \\
\hline Average mosaicity & 0.17 \\
\hline \multicolumn{2}{|l|}{ Refinement } \\
\hline Resolution $(\AA ̊)$ & $49-2.25(2.28-2.25)$ \\
\hline No. reflections & $90328(2866)$ \\
\hline$R_{\text {work }} / R_{\text {free }}$ & $0.2090 / 0.2409$ \\
\hline \multicolumn{2}{|l|}{ No. atoms } \\
\hline Protein & 13716 \\
\hline Ligand/ion & 95 \\
\hline Water & 1001 \\
\hline \multicolumn{2}{|l|}{ B-factors } \\
\hline Protein & 40.56 \\
\hline Ligand/ion & 36.72 \\
\hline Water & 41.05 \\
\hline \multicolumn{2}{|l|}{ R.m.s deviations } \\
\hline Bond lengths $(\AA)$ & 0.002 \\
\hline Bond Angles $\left(^{\circ}\right)$ & 0.504 \\
\hline
\end{tabular}


Table S3. Oligonucleotides used for site-directed mutagenesis.

\begin{tabular}{lll}
\hline Primer & $\begin{array}{l}\text { coding position } \\
\text { of primer }\end{array}$ & Sequence $\left(5^{\prime} \rightarrow 3^{\prime}\right)^{b}$ \\
\hline R163Q_F & $476-501$ & CCACAGAAGAGCAAAAACATCTGTCG \\
\hline R163Q_R & $501-476$ & CGACAGATGTTTTTGCTCTTCTGTGG \\
\hline L234G_F & $681-718$ & GAATTTATTGACAGGCCTTGGGCAGTTCCCTCCAGAGC \\
\hline L234G_R & $718-681$ & GCTCTGGAGGGAACTGCCCAAGGCCTGTCAATAAATTC \\
\hline Q305H_F & $897-931$ & CAAAACTCGCGGCAGGCACCAGTCTCGCCAAGACG \\
\hline Q305H_R & $931-897$ & CGTCTTGGCGAGACTGGTGCCTGCCGCGAGTTTG \\
\hline V360A_F & $1062-1099$ & CAGAATTGGTGGGAGTGCGCATTTGATTGTTAATAACC \\
\hline V360A_A & $1099-1062$ & GGTTATTAACAATCAAATGCGCACTCCCACCAATTCTG \\
\hline R455Q_F & $1347-1380$ & CAAAATCATCAGAGCTCAAAAGAGCATTCCAGAC \\
\hline R455Q_R & $1380-1347$ & GTCTGGAATGCTCTTTTGAGCTCTGATGATTTTG \\
\hline R715C_F & $2129-2159$ & CCTGTCGAATAGAGTGTTTCCTGCAGATGTG \\
\hline R715C_R & $2159-2129$ & CACATCTGCAGGAAACACTCTATTCGACAGG \\
\hline G729R_F & $2170-2202$ & GAAGAGGGGGTGGACAGAGACACTGTGAACATG \\
\hline G729R_R & $2202-2170$ & CATGTTCACAGTGTCTCTGTCCACCCCCTCTTC \\
\hline P773L_F & $2301-2335$ & GATGTTACTCAGGCTCCTGGCAGCCGTG TCAACTC \\
\hline P773L_R & $2335-2301$ & GAGTTGACACGGCTGCCAGGAGCCTGAGTAACATC \\
\hline S777P_F & $2313-2347$ & GCTCCCGGCAGCCGTGCCAACTCTTCAAGAAATGG \\
\hline S777P_R & $2347-2313$ & CCATTTCTTGAAGAGTTGGCACGGCTGCCGGGAGC \\
\hline S862I_F & $2572-2601$ & GATCATATTTGGATTCAGGAGGAACCTCAG \\
\hline S862I_R & $2601-2572$ & CTGAGGTTCCTCCTGAATCCAAATATGATC \\
\hline Y190F_N & $564-598$ & GCGATTTGGAGGCGAAGGGGCTGAAAGCATGATGG \\
\hline Y190F_C & $574-541$ & CTCCAAATCGCTTCACTGTCGAGAACTTGGTGGC \\
\hline S288Y_N & $858-889$ & TCCCTATCACCTGGAGGCCGTCAACCCCGTGG \\
\hline S288Y_C & $868-834$ & GGTGATAGGGATTGGGCAACATTGTCACATGGAGG \\
\hline aGenBank accession number NM_018706.7. bMismatch nucleotides are shown in bold. \\
\end{tabular}




\section{References}

(1) Bradford, M. M. (1976) A rapid and sensitive method for the quantitation of microgram quantities of protein utilizing the principle of protein-dye binding. Anal. Biochem. 72, 248-254.

(2) Hubner, G., Schellenberger, A., Bernhardt, R., Khailova, S., and Severin, S. E. (1977) Inactivation of the pyruvate dehydrogenase component from pigeon breast muscle pyruvate dehydrogenase complex by alpha-ketobutyric acid. FEBS Lett. 84, 179-182.

(3) Khailova, L. S., Bernkhardt, R., and Khiubner, G. (1977) [Study of the kinetic mechanism of the pyruvate-2,6-dichlorophenolindophenol reductase activity of muscle pyruvate dehydrogenase]. Biokhimiia 42, 113-117.

(4) Balakrishnan, A., Nemeria, N. S., Chakraborty, S., Kakalis, L., and Jordan, F. (2012) Determination of pre-steady-state rate constants on the Escherichia coli pyruvate dehydrogenase complex reveals that loop movement controls the rate-limiting step. J. Am. Chem. Soc. 134, 18644-18655.

(5) Armstrong, J. M. (1964) The Molar Extinction Coefficient of 2,6-Dichlorophenol Indophenol. Biochim. Biophys. Acta 86, 194-197.

(6) Copeland, R. A. (2013) Evaluation of enzyme inhibitors in drug discovery : a guide for medicinal chemists and pharmacologists. 2nd ed., Wiley, Hoboken, N.J.

(7) Nemeria, N. S., Gerfen, G., Guevara, E., Nareddy, P. R., Szostak, M., and Jordan, F. (2017) The human Krebs cycle 2-oxoglutarate dehydrogenase complex creates an additional source of superoxide/hydrogen peroxide from 2-oxoadipate as alternative substrate. Free Radic. Biol. Med. 108, 644-654.

(8) Nemeria, N. S., Gerfen, G., Nareddy, P. R., Yang, L., Zhang, X., Szostak, M., and Jordan, F. (2018) The mitochondrial 2-oxoadipate and 2-oxoglutarate dehydrogenase complexes share their E2 and E3 components for their function and both generate reactive oxygen species. Free Radic. Biol. Med. 115, 136-145.

(9) Nemeria, N. S., Gerfen, G., Yang, L., Zhang, X., and Jordan, F. (2018) Evidence for functional and regulatory cross-talk between the tricarboxylic acid cycle 2-oxoglutarate dehydrogenase complex and 2-oxoadipate dehydrogenase on the I-lysine, I-hydroxylysine and I-tryptophan degradation pathways from studies in vitro. Biochim. Biophys. Acta Bioenerg. 1859, 932-939.

(10) Zhang, J. H., Chung, T. D., and Oldenburg, K. R. (1999) A Simple Statistical Parameter for Use in Evaluation and Validation of High Throughput Screening Assays. J. Biomol. Screen. 4, 67-73.

(11) Brideau, C., Gunter, B., Pikounis, B., and Liaw, A. (2003) Improved statistical methods for hit selection in high-throughput screening. J. Biomol. Screen. 8, 634-647.

(12) Le, A., Ng, A., Kwan, T., Cusmano-Ozog, K., and Cowan, T. M. (2014) A rapid, sensitive method for quantitative analysis of underivatized amino acids by liquid chromatography-tandem mass spectrometry (LC-MS/MS). J. Chromatogr. B Analyt. Technol. Biomed. Life Sci. 944, 166-174.

(13) Walter, T. S., Meier, C., Assenberg, R., Au, K. F., Ren, J., Verma, A., Nettleship, J. E., Owens, R. J., Stuart, D. I., and Grimes, J. M. (2006) Lysine methylation as a routine rescue strategy for protein crystallization. Structure 14, 1617-1622.

(14) Vonrhein, C., Flensburg, C., Keller, P., Sharff, A., Smart, O., Paciorek, W., Womack, T., and Bricogne, G. (2011) Data processing and analysis with the autoPROC toolbox. Acta Crystallogr. D Biol. Crystallogr. 67, 293-302.

(15) Evans, P. R., and Murshudov, G. N. (2013) How good are my data and what is the resolution? Acta Crystallogr. D Biol. Crystallogr. 69, 1204-1214.

(16) McCoy, A. J., Grosse-Kunstleve, R. W., Adams, P. D., Winn, M. D., Storoni, L. C., and Read, R. J. (2007) Phaser crystallographic software. J. Appl. Crystallogr. 40, 658-674.

(17) Bunkoczi, G., and Read, R. J. (2011) Improvement of molecular-replacement models with Sculptor. Acta Crystallogr. D Biol. Crystallogr. 67, 303-312.

(18) Terwilliger, T. C., Grosse-Kunstleve, R. W., Afonine, P. V., Moriarty, N. W., Zwart, P. H., Hung, L. W., Read, R. J., and Adams, P. D. (2008) Iterative model building, structure refinement and density modification with the PHENIX AutoBuild wizard. Acta Crystallogr. D Biol. Crystallogr. 64, 61-69.

(19) Adams, P. D., Afonine, P. V., Bunkoczi, G., Chen, V. B., Davis, I. W., Echols, N., Headd, J. J., Hung, L. W., Kapral, G. J., Grosse-Kunstleve, R. W., McCoy, A. J., Moriarty, N. W., Oeffner, R., Read, R. J., Richardson, D. C., Richardson, J. S., Terwilliger, T. C., and Zwart, P. H. (2010) PHENIX: a comprehensive Python-based system for macromolecular structure solution. Acta Crystallogr. $D$ Biol. Crystallogr. 66, 213-221. 
(20) Painter, J., and Merritt, E. A. (2006) Optimal description of a protein structure in terms of multiple groups undergoing TLS motion. Acta Crystallogr. D Biol. Crystallogr. 62, 439-450.

(21) Painter, J., and Merritt, E. A. (2006) TLSMD web server for the generation of multi-group TLS models. J. Appl. Crystallogr. 39, 109-111.

(22) Emsley, P., Lohkamp, B., Scott, W. G., and Cowtan, K. (2010) Features and development of Coot. Acta Crystallogr. D Biol. Crystallogr. 66, 486-501.

(23) Moriarty, N. W., Grosse-Kunstleve, R. W., and Adams, P. D. (2009) electronic Ligand Builder and Optimization Workbench (eLBOW): a tool for ligand coordinate and restraint generation. Acta Crystallogr. D Biol. Crystallogr. 65, 1074-1080.

(24) The PyMOL Molecular Graphics System. Version 1.5.0.4 ed., Schrödinger, LLC.

(25) Dharmasena, S. P., Wimalasena, D. S., and Wimalasena, K. (2002) A slow-tight binding inhibitor of dopamine beta-monooxygenase: a transition state analogue for the product release step. Biochemistry 41, 12414-12420.

(26) Wagner, T., Barilone, N., Alzari, P. M., and Bellinzoni, M. (2014) A dual conformation of the postdecarboxylation intermediate is associated with distinct enzyme states in mycobacterial KGD (alpha-ketoglutarate decarboxylase). Biochem. J. 457, 425-434. 


\section{NMR spectra}

${ }^{1} \mathrm{H}-N M R$ spectra of $1 \mathrm{a}$.
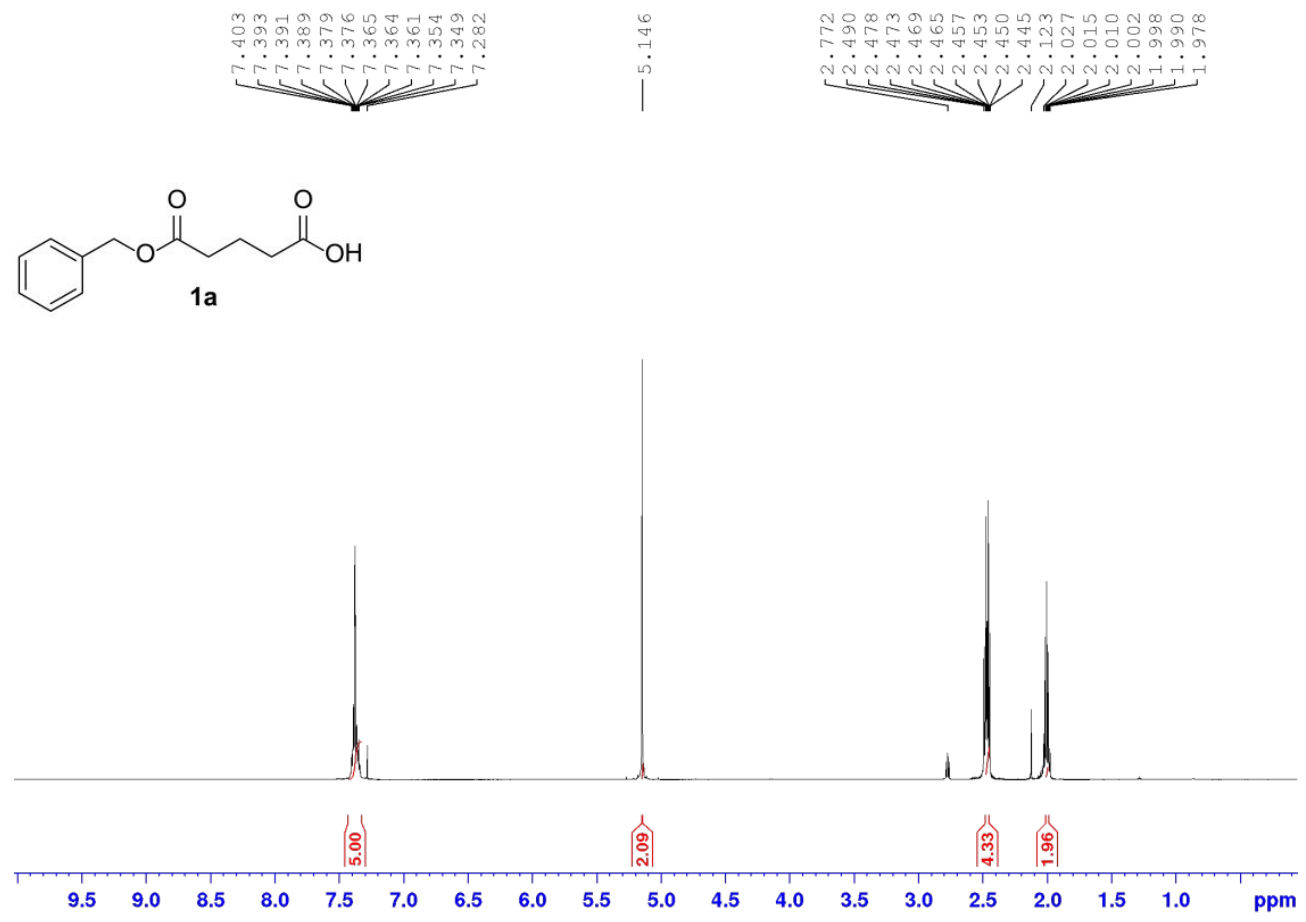

${ }^{1} \mathrm{H}-N M R$ spectra of $2 \mathrm{a}$.
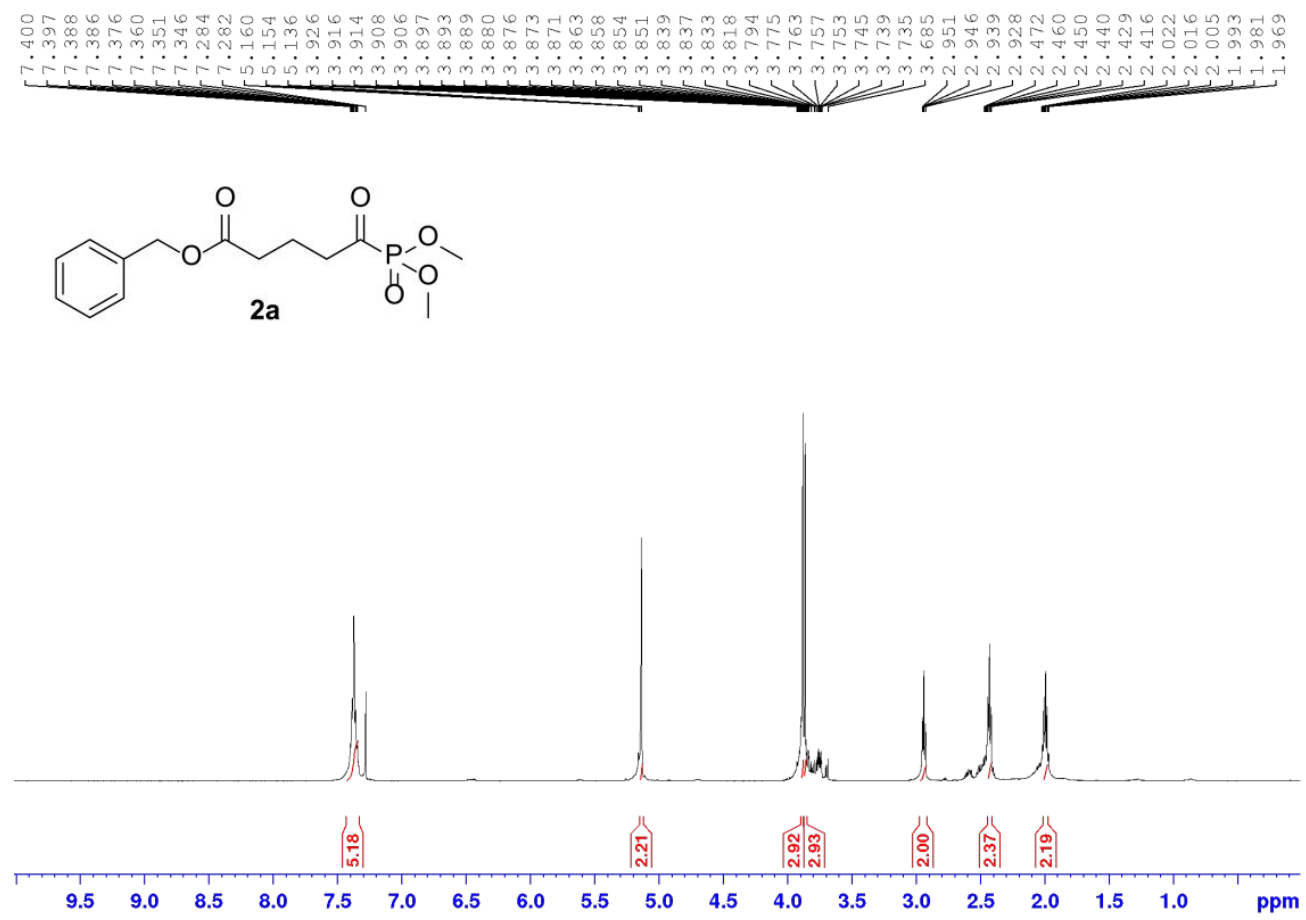
${ }^{1} \mathrm{H}-N M R$ spectra of $3 a$.

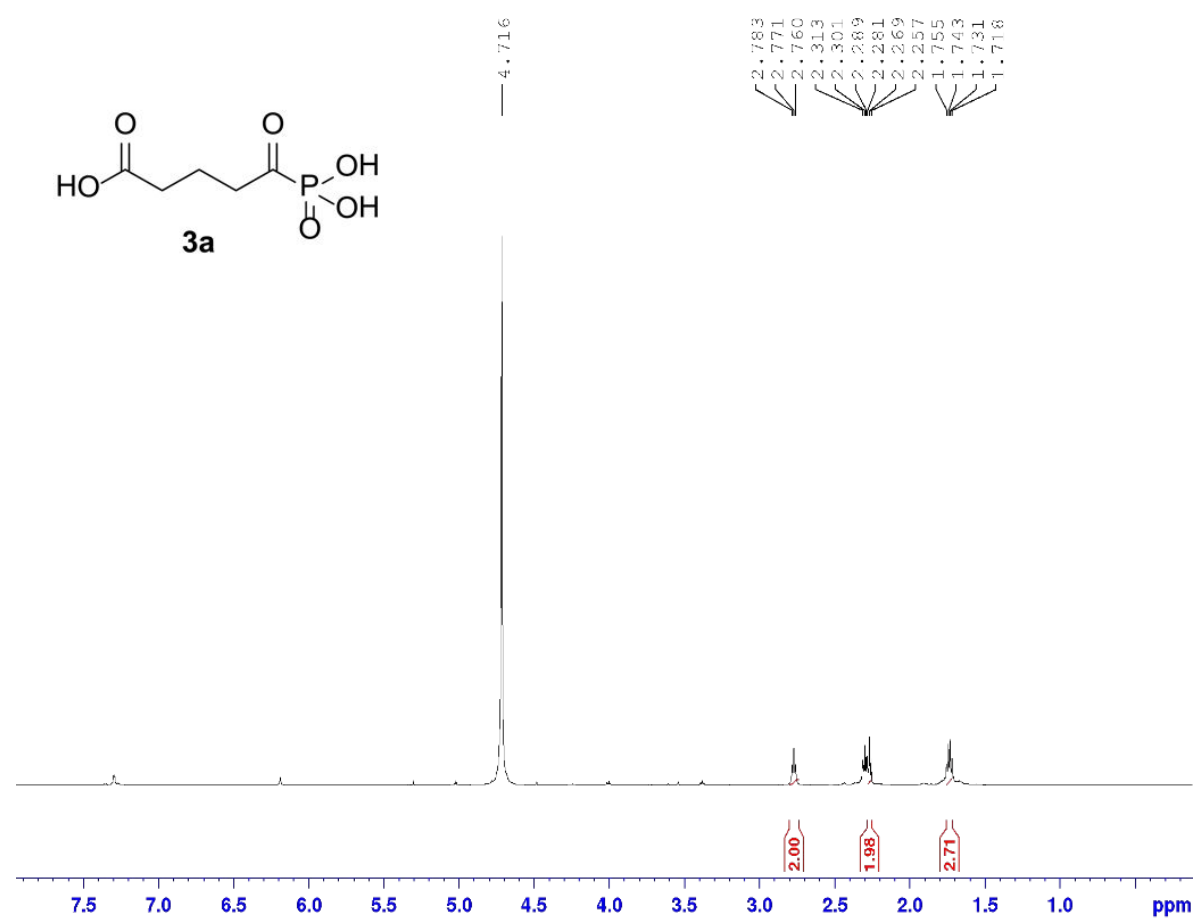

${ }^{1} \mathrm{H}-N M R$ spectra of $1 \mathrm{~b}$.
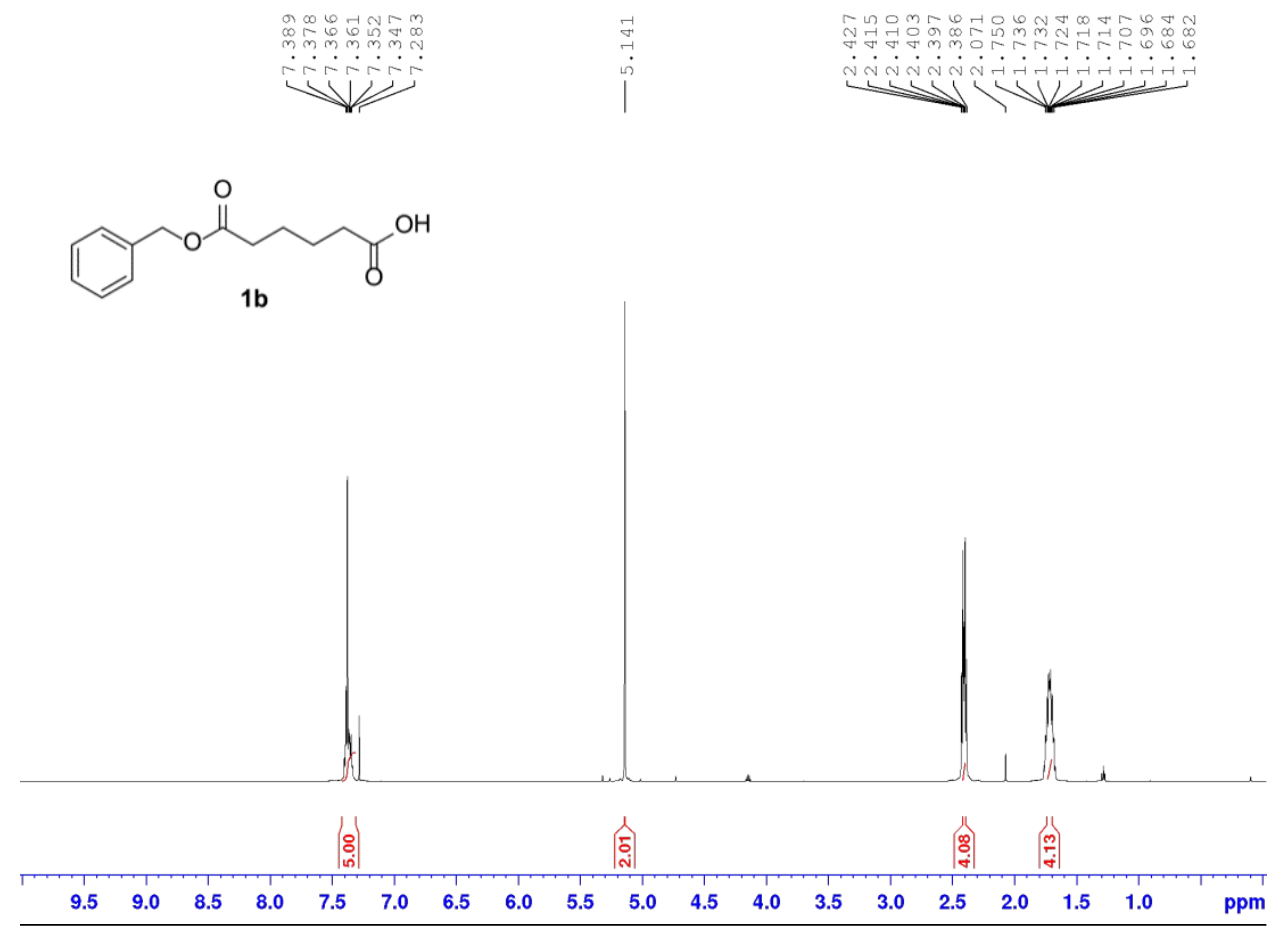
${ }^{1} \mathrm{H}-N M R$ spectra of $1 \mathrm{bl}$.

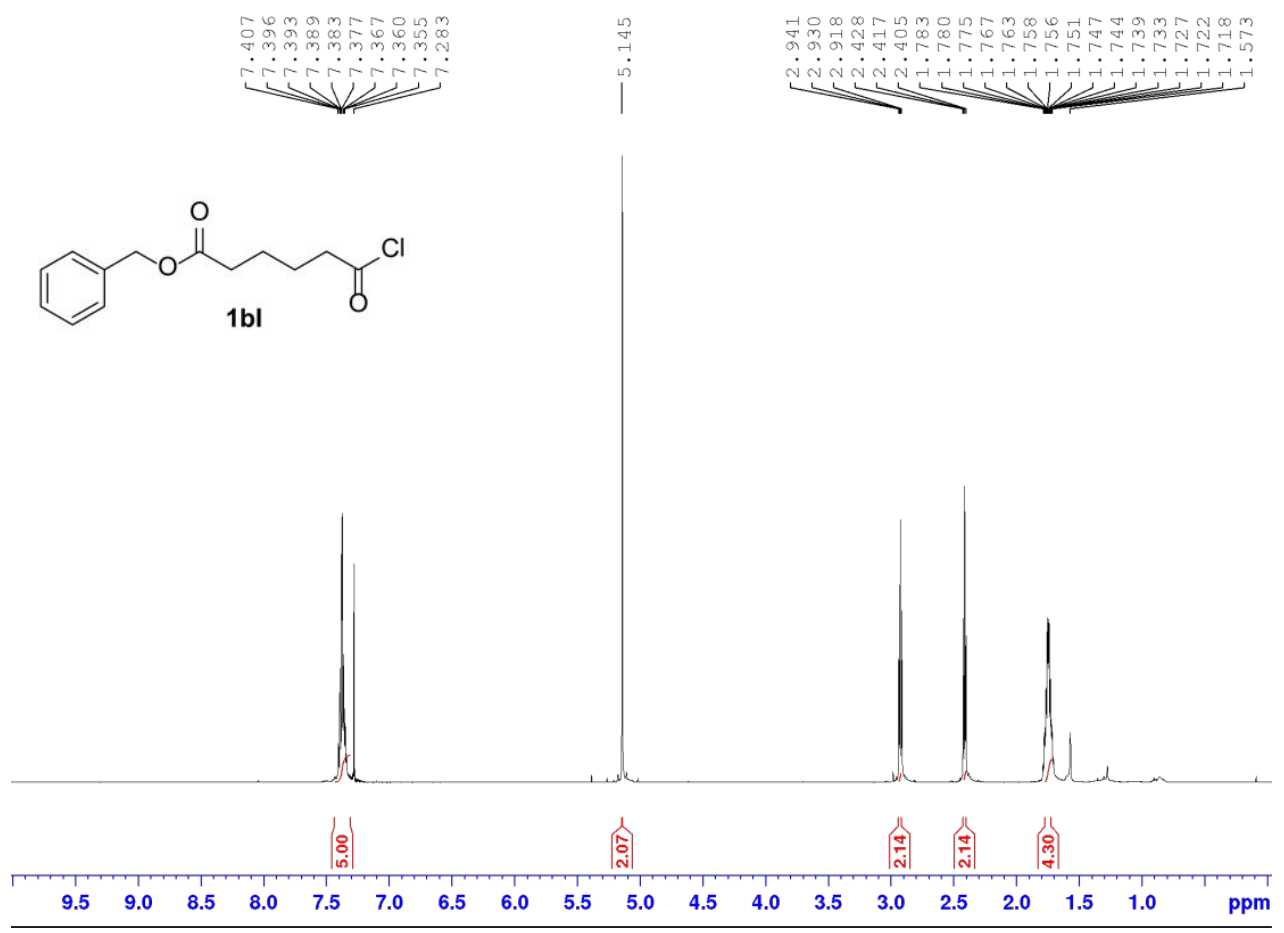

${ }^{1} \mathrm{H}-N M R$ spectra of $\mathbf{2 b}$.
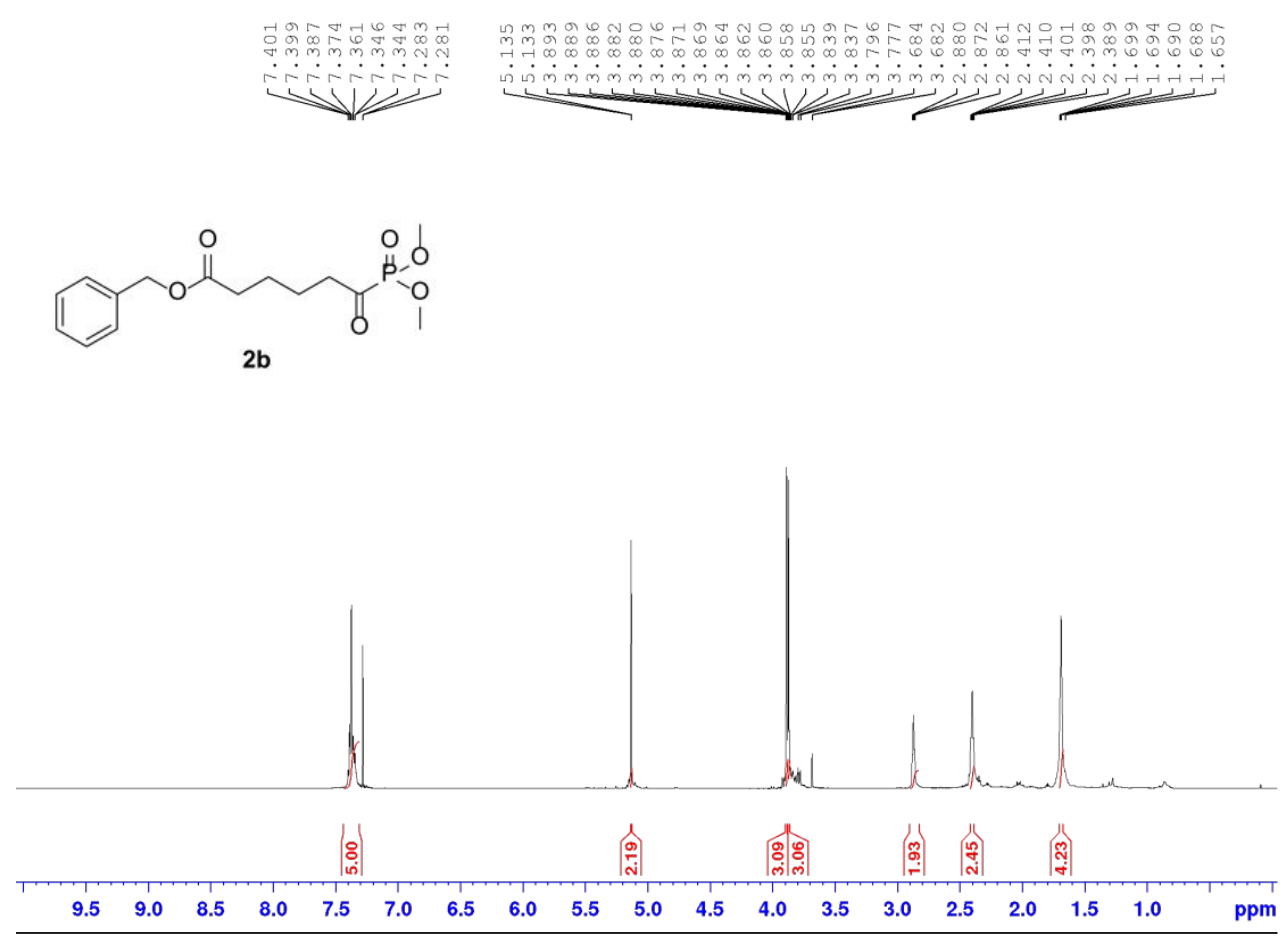
${ }^{1} \mathrm{H}-\mathrm{NMR}$ spectra of $3 \mathrm{~b}$.

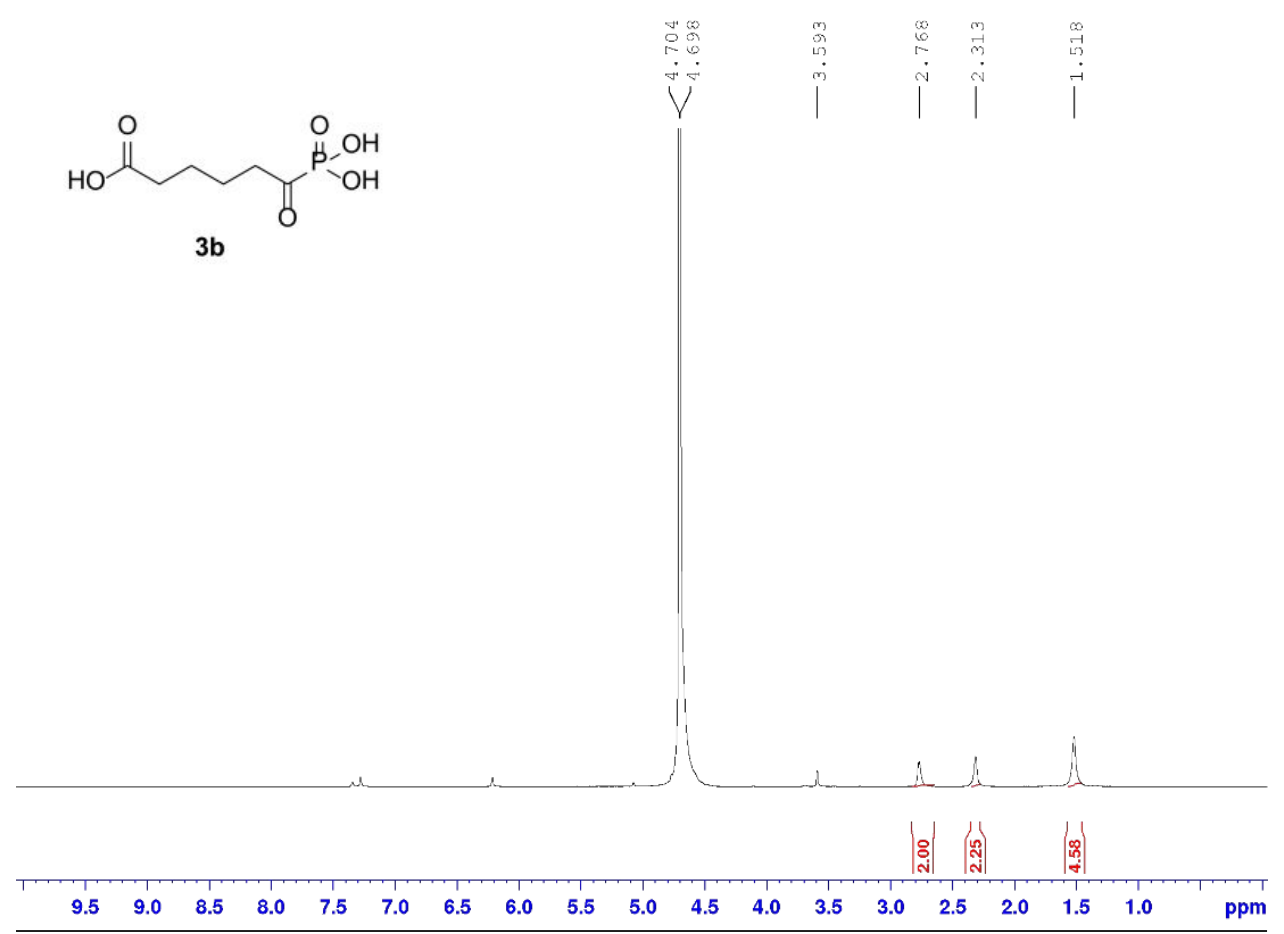

${ }^{1} \mathrm{H}-N M R$ spectra of $1 \mathrm{c}$.
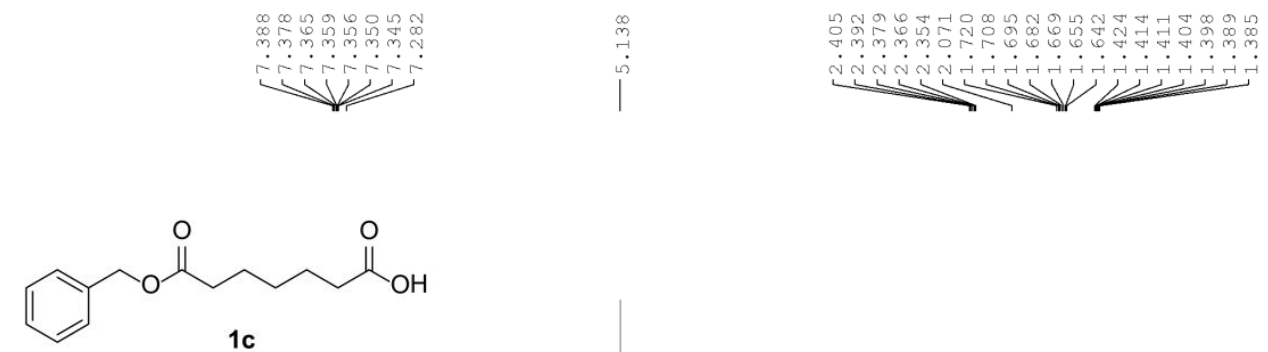

1c

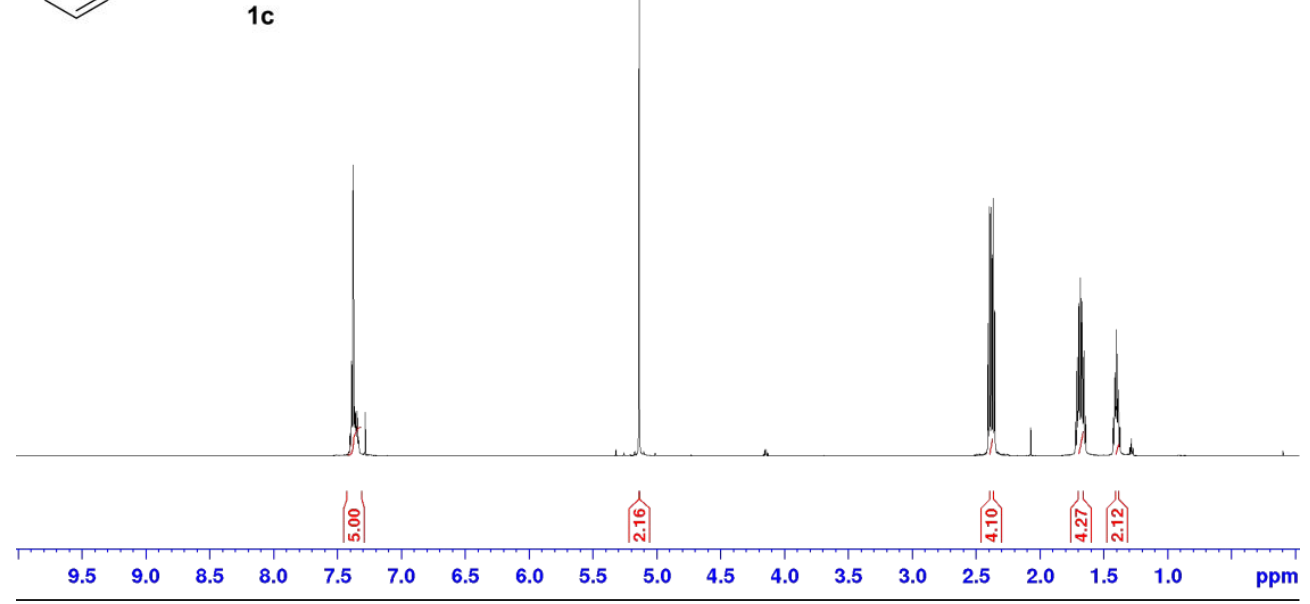


${ }^{1} \mathrm{H}-\mathrm{NMR}$ spectra of $1 \mathrm{cl}$.
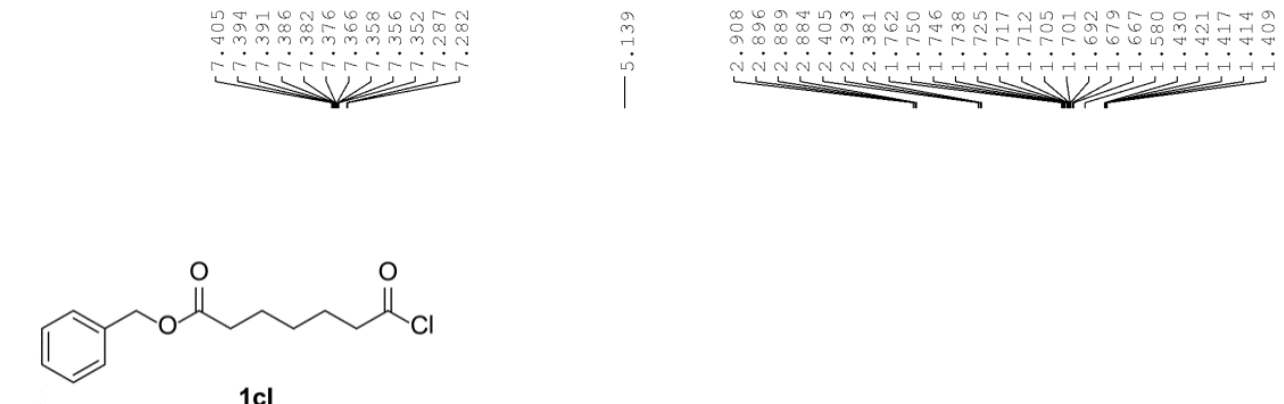

1cl

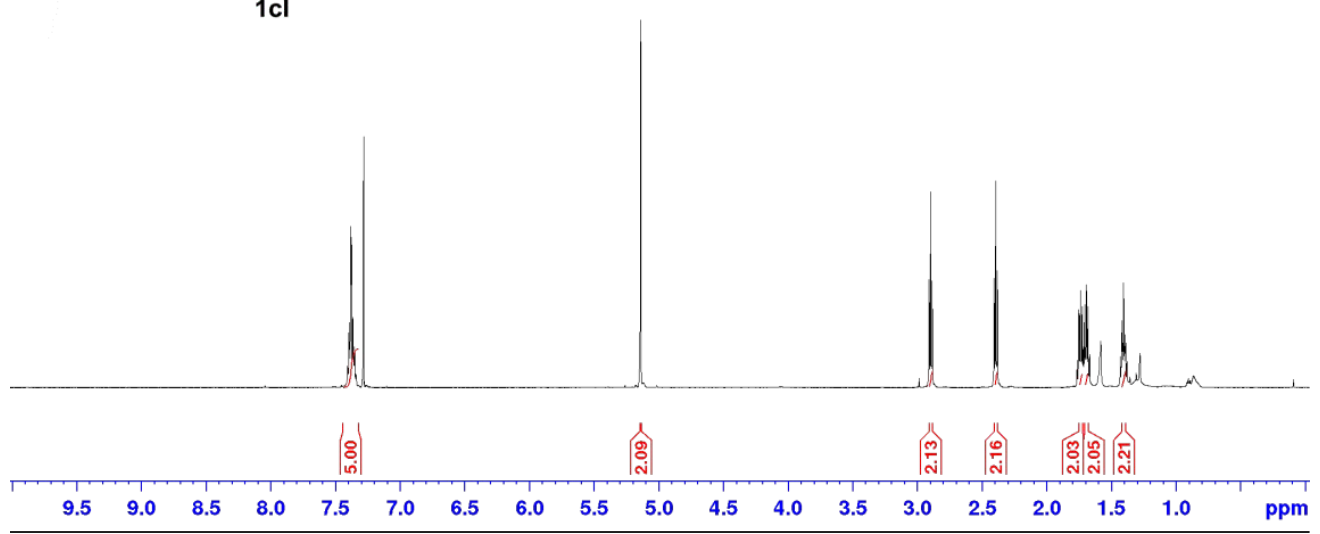

${ }^{1} \mathrm{H}-N M R$ spectra of $2 \mathrm{c}$.
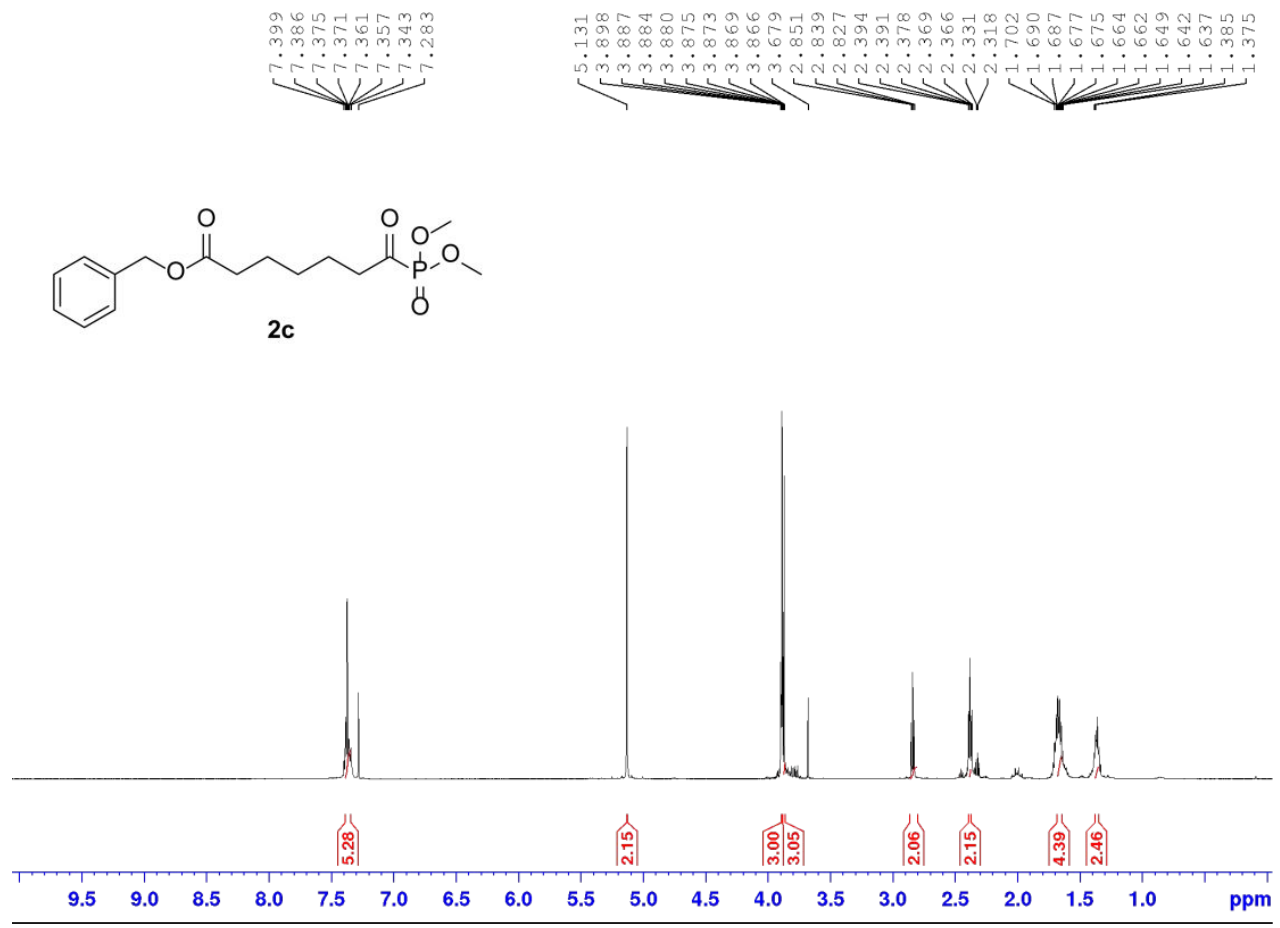
${ }^{1} \mathrm{H}-\mathrm{NMR}$ spectra of $3 \mathrm{c}$.

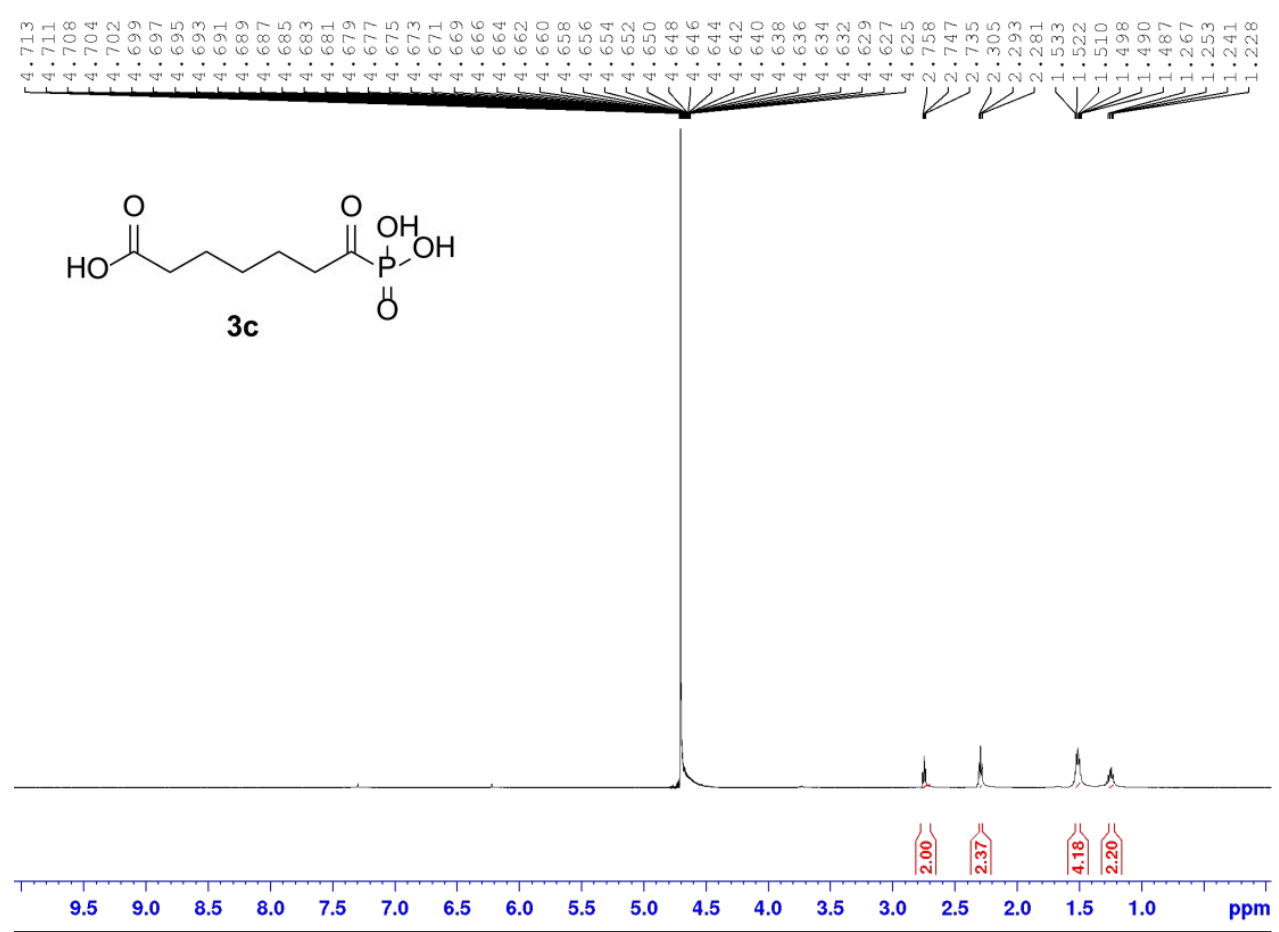

